\title{
OPTIMAL GENERATION EXPANSION PLANNING WITH INTEGRATION OF VARIABLE RENEWABLES AND BULK ENERGY STORAGE SYSTEMS
}

\author{
A Dissertation by \\ Zhouxing $\mathrm{Hu}$ \\ Master of Science, Wichita State University, 2010 \\ Bachelor of Science, Chongqing University, 2007
}

Submitted to the Department of Electrical Engineering and Computer Science and the faculty of the Graduate School of

Wichita State University

in partial fulfillment of

the requirements for the degree of

Doctor of Philosophy

May 2013 
(C) Copyright 2013 by Zhouxing $\mathrm{Hu}$

All Rights Reserved 


\section{OPTIMAL GENERATION EXPANSION PLANNING WITH INTEGRATION OF VARIABLE RENEWABLES AND BULK ENERGY STORAGE SYSTEMS}

The following faculty members have examined the final copy of this dissertation for form and content, and recommend that it be accepted in partial fulfillment of the requirement for the degree of Doctor of Philosophy, with a major in Electrical Engineering.

Ward T. Jewell, Committee Chair

Visvakumar Aravinthan, Committee Member

John Watkins, Committee Member

Janet Twomey, Committee Member

Lop-Hing Ho, Committee Member

Accepted for the College of Engineering

Vish Prasad, Dean

Accepted for the Graduate School

Abu S.M. Masud, Dean 


\section{DEDICATION}

To my parents, my wife, and my aunts 


\section{ACKNOWLEDGEMENTS}

I would like to express my deepest appreciation to my advisor, Dr. Ward Jewell. I have been receiving his great guidance, instructions and financial support throughout my Master's and doctoral studies. His valuable teaching and inspirations lead me to the deeper field of electrical power systems, and will continuously benefit my future career.

Meanwhile, I am so grateful to have my dissertation committee members, Dr. Visvakumar Aravinthan, Dr. John Watkins, Dr. Janet Twomey and Dr. Lop-Hing Ho. I want to thank for their valuable suggestions and instructions not only on my dissertation, but also in class.

Besides professors, I want to acknowledge my former colleagues, who are also good friends of mine for years, Miaolei Shao and Piyasak Poonpun for their guidance and encouragement from the beginning of my graduate studies. I am also pleased to thank my colleagues, Trevor Hardy and Haneen Aburub, for their helpful suggestions on the PSERC projects and the energy storage work.

Finally, I want to give my special thankfulness to my parents, my wife, and my aunts for their greatest love and support. 


\begin{abstract}
Wind and solar energy are clean, free of fuel cost and likely to have great potential in the future. However, besides the technical difficulties associated with integrating variable sources of generation with the electric grid, high capital cost and other indirect costs to power system operations, such as ancillary service requirements, delay more widespread investment in wind and solar power plants. Current energy policies, especially renewable incentives and $\mathrm{CO}_{2}$ emission regulations, remain controversial and uncertain.

Pumped-hydroelectric energy storage has proven to be valuable as bulk energy storage for energy arbitrage coordinating with conventional thermal generators. In the future grid, there are uncertainties, in terms of modeling and optimization, of assessing the value of bulk energy storage coordinating less with thermal generators and more with wind and solar. Moreover, the price of natural gas is predicted to have large variations in the next several decades. It is therefore necessary to construct a generation planning model with comprehensive modeling of wind, solar and energy storage under multiple scenarios of energy policies and natural gas prices.

This dissertation presents such an optimal planning model using a multi-period optimization formulation and its implementation in the MATPOWER's extensible optimal power flow structure. A 3-bus test system is constructed to test the sensitivity of the planning model. This model is further applied to the reduced 240-bus Western Electric Coordinating Council (WECC) system to study more practical planning results.
\end{abstract}




\section{TABLE OF CONTENTS}

Chapter

Page

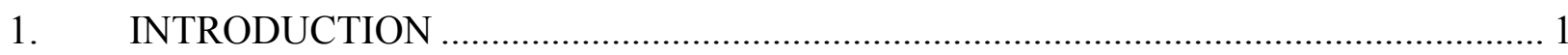

$1.1 \quad$ Energy Future

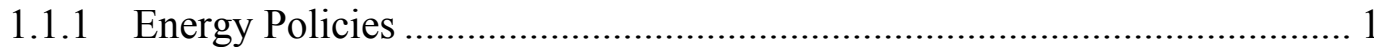

1.1.2 Impact of Wind and Solar Generation ............................................... 4

1.1.3 Potential of Storing Electricity.......................................................... 7

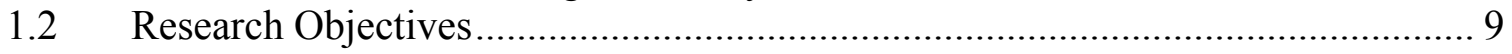

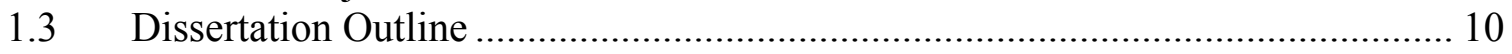

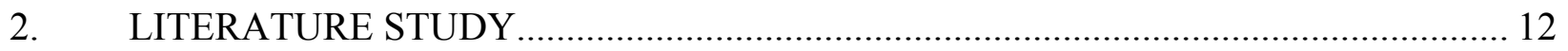

2.1 Modeling and Optimization of Bulk Energy Storage ..................................... 12

2.1.1 Coordination with Thermal Units .................................................... 12

2.1.2 Coordination with Wind Turbines ......................................................... 13

2.2 OPF-Based Generation Planning ................................................................. 15

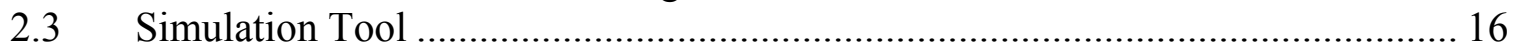

$3 \quad$ IMPACT OF RENEWABLES ON WECC SYSTEM ….......................................... 19

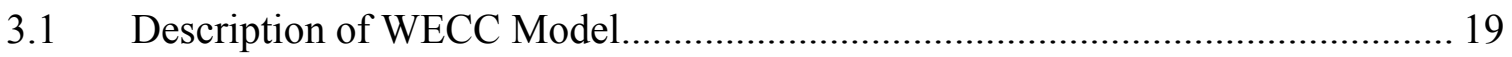

3.2 Model Setup in MATPOWER …................................................................... 21

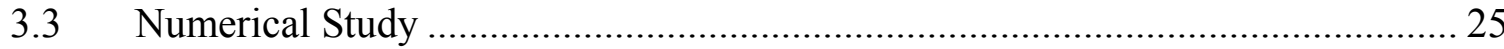

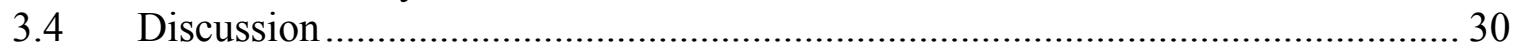

4 MODELING METHODOLOGY AND DATA COLLECTION ................................. 31

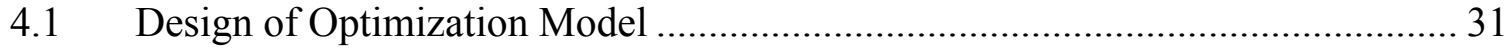

4.1.1 Objective Function.............................................................................. 31

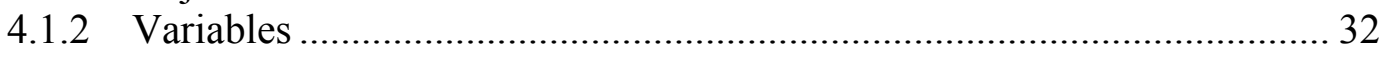

4.1.3 DC Network Constraints............................................................... 33

4.1.4 Hydro Optimization Constraints ....................................................... 34

4.1.5 Generation Expansion Planning Constraints ....................................... 34

4.1.6 Energy Storage Optimal Planning Constraints ...................................... 35

4.1.7 Additional Operating Constraints ..................................................... 37

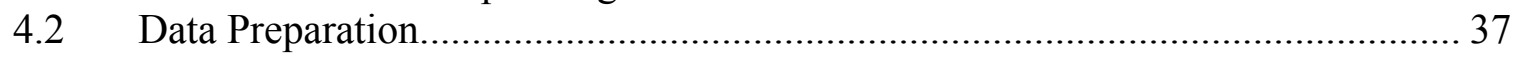

4.2.1 Generation and Load Profile ............................................................... 37

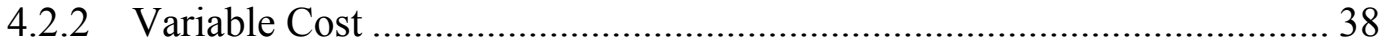

4.2.3 Fixed Cost ................................................................................... 40

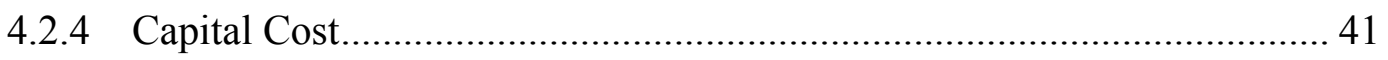

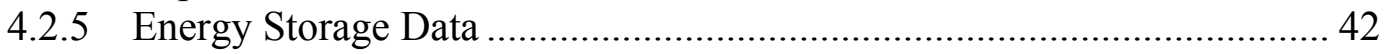


TABLE OF CONTENTS (continued)

Chapter $\quad$ Page

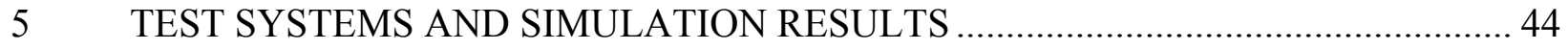

5.1 Simple 3-Bus Test System ..................................................................... 44

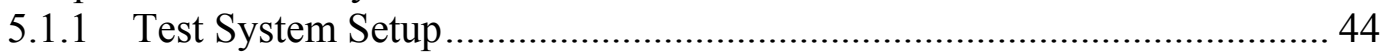

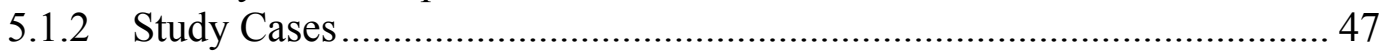

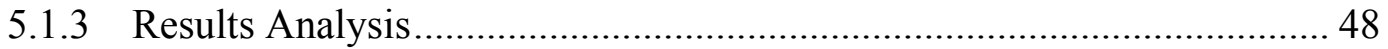

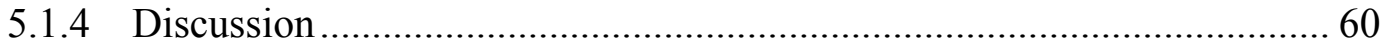

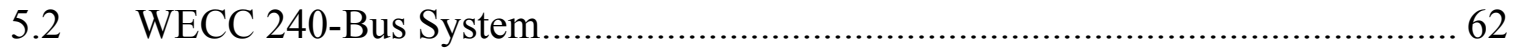

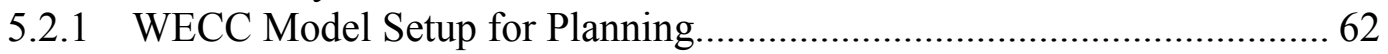

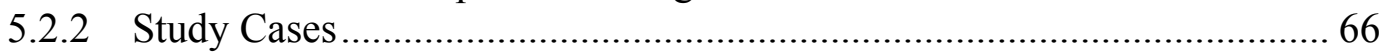

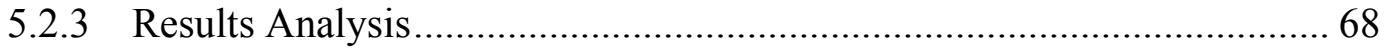

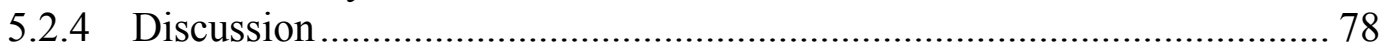

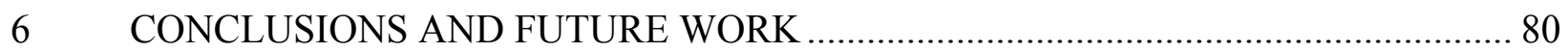

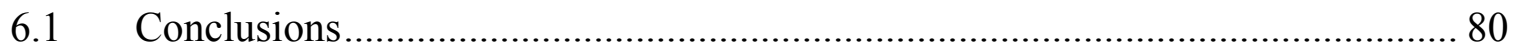

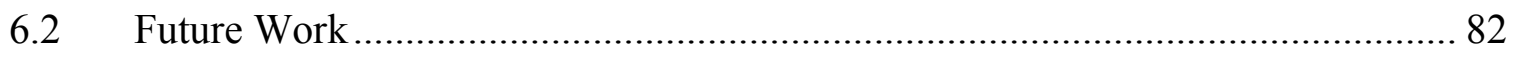

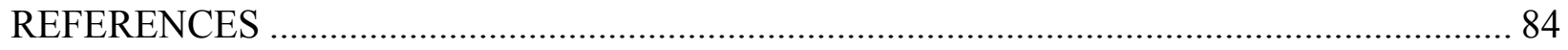

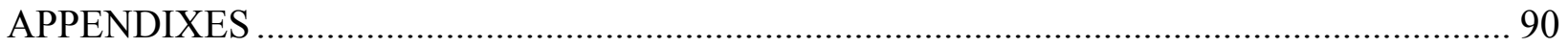




\section{LIST OF TABLES}

Table

3.1 OPF Results Comparison of Daily Operation .................................................... 29

4.1 Levelized Fuel Cost and O\&M Cost ................................................................ 39

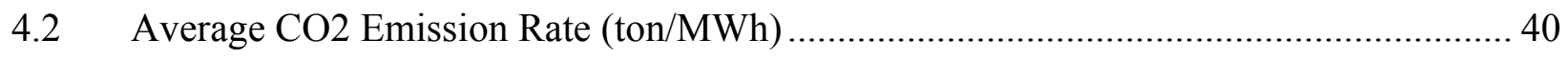

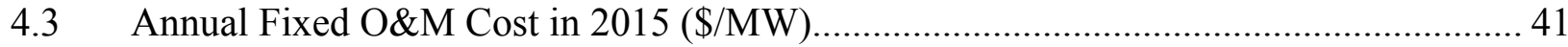

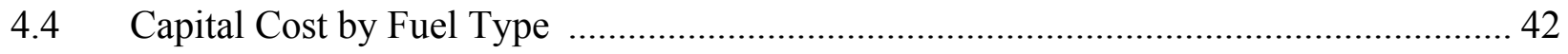

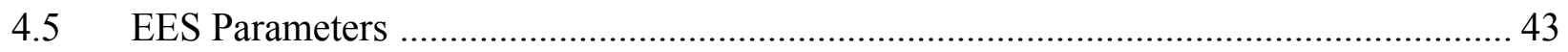

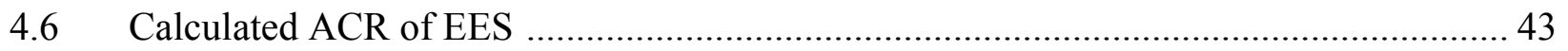

5.1 Generator Parameters in 3-Bus Test System ....................................................... 47

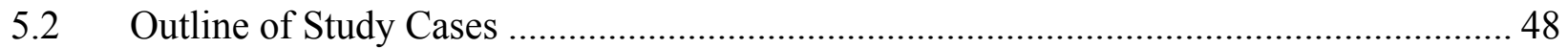

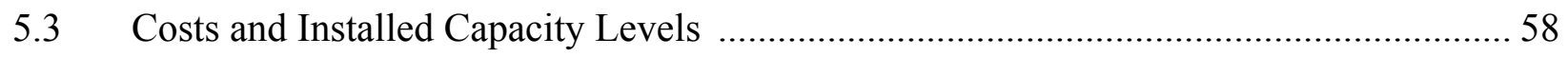

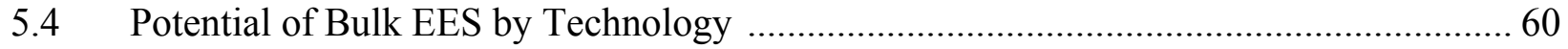

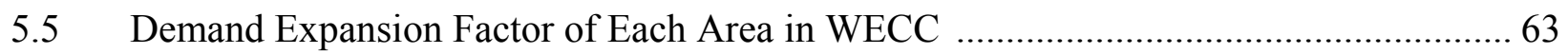

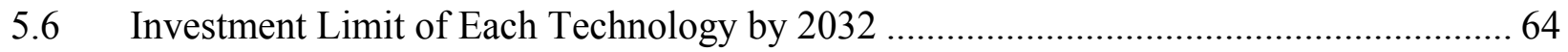

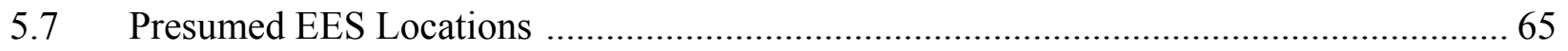

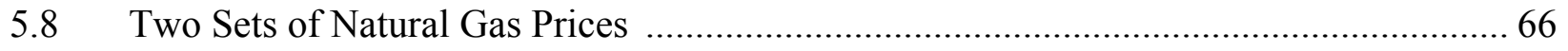

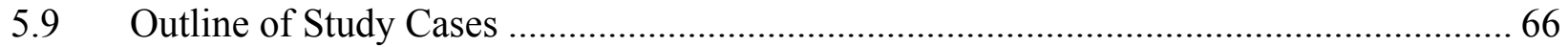

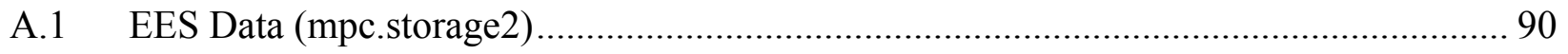

A.2 Generator Retirement Data (mpc.retire) …............................................................ 91

A.3 Generator Investment Data (mpc.invest) ...................................................... 91

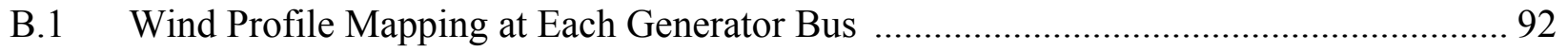

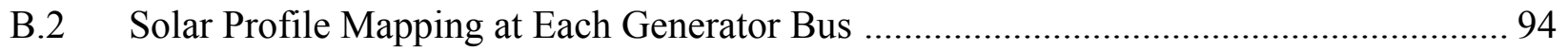




\section{LIST OF FIGURES}

Figure $\quad$ Page

1.1 New renewable energy required to meet existing state RPS policies [5] ...................... 3

1.2 CAISO's daily renewables watch for November 22 (top) and November 24 (bottom)

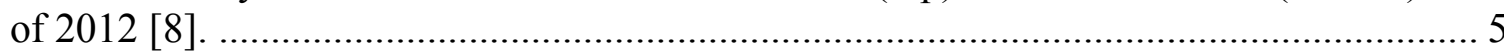

1.3 Penetration level of different renewables during 2010 (historical record) ..................... 6

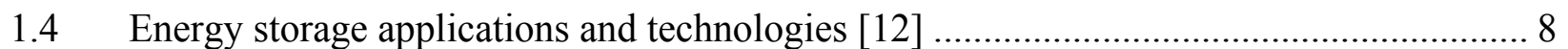

3.1 Network topology of 240-bus WECC model....................................................... 20

3.2 One-line diagram of 240-bus WECC model in PowerWorld ..................................... 21

3.3 Transmission map of WECC 240-bus model. ......................................................... 23

3.4 Generation dispatch by source type in base case and future case of a summer day ........ 26

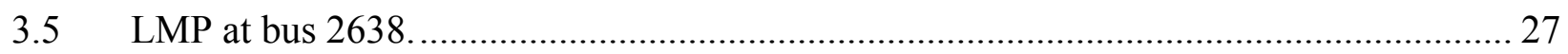

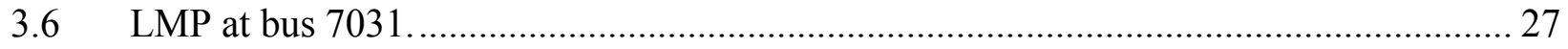

Impact of renewables on SCIT import with........................................................ 28

3.8 Impact of renewables on PDCI with north to south............................................. 28

4.1 Henry Hub Golf Coast Natural Gas Spot Price ........................................................ 39

5.1 Network configuration of 3-bus test system ....................................................... 45

5.2 Normalized 672-hour profile of load, wind and solar............................................. 46

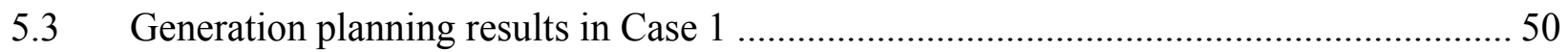

5.4 Annual $\mathrm{CO}_{2}$ emissions and average production cost in Case 1 ................................ 51

$5.5 \quad$ Percentage of installed capacity (IC) in Case 1 .................................................... 51

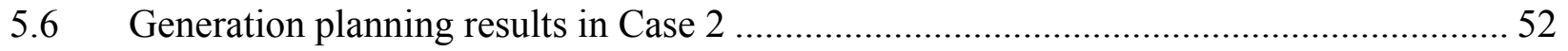

5.7 Annual $\mathrm{CO}_{2}$ emissions and average production cost in Case 2 ............................... 53 


\section{LIST OF FIGURES (continued)}

Figure

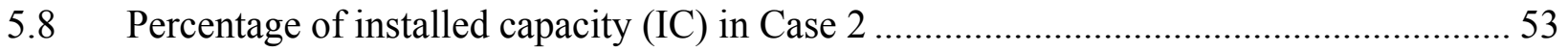

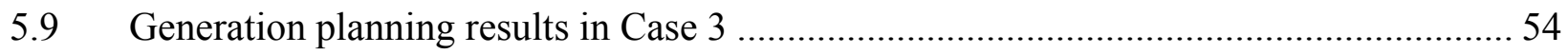

5.10 Annual $\mathrm{CO}_{2}$ emissions and average production cost in Case 3 ................................. 55

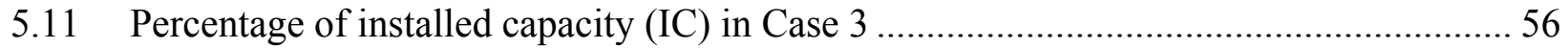

5.12 Planning results of other resources with and without CAES as an option.................... 57

5.13 Annual $\mathrm{CO}_{2}$ emissions with and without CAES as an option ................................... 58

5.14 Hourly operational results of CAES and wind generator .......................................59

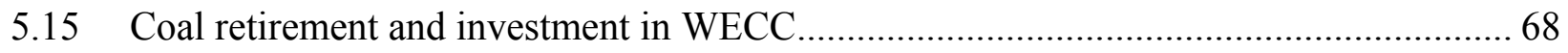

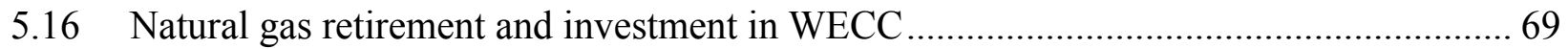

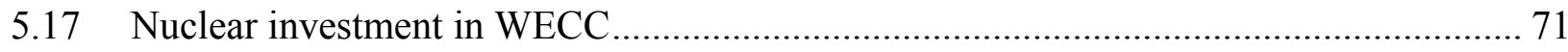

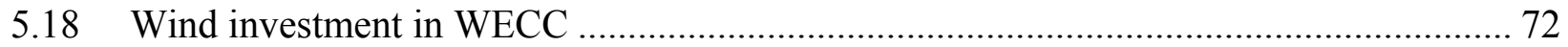

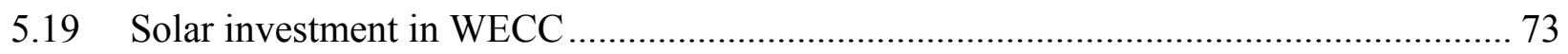

5.20 Power capacity of EES investment in WECC …................................................. 74

5.21 Energy capacity of EES investment in WECC .................................................... 74

5.22 CAES investment at each location in EPA HG case ............................................ 75

5.23 2032 wind and solar installed capacity level and CAES installed capacity level............76

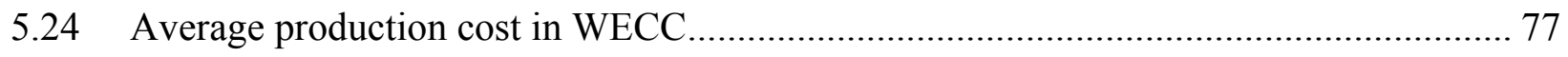

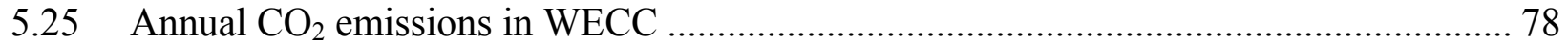




\section{LIST OF ABBREVIATIONS}

\begin{tabular}{|c|c|}
\hline $\mathrm{AC}$ & Alternating Current \\
\hline ACR & Annual Capital Recovery \\
\hline CAES & Compressed Air Energy Storage \\
\hline CAISO & California Independent System Operator \\
\hline $\mathrm{CC}$ & Combined Cycle \\
\hline $\mathrm{CO}_{2}$ & Carbon Dioxide \\
\hline CRF & Capital Recovery Factor \\
\hline CT & Combustion Turbine \\
\hline C\&T & Cap and Trade \\
\hline $\mathrm{DC}$ & Direct Current \\
\hline EES & Electric Energy Storage \\
\hline EIA & U.S. Energy Information Administration \\
\hline FNM & Full Network Model \\
\hline GHG & Greenhouse Gas \\
\hline GW & Giga Watt \\
\hline GWh & Giga Watt Hour \\
\hline $\mathrm{HG}$ & High Natural Gas Pricing \\
\hline HVDC & High-Voltage Direct Current \\
\hline $\mathrm{IC}$ & Installed Capacity \\
\hline LCOE & Levelized Cost of Energy \\
\hline LG & Low Natural Gas Pricing \\
\hline Li-ion & Lithium-ion \\
\hline
\end{tabular}




\section{LIST OF ABBREVIATIONS (continued)}

$\begin{array}{ll}\text { LMP } & \text { Locational Marginal Pricing } \\ \text { LP } & \text { Linear Programming } \\ \text { MBTU } & \text { Million British Thermal Units } \\ \text { MIPS } & \text { MATLAB Interior Point Solver } \\ \text { MPO } & \text { Multi-period Optimization } \\ \text { MW } & \text { Mega Watt } \\ \text { MWh } & \text { Mega Watt Hour } \\ \text { Na-S } & \text { Sodium Sulfur } \\ \text { NGCC } & \text { Natural Gas Combined Cycle } \\ \text { NREL } & \text { National Renewable Energy Laboratory } \\ \text { WCIT } & \text { Southern California Import Transmission } \\ \text { OCC } & \text { Overnight Capital Cost } \\ \text { PH } & \text { Proming }\end{array}$




\section{LIST OF NOMENCLATURE}

A Spare matrix of coefficients of basic control variables and additional control variables

c Superscript or subscript indicating storage charge

$C^{F} \quad$ Fixed cost

$C^{V} \quad$ Variable cost

$d \quad$ Superscript or subscript indicating storage discharge

E Energy status in storage

$f \quad$ Cost function of active and reactive power generation

$f_{u} \quad$ Additional cost function defined by user

g Existing generators

$i \quad$ Index of generators allow to be retired

I Invested capacity in MW

IE Invested capacity of energy storage in MWh

IP Invested capacity of energy storage in MW

$j \quad$ Index of generators allow to be invested

$k \quad$ Bus index

$l \quad$ Lower limit of user-defined constraints

$p u \quad$ Per unit value

$P \quad$ Active power output of generator

$Q \quad$ Reactive power output of generator

$R \quad$ Retired capacity in MW

$s \quad$ Fuel type

$t \quad$ Index of time interval 


\section{LIST OF NOMENCLATURE (continued)}

$T \quad$ Optimization time horizon

$u \quad$ Upper limit of user-defined constraints

$V \quad$ Bus voltage magnitude

$x \quad$ Vector of basic control variables of power system

$z \quad$ Vector of additional control variables defined by user

$\alpha \quad$ Initial status of energy storage

$\delta \quad$ Resource availability at each time point

$\triangle \quad$ Capacity factor

$\eta \quad$ Efficiency of energy storage

$\theta \quad$ Bus voltage angle

$\tau \quad$ Annual scale factor (equal to $8760 / \mathrm{t}$ ) 


\section{CHAPTER 1 \\ INTRODUCTION}

This chapter briefly introduces the current and future situation of our electric power system and the research background of this dissertation. The potential impact of energy policies, renewable energy, and energy storage are discussed in section 1.1. The research objective of this dissertation is outlined in section 1.2. Section 1.3 describes the organization of this dissertation.

\subsection{Energy Future}

\subsubsection{Energy Policies}

In recent years, renewable energy sources - mostly wind and solar-have become one of the hot topics in the energy field. Many efforts have been to improve energy conversion efficiency and grid-integration reliability of renewables, as well as reduce the capital and maintenance costs. However, in those locations that are either remote from load centers or lack abundant resources, the overall performance of wind and solar generation, as well as other renewables, is still not economically competitive with traditional technologies such as coal and natural gas. The federal renewable electricity production tax credit (PTC) [1], originally enacted in 1992, aimed to compensate the high capital cost of renewables and stimulate their investment. Although it was a short-term policy in the beginning, it has been revised and extended six times. It is still active today. The policy was recently renewed and is believed to last another ten to twenty years in order to encourage more renewables which could replace most of the fossil-fuelfired electric generators.

Meanwhile, various policies are produced both regionally and nationwide to reduce greenhouse gas (GHG) emissions by replacing fossil-fuel-fired power plants with renewables. Early in 2006, Assembly Bill (AB) 32 became a California state law [2]. Passage of this bill led 
to the nationwide action of environmental protection relative to GHG emissions. One of the most important and challenging goals of AB 32 is to reduce, before the end of year 2020, the state's GHG emission levels to those of 1990. In addition, the California Energy Commission proposed a policy stating that the state of California would prohibit any coal plant operation as well as the import of electricity generated from coal plants located out of state [3]. Under emission regulations, replacement of fossil fuels (coal, natural gas, and oil) by renewable resources (wind, solar, biomass, geothermal, and small hydro) is an effective way to sustain increased energy consumption and reduce GHG emissions. As a response from the electrical power industry, most states across the country have set renewable targets, referred to as a Renewable Portfolio Standard (RPS), for the near future. The RPS for California [4], last revised in 2011, aggressively requires that $33 \%$ of electricity consumption come from renewable resources by the year 2020. In order to meet the RPS requirement, approximately $9 \mathrm{GW}$ of new renewable generators must be installed in California, as shown in Figure 1.1.

Both the power industry and the transportation sector are major sources of GHG emissions. Reducing $\mathrm{CO}_{2}$ and other GHG emissions is essentially a resource-alternating process for both the power and transportation industries. Under emission regulations, resources that produce energy will be forced to shift gradually from coal to natural gas, and from fossil fuel (coal, natural gas, oil) to sustainable non-fossil fuel (wind, solar, small hydro, tide, geothermal, biomass fuel, etc.). The electric vehicle is an example that uses electricity instead of gasoline to operate. However, if most of the energy consumed by electric vehicles comes from fossil-fuelfired power plants, then the overall emissions from both the transportation industry and the power industry will not notably decline and might even increase due to transmission loss and lower energy conversion efficiency on the electricity production side. In order to prepare for this 
additional energy consumption that is shifted from the transportation sector with the increased number of electric vehicles, it is very important to increase the penetration of renewable generation in the power industry.

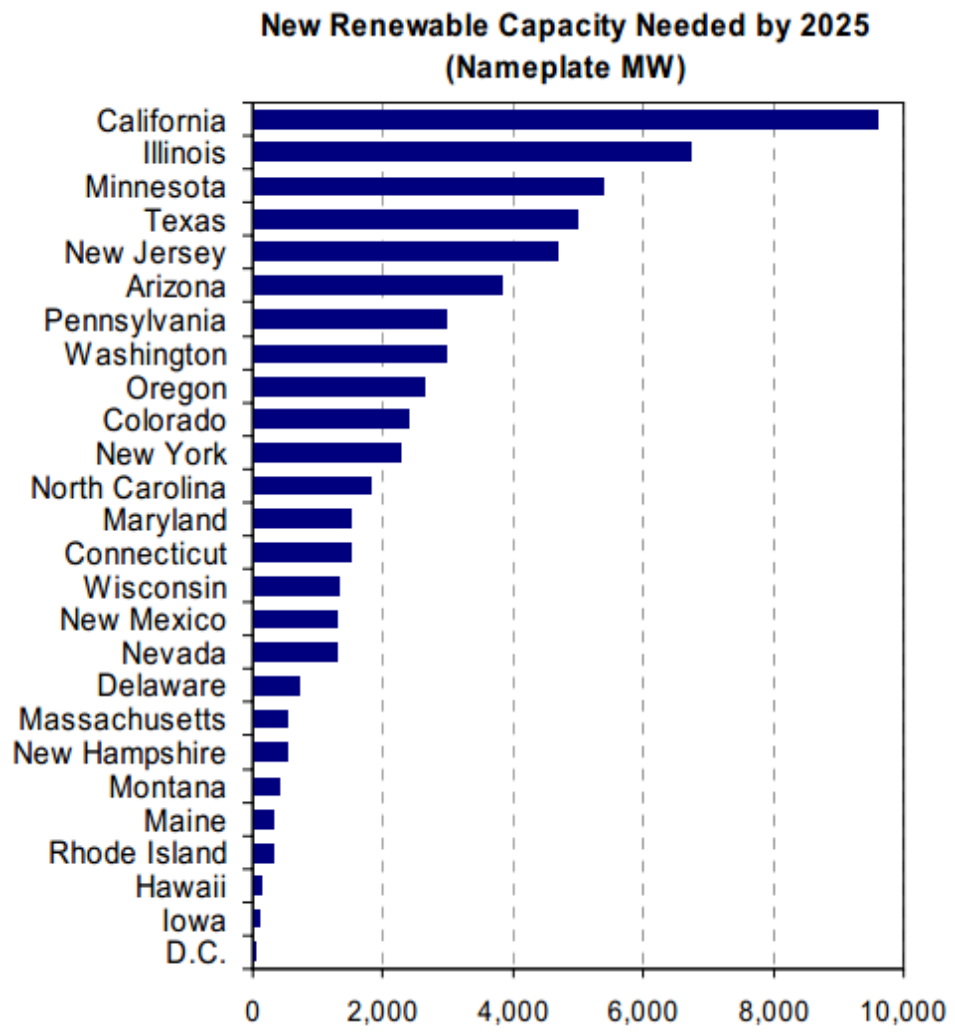

Figure 1.1. New renewable energy capacity required to meet existing state RPS policies [5].

To directly restrict $\mathrm{CO}_{2}$ emissions, emission regulation policies are being proposed and debated widely across the country. For example, the American Clean Energy and Security Act, known as the Waxman-Markey Bill and later revised as the American Power Act (KerryLieberman Bill), requires the capping of carbon emissions at $83 \%$ of the 2005 level by 2020 and $17 \%$ by 2050 [6]. A number of methods have been discussed to meet this requirement, such as cap-and-trade, command-and-control, and carbon tax. In power-flow studies, incorporating the cost of $\mathrm{CO}_{2}$ emissions into the generator heat rate function is a straightforward method to represent the $\mathrm{CO}_{2}$ regulation [7]. In addition, adding a constraint to cap the total $\mathrm{CO}_{2}$ emissions 
within a simulation time horizon (i.e. multiple time periods) is another feasible method in the planning study.

\subsubsection{Impact of Wind and Solar Generation}

The greatest disadvantage of wind and solar resources is their uncertainty of production, thus posing a major challenge to planning, day-ahead dispatching, or even hour-ahead dispatching. Generally, wind and solar generation are limited by the availability of resources. Their outputs are not dispatchable as needed by demand, except to be curtailed. Other renewables, such as geothermal, biomass, and small hydro, have operational flexibility, yet their expansion is restricted by resource availability, site location, or high capital costs.

The variability of wind and solar generation brings new challenges to system operators and market operators, especially when dealing with a high penetration of wind production. Since renewable generators are given preference in the market, they normally have higher priority than other generators to be dispatched. Transmission congestion and operation reliability are two major limitations of a renewable penetration level. With large-scale renewable generators online, gas and hydro generators with a higher ramp rate hold part of their capacity as reserves, which back up the unpredicted decrease of renewable generation or increase of energy demand.

Figure 1.2 shows an hourly renewable resources sample profile on two different days in 2012 observed by the California Independent System Operator (CAISO). The output of geothermal, biomass, biogass and small hydro generation is fairly constant and similar to fossilfuel-fired generation. The shape of the solar curve is relatively deterministic for sunny days, where the peak occurs around noon. Although the demand always peaks around hours 10 to 12 and 18 to 20, the solar profile aligns much better with the demand curve most of the time, compared to the wind profile. In the profile for November 22, wind was generating about 2000 
MW at midnight and dropped down to few hundred MW after 8 a.m., where demand was climbing. In this case, the power system needed at least 2,000 MW capacity as a spinning reserve or fast-start reserve to back up the wind. For November 24, a day where the wind was barely blowing, the system should have enough installed capacity (IC) to meet the demand and reserve requirement without wind generation.
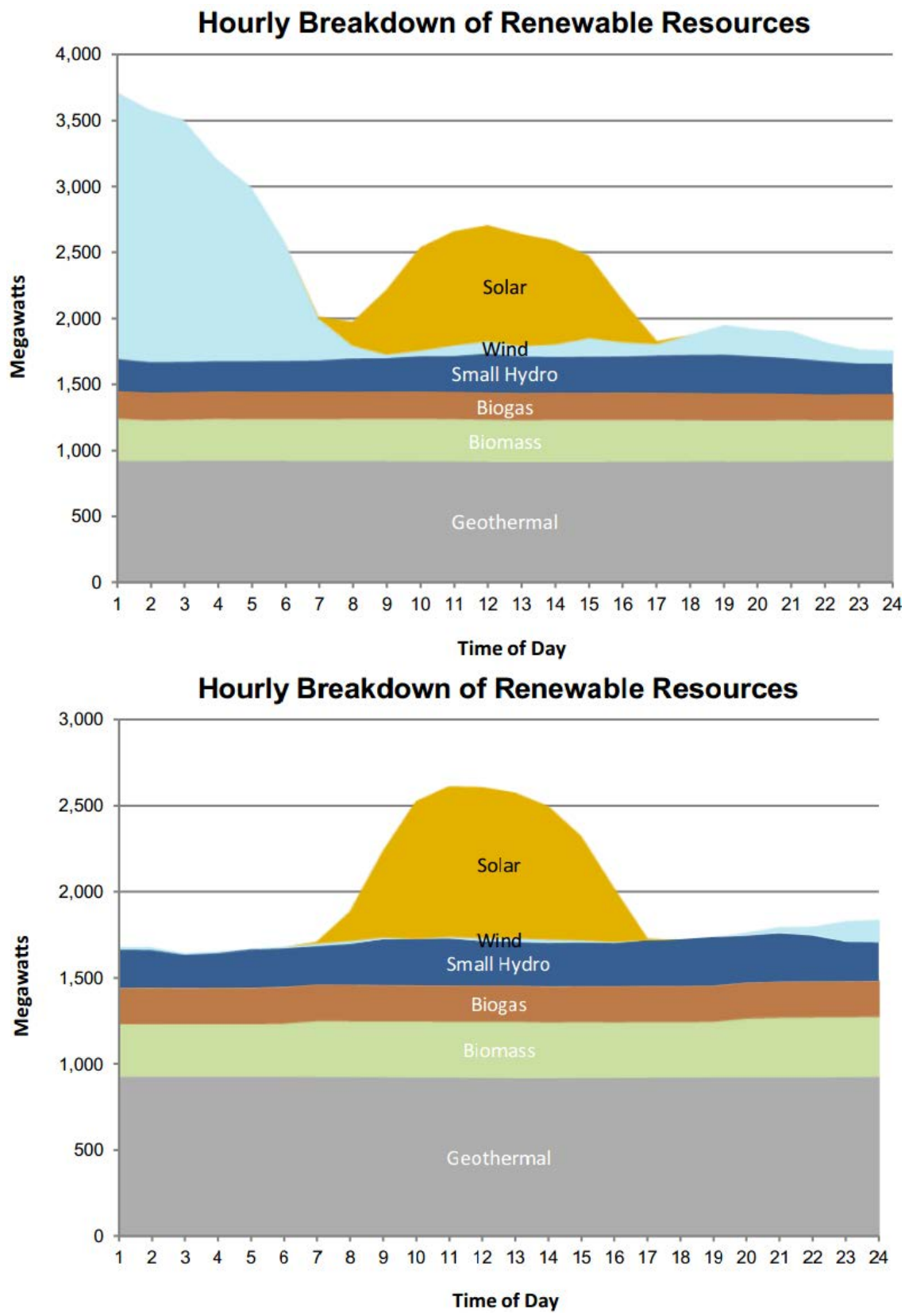

Figure 1.2. CAISO's daily renewables watch for November 22 (top) and November 24 (bottom) of 2012 [8]. 
In general, enough installed capacity or reserves should be operated as a backup for wind generation. These extra capacities are usually underused or inefficiently used (i.e., during fast ramping up) in terms of capital cost, operational cost, and $\mathrm{CO}_{2}$ emissions. These effects are even greater with a higher penetration level of wind and solar. The current penetration level ${ }^{1}$ of renewables and the projected level of 2015 in the Western Electricity Coordinating Council $(\text { WECC })^{2}$ system are compared in Figure 1.3, with data provided by Price and Goodin [9]. Under such circumstances, bulk energy storage systems could be utilized to operate as non-fuel cost and non-emitting reserves that replace underused generators. One of the research objectives in this dissertation is to assess the value of bulk energy storage in generation expansion planning with high potential of wind and solar sources.

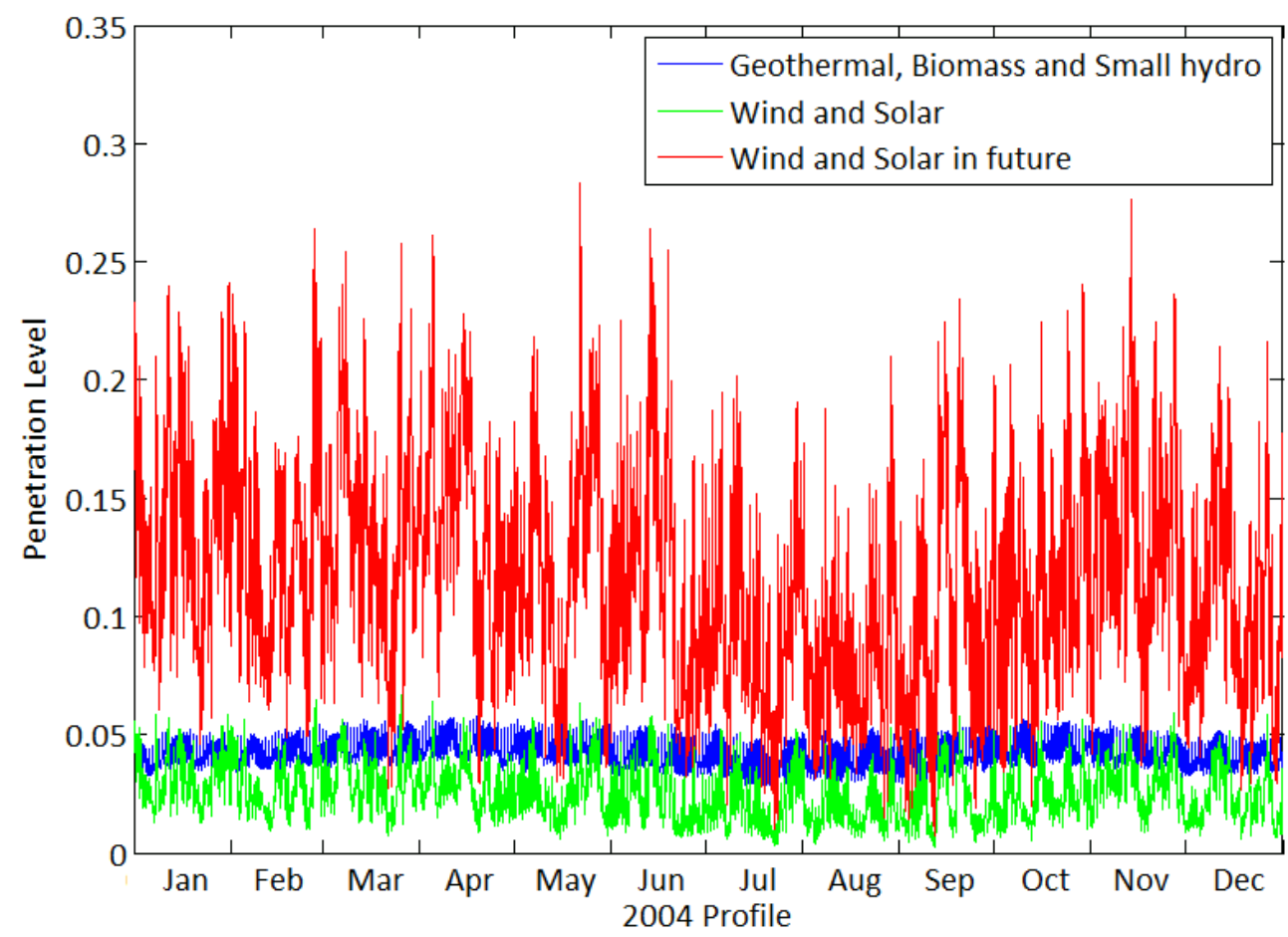

Figure 1.3. Penetration level of different renewables during 2010 (historical record) and forecast for 2015 according to 2004 load profile.

\footnotetext{
${ }^{1}$ In this research, penetration level is defined as energy consumed from renewable generation divided by total energy consumption.

${ }^{2}$ The WECC is the regional entity responsible for coordinating and promoting bulk electric system reliability in the Western Interconnection [10].
} 


\subsubsection{Potential of Storing Electricity}

Many advantageous features of the electric energy storage (EES) system have been explored following the growth of wind and solar generation. Traditionally, large pumped-hydro plants are designed and scheduled to accommodate the operation of thermal units, which were previously predominant in the power system. This is known as peak shaving operations [11]. Today and in the near future, thermal units that burn fossil fuels and emit a large quantity of GHGs are subject to graduate retirement. Operation of the EES may be determined by more economic or reliability criteria other than peak shaving. It could provide a valuable backup for variable wind and solar generators.

Many types of technologies have been used to store energy. Those that utilize a "physical" method of storing electricity are pumped-hydro, flywheel, electrochemical supercapacitor, and compressed air, while those that utilize a "chemical" method to store electricity are different types of batteries, such as lithium-ion (Li-ion), sodium sulfur (Na-S), vanadium redox (VR), and zinc bromine ( $\mathrm{Zn}-\mathrm{Br})$. Each type of EES system has some unique characteristics in terms of size, capital cost, operation and maintenance (O\&M) cost, cycle efficiency, ramp-rate capability, and life span. These characteristics primarily determine the application of an EES system. In general, the energy service market prefers EES with a larger capacity (both in MW and MWh) and higher cycle efficiency, and the ancillary service market prefers EES with higher ramping capability. For example, small-scale distributed EES (usually batteries) may be more suitable to smoothing out the fluctuating output of wind turbines [12] and providing voltage regulation. Flywheels are usually utilized to provide frequency regulation or short-term emergency power. Generally, most energy storage systems do not provide a positive net energy output during its operation lifetime. Conversely, they have net energy consumption due to energy-conversion losses, which are 
summarized as cycle efficiency $\eta$. Energy conversion losses are the major factor that reduces the economic value of installing an EES system. It is necessary to assess the economic value of each technology associated with its application and consider cycle efficiencies in order to guide the planning of future investment.

According to a report from the National Renewable Energy Laboratory (NREL) [13], EES applications in the current power system can be summarized as follows: load leveling or arbitrage, firm capacity, operating reserves, ramping or load following, transmission and distribution (T\&D) replacement and deferral, black start, and end-use applications. These applications can be categorized into three groups by functionality: energy management, bridging power, and power quality [13]. The possible size of each EES technology, in MW and MWh (expressed as discharge time) corresponding to the applications are summarized in Figure 1.4 . More details about planning and operating EES are discussed in the first section of Chapter 2.

\section{System Ratings}

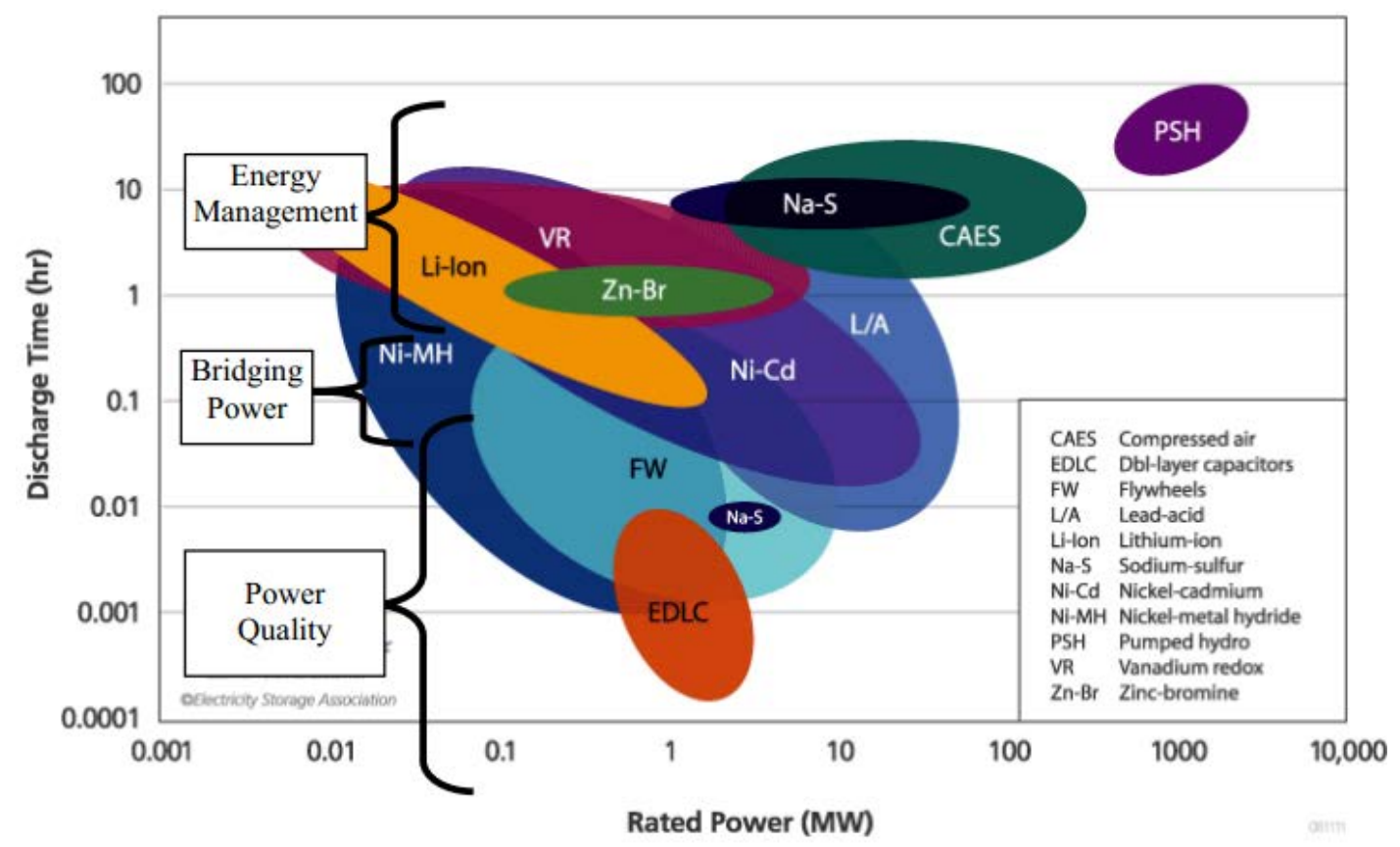

Figure 1.4. Energy storage applications and technologies [13] 


\subsection{Research Objectives}

The key objective of this research is to develop a generation planning model that considers variable outputs of wind and solar generators and explores optimal investments of energy storage in multiple locations. This research also analyzes the results through application of two test systems-a small 3-bus test system and a reduced 240-bus Western Electric Coordinating Council model. The outcome of this research-a proposed optimal planning model — could be utilized to analyze other power systems for policy-regulated planning or even operation purposes. The general conclusions derived from the test systems may provide limited references to the resource planning engineers and policies makers.

The following tasks are covered in this work:

- Construct the 240-bus WECC model in MATPOWER ${ }^{3}$ from raw data, including profiles of loads and renewables, and parameters of the transmission system and generators, provided by Price and Goodin [9].

- Run 24-hour operation simulations using alternating current optimal power flow (AC OPF) to study the impact of increased wind and solar generation to some major transmission paths, as well as locational marginal pricing (LMP) at the pumped-hydro storage buses in the WECC system.

- Develop a methodology that co-optimizes the operations of EES at multiple locations, and extend it to the generation planning model.

- Develop a generation planning model that includes the objective function, variables to be optimized, equality and inequality constraints, and variable bounds.

\footnotetext{
${ }^{3}$ An open-source MATLAB-based power system simulation package developed by Zimmerman et al. at Cornell University [15].
} 
- Collect the average or levelized cost data of each generator including EES by fuel type or by technology.

- Incorporate the price of $\mathrm{CO}_{2}$ emissions [7] and renewable incentives into the model inputs according to each study scenario.

- Use MATPOWER's extensible standard direct current optimal power flow (DC OPF) framework to solve the optimal planning problem.

- Analyze the planning results, including assessing the value of different energy storage technologies and the impact of multiple regulatory policies.

The planning model of this research is relatively detailed concerning energy storage optimization and therefore simplifies other operation criteria, for example, using DC OPF to solve the planning model, applying a linear cost model to all generators except for natural gas, and using an estimated limit for each transmission line where interface flow limits are ignored. When applying regulatory policies to this planning model in order to evaluate the impacts to the test systems, only two of them, in terms of $\mathrm{CO}_{2}$ emissions and renewable incentives, are used in this research. However, other policies, if designated, are possible to be incorporated into this optimal planning model as well by modifying the data inputs.

\subsection{Dissertation Outline}

The main body of this dissertation consists of six chapters. The first chapter introduces the prospective impact of energy regulatory policies, soaring wind and solar generation, and value of EES in the future grid. Chapter 2 reviews existing algorithms of EES modeling and optimization, generation planning, and simulation platforms. The AC OPF-based operation test of the WECC model to demonstrate the potential value of EES is discussed in Chapter 3. Chapter 4 presents the proposed optimal planning model and cost model for the planning simulations in 
this research. Chapter 5 introduces two test systems that were prepared for the planning study and analyzes the numerical results. Chapter 6 presents some general conclusions and future work. 


\section{CHAPTER 2}

\section{LITERATURE STUDY}

This chapter reviews the literature related to energy storage planning and operation, generation investment planning, and power-flow study tools. Section 2.1 compares the modeling and optimization of bulk energy storage with thermal generators and with renewables. The planning model of generation investment is investigated in Section 2.2. Finally, Section 2.3 introduces the simulation tools and some popular optimization solvers related to this work.

\subsection{Modeling and Optimization of Bulk Energy Storage}

\subsubsection{Coordination with Thermal Units}

Essentially, EES could be imagined as a virtual transmission line connected between different time periods of one location rather than a real transmission line connected between two different locations. With EES, a virtual transmission line, surplus (usually cheaper) energy at one period could be transported to another time period when energy is more valuable. With this unique feature, the modeling and optimization of energy storage need to consider the power flow status of multiple time periods in order to find the best solution.

Optimization of EES has been studied for more than a half century, beginning with an early study of hydrothermal coordination in 1963 [16]. Hydroelectric generator scheduling and pumped-hydro scheduling could be similar since both have storage (energy capacity) limitations among certain operating time intervals. Several algorithms have been developed to coordinate pumped-hydro storage and thermal generators, e.g., the gradient method [11], $\lambda-\gamma$ iteration [11], dynamic programming [17], and Lagrangian relaxation [18]. However, these algorithms could be more difficult to apply to a more detailed model that has large capacities of renewables and multiple EES units. Replacement of thermal plants by renewable generators causes traditional 
hydro-thermal coordination to be less applicable in future power systems because approximated cubic or quadratic heat rate curves, on which existing algorithms are based, do not apply to renewable generators such as wind and solar. Thus, a new EES scheduling algorithm needs to be developed.

\subsubsection{Coordination with Wind Turbines}

In the future grid, the scheduling of EES needs to focus more on renewable generation and the transmission system for at least two reasons: (1) renewable generators are given market preference and often have a lower operating cost than fossil-fuel-fired generators, especially with the added cost of GHG emissions, and (2) transmission congestion or variation occurs more frequently when handling generation from variable renewable resources like wind and solar. The power output of wind and solar units often has more variations and larger deviations compared to traditional generators and other renewables. Operational issues such as deficit of operating reserve, ramping capability, or voltage support are also involved. In general, coordinating with a high penetration level of renewables, an EES unit could make a profit or reduce the system operating cost, not only through energy arbitrage and congestion relief by participating in an energy market but also through ancillary services or other applications by participating in an ancillary market [19]. Assessing the value of EES providing ancillary service is beyond the scope of this work.

In a future grid dominated by wind and solar generators, which are modeled using flat operation curves instead of cubic or quadratic heat rate curves of thermal units, bulk energy storage appears to be less valuable by operating for energy arbitrage. However, through a shortterm operation study of a wind-enriched power system, a larger variation of LMP [20], which measures the marginal value of energy at certain locations, is usually observed. It reveals the 
potential value of energy arbitrage in such a system by alleviating the variation of wind output and relieving transmission congestion. To relieve transmission congestion, the scheduling of EES will be more economic by following the LMP, also referred to as nodal pricing, at the storage location [21]. In this approach, transmission loss and congestion need to be considered for energy storage scheduling, and therefore, AC OPF would be recommended. The LMP will have much larger and more frequent variance if there is a high penetration of variable renewable generation on the system. For example, in real practice, if wind generators produce more energy than a day-ahead or hour-ahead forecast, LMP will decrease drastically, and vice versa. Another situation is, when a forecast showing that wind will blow hard during the current off-peak period (midnight) but drop off during next the peak period, some slow-start generators (e.g. coal) would prefer to operate at their minimum output instead of completely shutting down during the current off-peak period, and wind generation has to be curtailed to meet the power balancing requirement (generation plus transmission loss equal to demand), which causes a significant drop of LMP (sometimes LMP even drops below zero at buses where wind generations are curtailed). EES operation could be designed intuitively as collecting energy at low-LMP periods and releasing it during high-LMP periods. This is the ideal situation whereby EES could make a profit by providing energy services as a participant in the energy market.

Recently, a multi-period optimization approach was proposed [22] [23] to modeling the energy arbitrage operation and optimal planning of EES coordinating with increasing renewables, especially wind. The methodology of modeling and scheduling EES slightly varies depending on the specific research scope, e.g., operation or planning. The planning study of EES needs to determine the sizes, both power and energy capacity, and even locations of energy storage and analyze their long-term investment, while the operation study uses pre-defined sizes and 
locations for energy storage and analyzes their short-term impacts. In long-term planning studies, a stochastic model of renewables and load are often adopted, and the effect of a transmission system is often ignored [22] [24]. These studies often focus on the modeling of long-term pricing and the investment rate of generators and EES units, and only utilize economic dispatch or DC OPF to deal with the linear model of the aggregated power system. Operational studies of EES often employ a deterministic model with a detailed AC transmission system and respect the power system reliability [23]. Other studies using a deterministic reliable operation model without considering the effect of the transmission system could be a compromise between operation and planning [25] [26]. However, it is notable from [26] that the security-constrained unit commitment is considered in the optimization model and solved by using mixed-integer programming.

In this research, the modeling of EES is similar to the planning model proposed by $\mathrm{Oh}$ [22], but it is combined with generation expansion planning modeling, which is discussed in Section 2.2. The optimization of the planning problem utilizes linear lossless DC OPF, deterministic renewable and load profiles, and multi-period optimization.

\subsection{OPF-Based Generation Planning}

Generation expansion planning and transmission expansion planning are two major planning topics in the power industry. Generally, these two topics should be combined because each one closely depends on the other. However, transmission planning is not considered in this research because either of the problems alone is a complex optimization model, and the major scope of this work is on planning for resource and energy storage.

The generation planning model in this work is developed based on the planning algorithm used in the PSERC project M-24 [27] with the SuperOPF planning tool [28]. SuperOPF is a 
MATLAB-based tool box that further utilizes MATPOWER's extensible OPF structure [29] to deal with stochastic, contingency-based, security-constrained OPF problems. The two-stage solver in the SuperOPF tool is capable of solving both day-ahead and real-time optimal operation problems. The first stage solver, c3sopf, can be easily modified to c3sopfi for the generation investment planning problem (details can be found in Appendix B in the User's Manual), and it has been tested and applied to the policy-regulated resource planning model developed in the M24 project.

Except the planning model of energy storage, the generation planning model for wind and solar will be different from the model proposed in the PSERC project, where all wind generators share an identical capacity factor (as well as solar generators) and ignore the hour-byhour variations. This is a typical planning algorithm that normally applies to traditional generators and is even applicable to hydro units. However, applying this algorithm to wind and solar is found to be unrealistic. It will enrich the value of wind and solar because their outputs are treated as dispatchable, both up and down, during the OPF simulation. In this work, hourly maximum outputs of wind and solar, referred to as profiles, will be applied to each wind and solar unit and will vary according to their locations. The negative side of this modeling algorithm is that the size of the problem is expanded with more simulated time points.

Moreover, the chronologic cost analysis with renewables developed by Poonpun [30] and a $\mathrm{CO}_{2}$ emissions-incorporated OPF algorithm developed by Shao [7] will be applied to the operations study and the optimal planning model, respectively, in this research.

\subsection{Simulation Tool}

In order to solve the OPF-based multi-period optimization problem, MATPOWER will be primarily used as the simulation tool. The whole optimization model proposed in this research 
is solved by utilizing MATPOWER's extensible OPF structure. The key portion of the generation planning model applied in the SuperOPF tool is rebuilt in MATPOWER to achieve faster processing speed because SuperOPF is built on top of MATPOWER and is repurposed to solve the generation investment problem.

MATPOWER's extensible standard OPF structure [29] is as follows:

Objective function:

$$
\min _{\mathrm{x}, \mathrm{z}} f(x)+f_{u}(x, z)
$$

Constraints:

$$
\begin{gathered}
g(x)=0 \\
h(x) \leq 0 \\
x_{\min } \leq x \leq x_{\max } \\
l \leq \mathrm{A}\left[\begin{array}{l}
x \\
z
\end{array}\right] \leq u \\
z_{\min } \leq z \leq z_{\max }
\end{gathered}
$$

For standard $\mathrm{AC} \mathrm{OPF}$, the optimization vector $x$ consists of voltage angle $\theta$, voltage magnitude $V_{m}$, active power injection $P_{g}$, and reactive power injection $Q_{g}$. The term $f(x)$ denotes the cost of active and reactive power output of all generators. The term $f_{u}(x, z)$ could be defined by users and is optional. In a standard AC OPF model, equation (2.2) represents the energy balance constraint; equation (2.3) is the inequality constraint or power flow constraint for each transmission line; equation (2.4) represents the bounded variables $\theta, V_{m}, P_{g}$, and $Q_{g}$; and equations (2.5) and (2.6) construct the additional variables and constraints associated with the user-defined objective function. For a standard DC OPF, $V_{m}$ and $Q_{g}$ are dropped, and transmission losses are ignored. 
In contrast to the previously used PowerWorld simulator, MATPOWER utilizes a standard OPF solver rather than primal linear programming (LP) OPF [31]. The LP OPF linearizes non-linear constraints before solving the model. This process improves the solution time but loses accuracy. Upper and lower bus voltage limits are not able to be added to PowerWorld's LP OPF model. PowerWorld is a commercial tool with predefined functions and add-ons whose source code is completely sealed in order to prevent users from adding more variables and constraints into the OPF model. MATPOWER is open source, and its extensible OPF architecture [29] provides more flexibility for modifying the optimization model based on the user's needs. The MATLAB Interior Point Solver (MIPS) [32] is a powerful nonlinear solver that can be utilized to solve both AC OPF and DC OPF. MATPOWER also has an interface to invoke other powerful nonlinear programming and quadratic programming solvers, e.g., MINOPF [33], TSOPF [34], BPMPD [35], MOSEK [36], CPLEX [37], GUROBI [38], etc., according to different types of optimization models. The sequential hourly simulation of operation study in this work is solved by using the default MIPS, while the long-term planning problem, a much larger one with multi-period optimization and energy-storage model, needs be solved by using more powerful solvers, e.g., GUROBI or CPLEX.

However, MATPOWER, as a power flow study tool, certainly has some drawbacks. It does not have any user-friendly interfaces or windows, which allow input or output data to be sorted easily. Without a one-line diagram display, the power grid parameters and real-time power flow are not easily viewable. 


\section{CHAPTER 3}

\section{IMPACT OF RENEWABLES ON WECC SYSTEM}

Before developing the planning study, fundamental analysis of the reduced 240-bus WECC model in terms of AC OPF simulation is necessary to help understand the simulation tool, power network topology, modeling issues, marginal price variations, etc. Details of the WECC model are described in the first section. Section 3.2 introduces the model setup in MATPOWER and discusses some modeling experiences. Section 3.3 provides the numerical results of the WECC model for a 24-hour sequential run using AC OPF. Finally, some discussion is provided in Section 3.4.

\subsection{Description of WECC Model}

The full network model (FNM) of the WECC coordinated power system is currently not publicly available. The test system of the reduced WECC 240-bus model was provided by Price and Goodin [9] at CAISO. The development of this model was based on a previous 225-bus model for a market operation study [39], where it was extended from a 179-bus model originally built for power system operation analysis [40]. These reduced models were constructed by aggregating the bulk transmission system ${ }^{4}$ and generators, and estimating the transmission line parameters at their best effort. Fortunately, the 240-bus model was provided as a validated model for a market study after being verified with the results of the WECC FNM.

The network model of the WECC was received as a raw data file in PTI format [41], the topology of which is displayed in Figure 3.1. The model was first imported into PowerWorld, and the economic dispatch was studied visually by creating a one-line diagram, as shown in Figure 3.2. In order to conduct research in MATPOWER, this WECC model was converted to

\footnotetext{
${ }^{4}$ There is no unified definition for a bulk transmission system. Normally, it refers to the transmission system with voltage level of $115 \mathrm{kV}$ or above.
} 
the MATPOWER format and tailored for operation studies. For example, the interface (i.e., a group of transmission lines connected between two areas) limits could be bounded instead of imposing MVA limits for each transmission line in MATPOWER, but this is not feasible in PowerWorld. System reserves could also be co-optimized with power flow in MATPOWER.

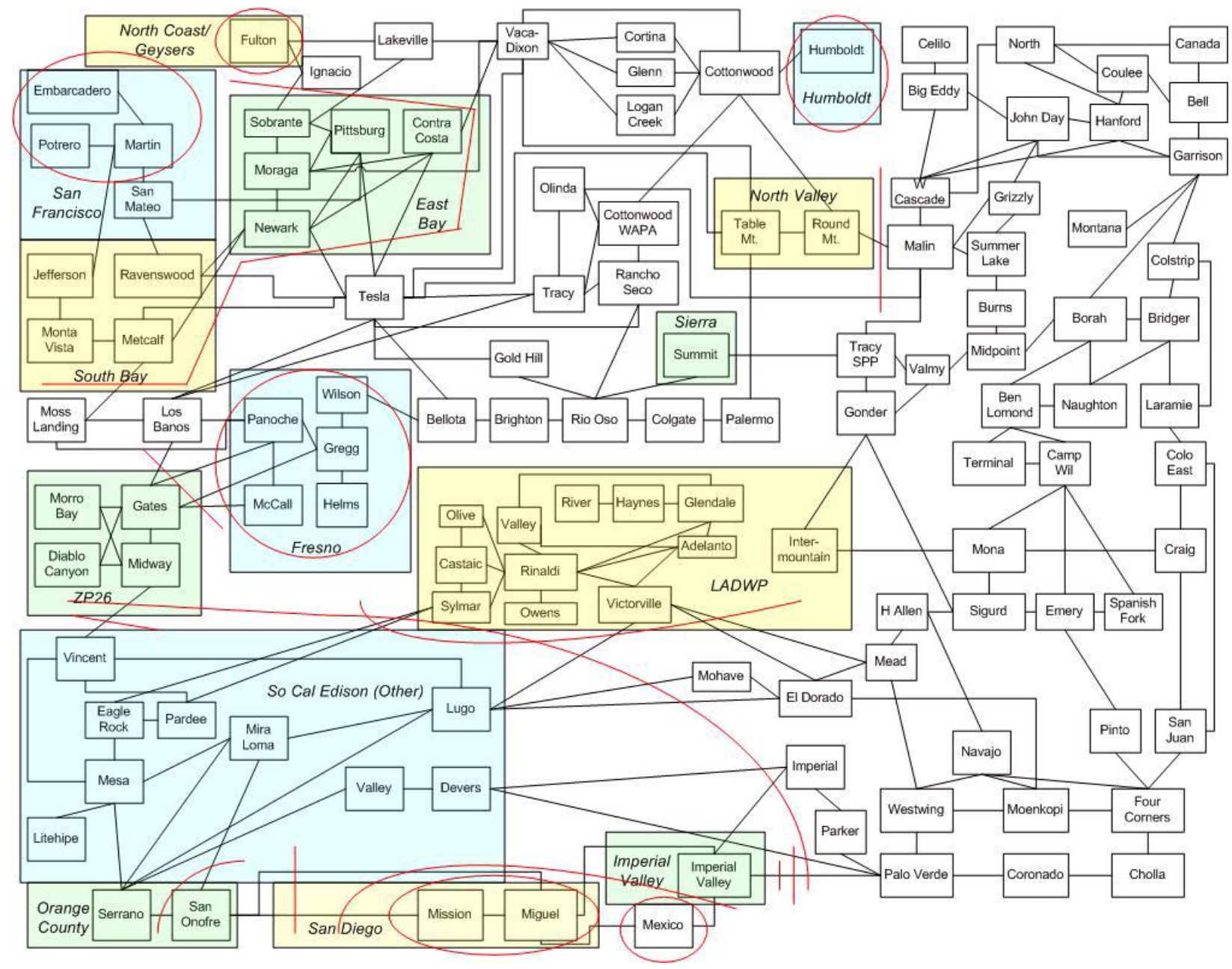

Figure 3.1. Network topology of 240-bus WECC model. 


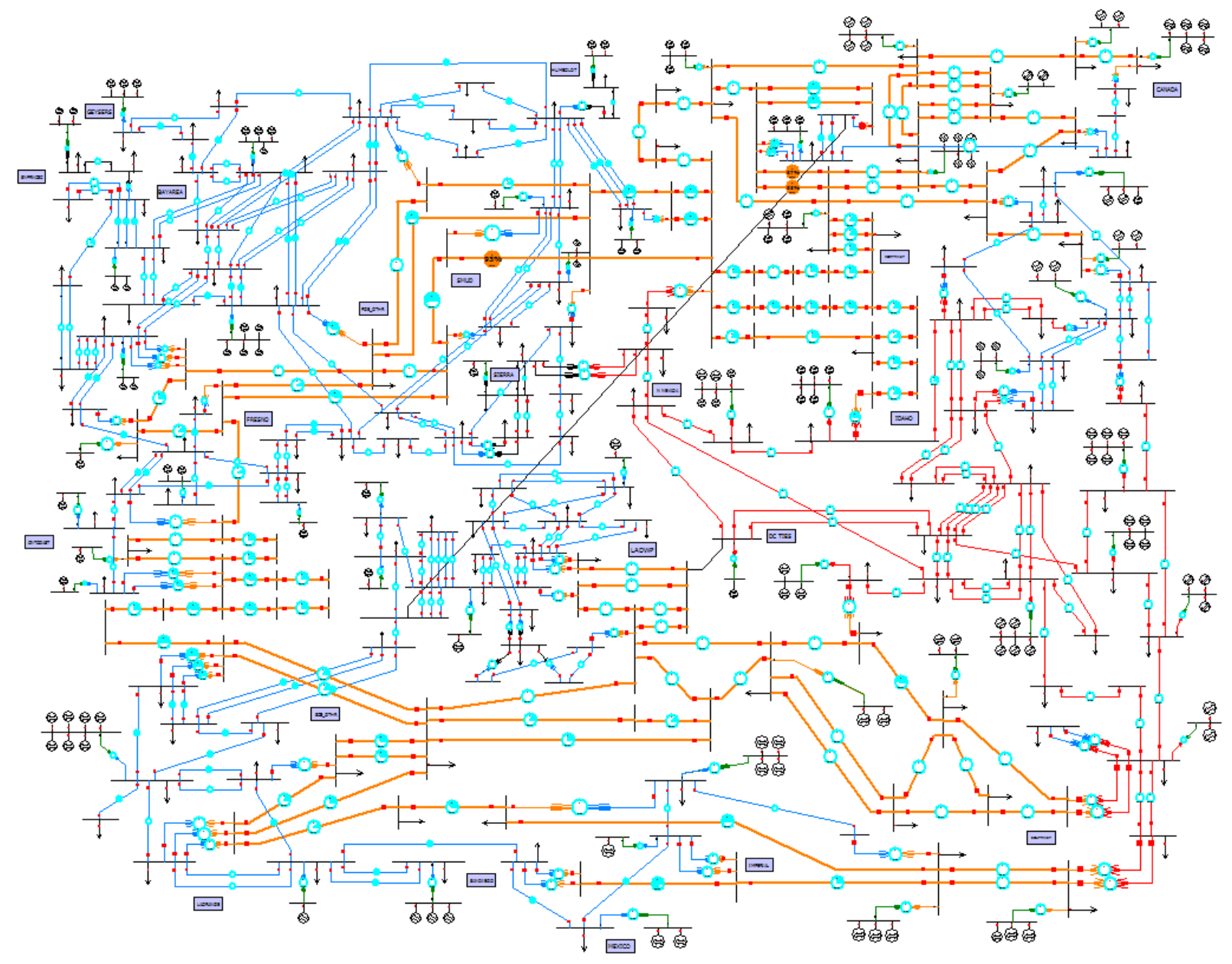

Figure 3.2. One-line diagram of 240-bus WECC model in PowerWorld.

\subsection{Model Setup in MATPOWER}

The WECC model constructed in MATPOWER is consistent with the settlements of major components as proposed by Price and Goodin [9], except for the added optimization of two high-voltage direct current (HVDC) transmission lines - the Pacific DC Intertie (PDCI) and the Intermountain HVDC (Path 27). Hourly outputs of hydro generators, both coordinating with current renewables and future renewables, are directly applied with the profile data, which is optimized by Price and Goodin [9]. However, in the planning simulation described in the next two chapters, the hydro generators are optimized according to the best investment decision. 
Following the PTI file, Bus 3933 "Tesla" is selected as the system reference bus (slack bus). Lower and upper limits of the bus voltages are set at 0.95 and $1.11 p u$, respectively. Maximum power outputs $\left(P_{\max }\right)$ of the hydro and renewable generators are imported from hourly profiles. The $P_{\max }$ of coal units are set at $85 \%$ of maximum capacity, based on average performance of the coal generators. The $P_{\min }$ of gas, hydro, and nuclear units are set at 5\%, 20\%, and $90 \%$ of maximum capacity, respectively.

For simplicity in this WECC model, a linear cost model is applied to coal, nuclear, hydro, and renewable generators, with operating costs (linear coefficients) of 16.04, 5, 25, and 5 $\$ / M W h$, respectively. Only gas units, with the highest installed capacity by fuel type in the WECC system, have a quadratic cost model. The operating cost of the nuclear, hydro, and renewable generators described above are suggested values from Price and Goodin [9]. The operating costs $(\$ / \mathrm{MWh})$ of coal and gas generators are calculated by using the fuel price (\$/MBTU) multiplied by the heat rate (MBTU/MWh) of each generator. Since heat rate data of coal units in the WECC model is not provided, an annual average operating heat rate of 10.414 MBTU/MWh [43] is assigned to all coal generators in this model. Fuel prices of $\$ 1.54 / \mathrm{MBTU}$ and \$5/MBTU [9] are used for all coal and gas generators, respectively. As a result of this price setting, nuclear and renewable units have top priority to be dispatched, followed by coal, hydro, and gas.

Since thermal limits of all transmission lines are not publicly available, interface (path, corridor) flow limits are suggested to apply to the OPF study. The transmission-constrained interfaces in this model are shown in Figure 3.3. The interface flow is the summation of power flows through a group of transmission lines with a predefined direction. Interface flow often represents a net import to or export from an area or zone. Its limit is derived from a reliability 
study by operations engineers and is normally lower than the summation of thermal limits of each individual transmission line. Modeling of the transmission system in this study makes a tighter area interchange and looser inner area power flow.

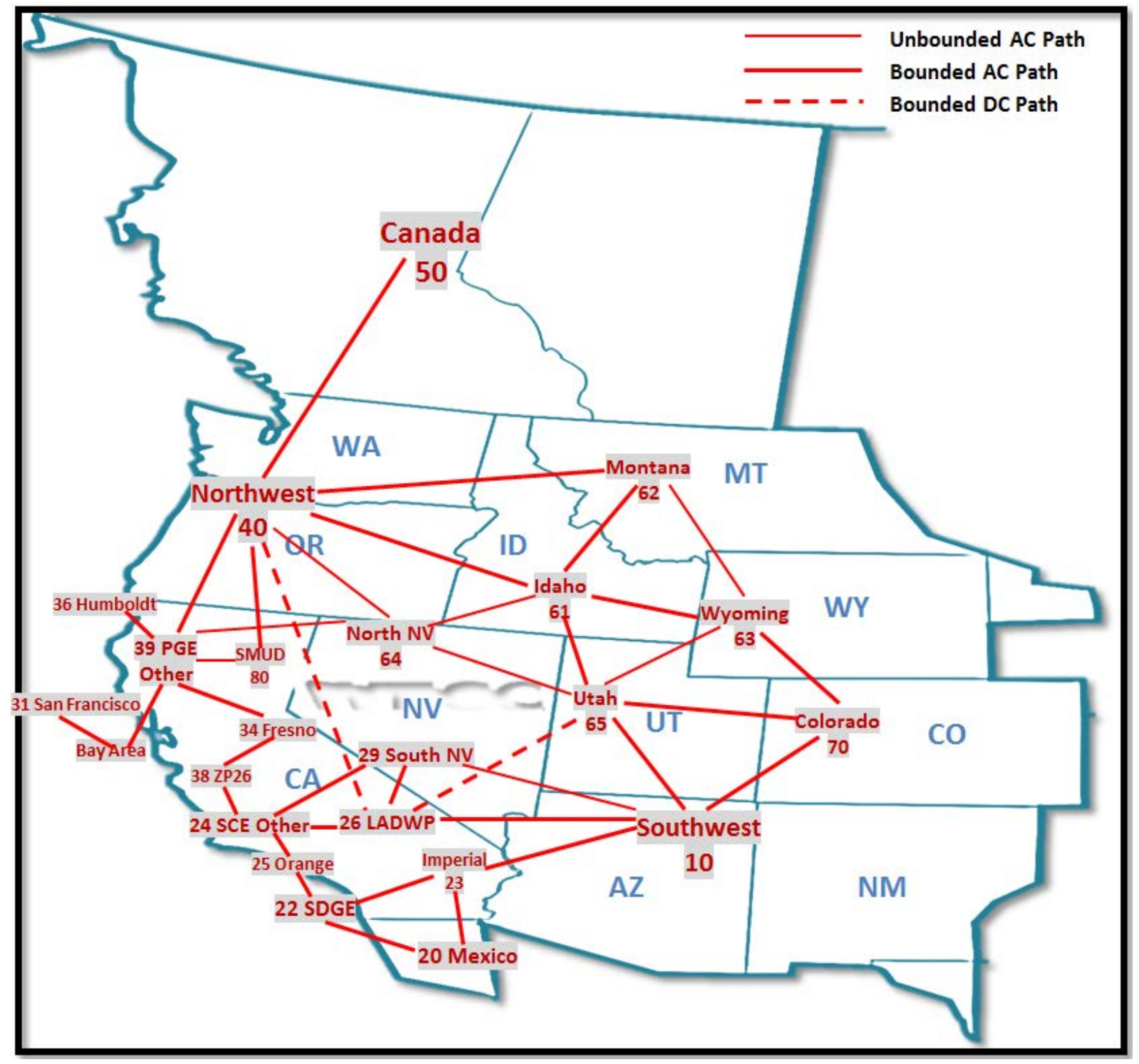

Figure 3.3. Transmission map of WECC 240-bus model.

The reduced 240-bus model is a larger, more-realistic, and detailed model compared to some frequently used small test models, e.g., the IEEE 24-bus reliability test system [42]. It brings more challenges relative to constructing, solving, error checking, and collecting and 
analyzing results. The specifications, challenges, and suggestions through the model setup for AC OPF operation studies in MATPOWER are summarized as follows:

- 240 Buses: Appropriate voltage range must be assigned for each bus, which could affect the solving time and results of AC OPF. Also, lower and upper voltage limits of each bus can be different.

- 448 Branches: No specific thermal limits are available for all branches including transformers. It is suggested to use interface flow (transmission path or corridor) limits and often reliability limits for the operation study. Two HVDC transmission lines could be modeled in the lasted version of MATPOWER (v. 4.1) (see User's Manual, Section $6.5 .3)$

- 145 Generators: Even though hydro generators are optimized in both the base case and the future case according to load and renewables, it is necessary to redo the optimization if a new study scenario is created, for example, further increased renewable generation, less amount of water capacity available for hydro generation, unit commitment with ramp rate and reserve added, etc. Other generators have constant maximum and minimum power output range as specified by Price and Goodin [9].

- Cost: Appropriate cost curves, necessary for all generators, are based on certain study scenarios. The cost curve provided by Price and Goodin [9] is relatively flat for a large portion of the generators, which decreases the benefit of storing electricity and impairs the solver performance. Either generation cost or cycle efficiency of storage, or both, could be modified accordingly to reflect the real values of EES. 


\subsection{Numerical Study}

To test the modeling and OPF solver, a summer day (July 30, 2004) profile is selected to examine the OPF results of this model. All generators are committed online. The load profile is the same for both cases - the first with existing renewable generators and the second with projected future renewables. The generation profile of the base case contains the power output of existing renewable generators and optimized hydro generation, while that of the future case contains the power output of projected future renewable generation and an optimized hydro schedule in the future. There is no restriction or price on $\mathrm{CO}_{2}$ emissions in this case.

OPF results of 24-hour generation by fuel type in both the base case and the future case are plotted in Figure 3.4. Their comparison shows that generation from gas units decreases as much as $50 \%$ due to the increased renewables and almost hits the minimum $(93,420 \mathrm{MW})$ from 2 am to $4 \mathrm{am}$. With existing renewables, wind and solar (variable) generators have a total capacity of 7,199 MW, but an output of 2,857 4,519 MW for this daily period. Geothermal, biomass, and small hydro (invariable) generators have a total capacity of 5,145 MW, generating 3,939 4,078 MW. It is obvious that these "invariable" renewables have a much higher capacity credit and lower output variations. However, they are more resource-limited and therefore expand very slowly compared to wind and solar. In a future profile, the output of invariable renewables is almost the same, but wind and solar generation climbs to $11,559 \sim 19,126 \mathrm{MW}$, with more observable variations.

In a future case of this study day, generation from variable renewables is negatively correlated with daily demand. It is worse if only considering wind generation because the peak output of solar power is relatively fixed from $12 \mathrm{pm}$ to $5 \mathrm{pm}$, but wind often blows during the night. In this situation, hydro and gas generators are dispatched almost down to minimum during 
off-peak hours. If there is more output available from wind with a lower demand on the system, which likely will occur in the spring or fall, then the output from the coal generators must be lowered or wind generation itself must be curtailed, if transmission is congested.

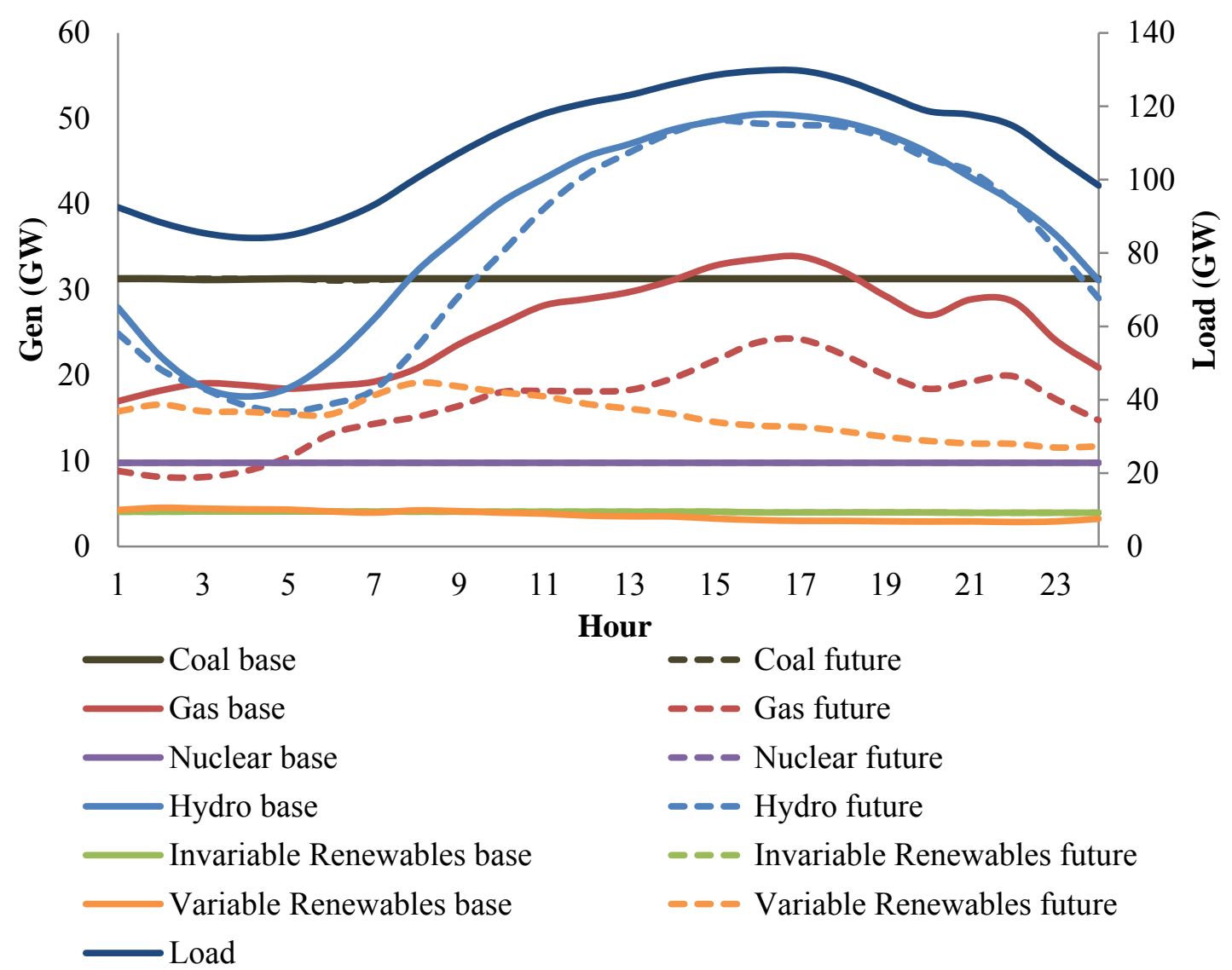

Figure 3.4. Generation dispatch by source type in base case and future case of a summer day (data profile of July 30,2004).

An increased renewable penetration level leads to decreased LMP with higher deviations in a daily period, as shown in Figure 3.5 and Figure 3.6. LMP is the marginal energy cost with transmission congestion and loss considered at particular location (i.e., bus). Normally, higher LMP indicates insufficient energy, and lower LMP indicates a surplus of energy at that location. This is a good indicator for energy arbitrage by EES. Theoretically, EES makes a profit within an operation cycle if the LMP at charging divided by the LMP at discharging exceeds cycle 
efficiency. For a particular EES, a higher deviation between lower and higher LMP within a certain period usually provides more profit for an energy-arbitrage operation.

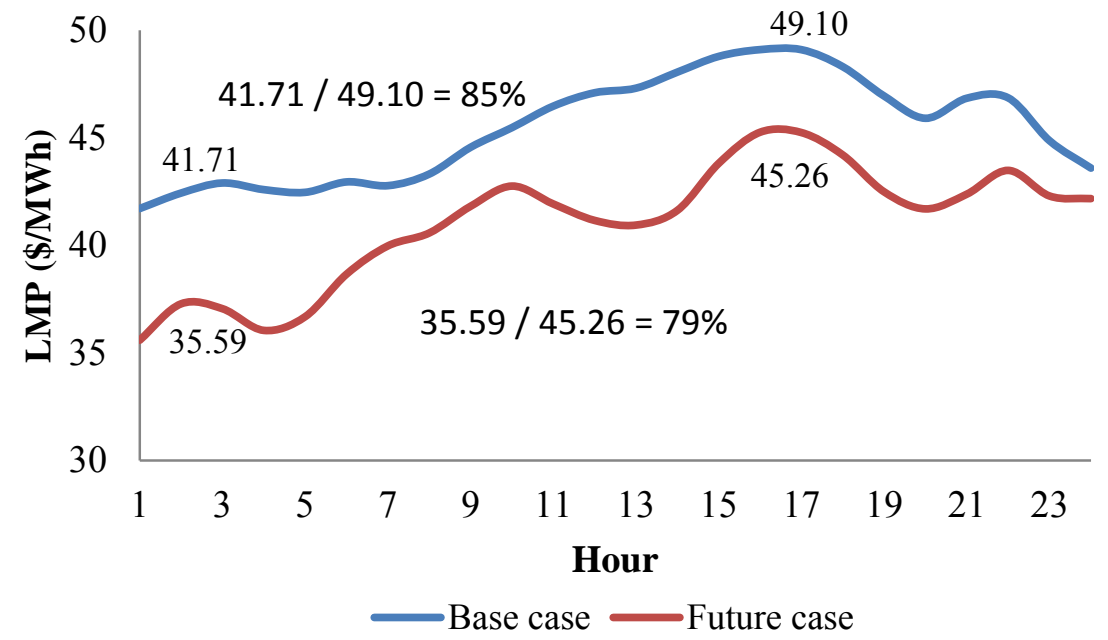

Figure 3.5. LMP at bus 2638.

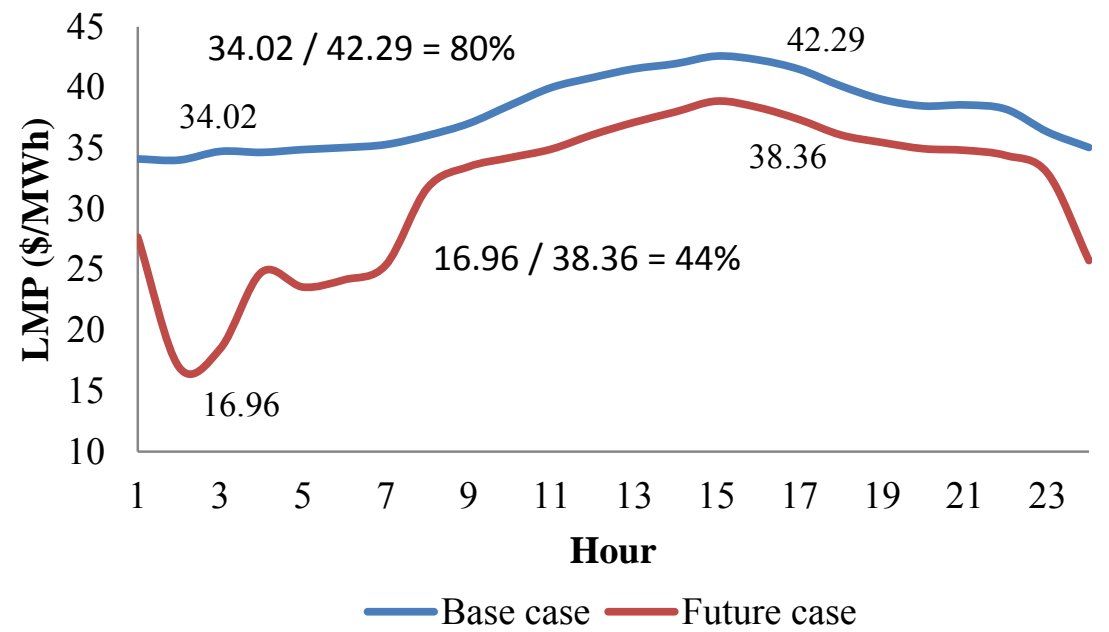

Figure 3.6. LMP at bus 7031.

As shown in both figures, energy arbitrage produces more economic benefits in the future case. For this particular day, pumped-hydro storage at bus 7031, "Colorado East," receives a higher profit in the future case. The LMP at bus 7031 drops as low as 16.96 at midnight because of high wind output and low load in that area (i.e., Colorado). 
Figure 3.7 and Figure 3.8 show the results of the impact of future renewables on the interface flow of Southern California Import Transmission (SCIT) and PDCI. SCIT is the largest corridor in this WECC model, containing fifteen $500-\mathrm{kV}$ and three $230-\mathrm{kV}$ AC transmission lines with a reliability limit of $10,000 \mathrm{MW} .{ }^{5}$ SCIT connects southern California, including the Los Angeles Department of Water and Power, to northern California via path 26, to the northwest area (Oregon) via PDCI, and to the southwest area (Arizona) via path 46.

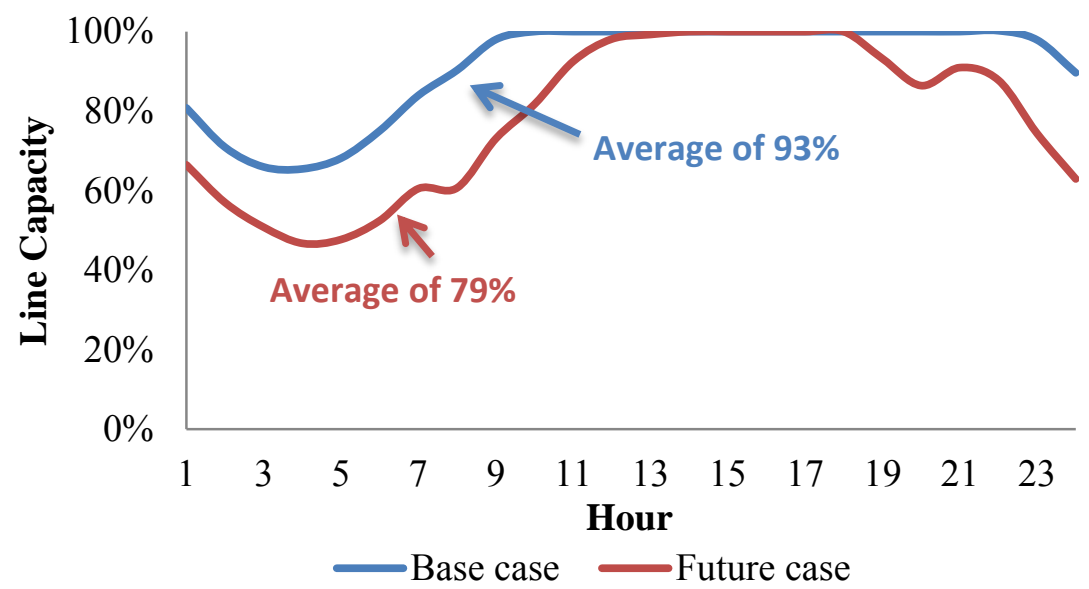

Figure 3.7. Impact of renewables on SCIT import with maximum transmission capacity of 10,000 MW.

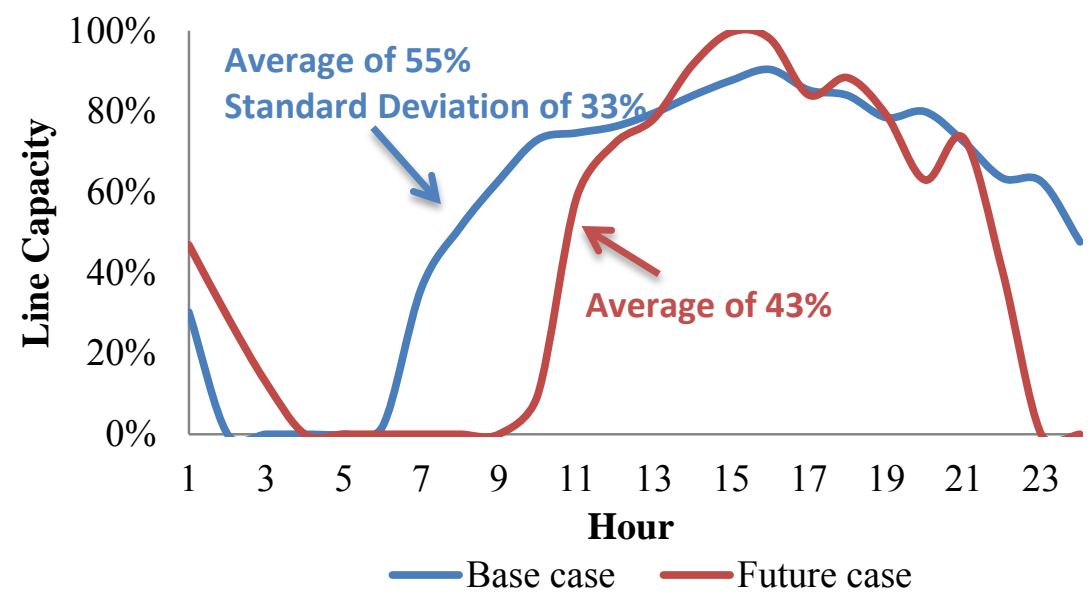

Figure 3.8. Impact of renewables on PDCI with north to south maximum transmission capacity of 3,313 MW.

${ }^{5}$ The SCIT limit varies with system conditions [9]. It is suggested to use 10,800 MW for June, July, August, and September, and 10,000 MW for a typical week profile. 
After analysis, it was found that, as a result of the increased renewable penetration level, the average power transmission level decreases and the deviation increases. However, it is interesting to see that the hours of maximum flow decrease in the future case of SCIT. This is mainly affected by off-peak generation from wind and on-peak generation from solar power at bus 2438 "Mesa" in the Southern California Edison (SCE) footprint.

Other results like daily $\mathrm{CO}_{2}$ emissions and transmission losses of the WECC model in both cases are listed and compared in Table 3.1. It is worth pointing out that transmission losses are greater in the future case. This is nothing to be concerned about because energy from renewables is cheap and clean. It is better to use the energy rather than curtail it, as long as the system operating cost and $\mathrm{CO}_{2}$ emissions are lowered.

TABLE 3.1

OPF RESULTS COMPARISON OF DAILY OPERATION

\begin{tabular}{|l|c|c|}
\hline & Base Case & Future Case \\
\hline Load $(\mathrm{GWh})$ & $2,619.2$ & $2,619.2$ \\
\hline Renewable penetration level (\%) & 7 & 17.5 \\
\hline $\mathrm{CO}_{2}$ emissions from coal (ton) & $746,724.4$ & $746,552.2$ \\
\hline $\mathrm{CO}_{2}$ emissions from gas (ton) & $263,616.4$ & $172,029.1$ \\
\hline Total $\mathrm{CO}_{2}$ emissions (ton) & $1,010,340.9$ & $918,581.4$ \\
\hline Highest LMP of P (\$/MWh) & $51.27 @ 3301$ & $51.07 @ 3301$ \\
\hline Lowest LMP of P (\$/MWh) & $-21.92 @ 6205$ & $14.60 @ 6205$ \\
\hline Highest LMP of Q (\$/MWh) & $2.75 @ 6104$ & $9.46 @ 5004$ \\
\hline Lowest LMP of Q (\$/MWh) & $-477.3 @ 6235$ & $-53.76 @ 6235$ \\
\hline Transmission losses (GWh) & 49.4 & 55.7 \\
\hline Transmission losses (\% of generation) & 1.85 & 2.08 \\
\hline Total system operating cost (\$ million) & 59.2 & 50.6 \\
\hline
\end{tabular}




\subsection{Discussion}

With the increased penetration level of renewable energy, mostly wind and solar, the power flow on transmission paths fluctuates more and the usage rate of transmission lines is lowered. Meanwhile, LMP at selected buses experience higher deviations with more wind and solar generation. These observations could be generalized to all buses and transmission lines in the system. The operation analysis of the WECC system provides a hint that energy storage investment is a feasible solution with increased wind and solar penetration in the future grid. The planning study in the next two chapters determines the optimal investment size of EES in selected locations and further analyzes the potential of each technology for bulk storage and impact on the planning model. 


\section{CHAPTER 4}

\section{MODELING METHODOLOGY AND DATA COLLECTION}

The planning model begins with this chapter, where formulation of the entire optimization problem and cost parameters that support optimal planning in this research are presented. Section 4.1 describes the construction of the mathematical optimization model that provides optimal operation-based generation expansion planning with EES and hydro optimization, which are new contributions in this dissertation. Section 4.2 analyzes the data sources that are used as input parameters of the optimization model.

\subsection{Design of Optimization Model}

\subsubsection{Objective Function}

The objective function is to minimize the total cost across the simulated time horizon $(t)$, as shown in equation (4.1). The total cost in the optimal operation-based generation expansion planning model here contains variable cost (i.e., $C_{g}^{V}$, including fuel cost and O\&M cost) of existing generators $(g)$, fixed cost $\left(C_{i}^{F}\right)$ savings from retired power capacity $\left(R_{i}\right)$ of generators allowed to be retired (i); and variable cost $\left(C_{j}^{V}\right)$, fixed cost $\left(C_{j}^{F}\right)$, and investment cost (i.e., capital cost recovery, $C_{j}^{I}$ ) of new generators $(j)$ including EES.

$$
\min _{\theta_{k}, P_{i j t}, R_{i}, I_{j}, I P_{j}, I E_{j}}\left\{\begin{array}{c}
\tau \sum_{t} C_{g}^{V} P_{g t}+\sum_{i}\left[C_{i}^{F}\left(P_{i}^{0}-R_{i}\right)\right]+ \\
\sum_{j}\left[\tau \sum_{t} C_{j}^{V} P_{j t}+\left(C_{j}^{I}+C_{j}^{F}\right)\left(I_{j}+I P_{j}+I E_{j}\right)\right]
\end{array}\right\}
$$

This objective function co-optimizes the hourly operation (i.e., first term), the retirement of generation capacity (i.e., second term), and the operation of optimal-invested capacity (i.e., third 
term) across the entire planning horizon $(t)$. It drives down the total cost by retiring those underused capacities with a higher fixed cost and installing new generators with both lower capital cost and fixed cost. Compared to the objective function used in the PSERC M-24 project (i.e., equation (3.1) on page 47 of the report [27]) this objective function drops the benefit function of demand response (i.e., $B_{j k}$ as expressed in the report) but adds the investment function of energy storage (i.e., $I P_{j}$ and $I E_{j}$ in the objective function of equation (4.1).

In MATPOWER, the generator cost function is specified in the mpc.gencost struct. It can be expressed in terms of piecewise linear or polynomial. The variable cost $C^{V}(\$ / \mathrm{MWh})$ associated with power output and the fixed cost $C^{F}(\$ / \mathrm{MW})$ associated with power capacity can be incorporated into either of the two cost models of each generator. For example, the cost of emissions or other penalties could be incorporated into the objective function by adding an extra

$\$ / \mathrm{MWh}$ cost to the $C^{V}$ in the generator cost function, if needed, e.g., $\mathrm{CO}_{2}$ emissions-incorporated OPF [7].

Other costs associated with user-defined variables $(R, I, I P, I E)$, which represent the retired MW capacity, invested MW capacity, invested MW capacity of EES, and invested MWh capacity of EES, respectively, must be specified in the user-defined cost function. The details of how to add user-defined cost are introduced in Section 5.3.1 of the MATPOWER 4.1 User's Manual.

\subsubsection{Variables}

The variables in this optimization problem consist of standard variables from MATPOWER's standard AC OPF or DC OPF frame, and user-defined variables that are new contributions in this dissertation using the extended OPF formulation. For faster-solving performance, simulations in this research are based on standard DC OPF with variables $\theta$ and $P_{g}$, 
the voltage angle at each generator bus and the power output of each generator, respectively. Voltage magnitude $V_{m}$ and generator reactive power output $Q_{g}$ will be dropped to reduce the size of the problem. The user-defined variables added in this research are $R, I, I P$, and $I E$, which are vectors with specified upper and lower bounds. Equation (4.2) to equation (4.8) indicate the upper and lower bounds of each variable.

$$
\begin{gathered}
\theta_{k}^{\text {ref }} \leq \theta_{k} \leq \theta_{k}^{\text {ref }}, \quad k \in[\text { reference bus }] \\
\theta_{k}^{\text {min }} \leq \theta_{k} \leq \theta_{k}^{\text {max }}, \quad k \notin[\text { reference bus }] \\
P_{i j}^{\text {min }} \leq P_{i j} \leq P_{i j}^{\max } \\
R_{i}^{\text {min }} \leq R_{i} \leq R_{i}^{\max } \\
I_{j}^{\text {min }} \leq I_{j} \leq I_{j}^{\max } \\
I P_{j}^{\text {min }} \leq I P_{j} \leq I P_{j}^{\max } \\
I E_{j}^{\text {min }} \leq I E_{j} \leq I E_{j}^{\max }
\end{gathered}
$$

\subsubsection{Network Constraints}

The standard DC OPF constraints, denoted as equations (2.2) to (2.4) were introduced in Chapter 2. For example, equation (4.9), which enforces power balance in the network, is categorized as the equality constraint in equation (2.2) in the OPF model.

$$
\sum_{i} \sum_{j} \sum_{t} P_{i j t}=\text { Total Annual Demand }
$$

Also, additional constraints are applied to MATPOWER's extensible framework, i.e. constraint equations (2.5) and (2.6), using the callback functions (see Section 6.2 in the MATPOWER 4.1 User's Manual). In this research work, constraints of hydro optimization, generation expansion planning, and energy storage investment are constructed and can be applied to the optimization model separately. 


\subsubsection{Hydro Optimization Constraints}

The constraint used for hydro optimization is written as equation (4.10) which enforces the condition that the total energy output from hydro generators in the simulated time horizon should not exceed the water availability of that period.

$$
\sum_{t} P_{t}^{\text {hydro }} \leq \Delta^{\text {hydro }} \sum_{t} P_{t}^{\text {hydro,max }}
$$

The water availability is expressed as the total energy capacity of all hydro units multiplied by the capacity factor. To be specific, different capacity factors could be applied to different hydro generators, which require that multiple constraints be added.

\subsubsection{Generation Expansion Planning Constraints}

Constraints, listed as equations (4.11) to (4.14), are used for generation expansion planning in this optimization model.

$$
\begin{gathered}
0 \leq P_{i t}+R_{i} \leq P_{i}^{\max } \\
P_{j t} \leq \delta_{j t} I_{j} \\
\sum I_{j}^{S} \leq I^{s, \max } \\
\sum_{i} \Delta_{i} R_{i} \leq \sum_{j} \Delta_{j}\left(I_{j}+I P_{j}\right)
\end{gathered}
$$

Equations (4.11) and (4.12) are constraints of power output from retired generators and invested generators, respectively. In this situation, the results of variable $R_{i}$ could be any optimal value between $\max \left[P_{i}^{\min }, R_{i}^{\min }\right]$ and $\min \left[P_{i}^{\max }, R_{i}^{\max }\right]$. In reality, a generator will be retired mostly in terms of an entire unit, which should be considered as a mixed-integer optimization problem. However, when dealing with a heavily reduced power system model with most of the generators aggregated by fuel type and location, e.g., the reduced 240-bus WECC model, it will be much easier to use linear programming method for the generation expansion planning problem without losing much accuracy. For the investment constraint in equation (4.12), $\delta_{j t}$ is a vector that 
reflects the resource availability for each generator $j$ at time point $t$. This vector is necessary to represent the hourly variable output of wind and solar. For those generators that are not resourcedependent, $\delta_{j t}$ is normally set as 1 for all $t$. Constraint equation (4.13) indicates that the sum of invested generator $j$ of fuel type $s$ should not exceed the maximum investment allowed for that fuel type. Constraint equation (4.14) enforces the fact that new invested capacity should cover the demand increase and the amount of retired capacity. The capacity factor $\Delta$ is considered for each generator according to the fuel type.

Constraint equations (4.11), (4.12), and (4.13) retain similar functions as those developed in the SuperOPF Investment Planning Tool. Constraint equation (4.14) is added to simply ensure the adequacy of resources and reserves. These variables and constraints are directly defined and added by using MATPOWER's callback functions in order to minimize the computational overheads in terms of both execution time and memory consumption. In SuperOPF, the planning problem solver c3sopfi is modified from the day-ahead problem solver c3sopf and, therefore, contains more variables and constraints than needed for investment planning simulations. When running c3sopfi, those unnecessary variables and constraints are automatically relaxed to eliminate their functions yet generate extra computational overhead.

\subsubsection{Energy Storage Optimal Planning Constraints}

As stated previously, EES has unique operation features like limited power capacity and energy capacity. To respect these features, all time periods within an operation cycle of the EES should be incorporated into one single model to find the optimal operation schedule of the EES. The user-added $A$ matrix in constraint equation (2.5) associated with the storage variables is not as sparse as that with the generation planning variables and, of course, is much larger in size. In 
other words, if it is applied, the EES model will generate most of the constraints in this optimization model due to the time-related and energy-limited operation feature of EES.

The EES operation-related constraints are listed as equations (4.15) to (4.21).

$$
\begin{gathered}
0 \leq P_{j t}^{c} \leq I P_{j} \\
0 \leq P_{j t}^{d} \leq I P_{j} \\
0 \leq P_{j t}^{c} \leq \frac{I E_{j}-E_{j}^{t-1}}{\eta_{j}^{c}} \\
0 \leq P_{j t}^{d} \leq \eta_{j}^{d} E_{j}^{t-1} \\
E_{j}^{t}=E_{j}^{t-1}+\eta_{j}^{c} P_{j t}^{c}-\frac{P_{j t}^{d}}{\eta_{j}^{d}} \\
0 \leq E_{j}^{t} \leq I E_{j} \\
E_{j}^{T}=E_{j}^{0}=\alpha I E_{j}
\end{gathered}
$$

Constraint equations (4.15) and (4.16) indicate that the power input (i.e., charge) and the power output (i.e., discharge) at any time period should not exceed the installed power capacity of the EES. Equation (4.17) realizes the fact that charging power should not exceed the amount of empty capacity left from the previous time period. Similarly, equation (4.18) denotes that discharging power should not exceed the amount of energy remain from the previous time period. Equation (4.19) calculates the remaining energy in the EES for each time period. Equation (4.20) is a physical limit of the remaining energy for each time period. In order to maintain a fair economic analysis of energy storage, it is necessary to implement the binding equation (4.21), whereby the amount of energy left after one operation cycle should be equal to that at the initial status. Among these equality and inequality constraints, equations (4.17), (4.18), (4.19), and (4.21) are cross-period constraints that reflect the operational feature of the EES. 


\subsubsection{Additional Operating Constraints}

There might be other constraints used to represent normal operating conditions. For example, equations (4.22) and (4.23) indicate that conventional hydro generators and natural gas generators often hold a portion of their capacity, $13 \%$ and $10 \%$, respectively, as assumed in this research, for spinning reserves.

$$
\begin{gathered}
P_{\text {hydro }} \leq P_{\text {hydro }}^{\max } \times 87 \% \\
P_{\text {gas }} \geq P_{\text {gas }}^{\max } \times 90 \%
\end{gathered}
$$

\subsection{Data Preparation}

\subsubsection{Generation and Load Profile}

Load profile, which represents the instant power demand at specific buses of each time point, is preloaded to the optimization model for each simulation. Generation profile is typically used to set the maximum output of wind and solar generators according to the amount of wind and solar energy available at each time point.

In this research work, a sequence of hourly time periods will be applied to the optimal planning simulation for all testing cases. In order to minimize the optimization model size and solving time, a typical week profile will be used instead of running through all 8,760 hours of one year. Generally, this work uses four typical weeks, each week representing a season in a year. The typical week profile of generation and load will preserve the peaks, minimums, and averages of each season, and represent the changes between neighboring hours [9]. Another method of reducing problem size is by using typical hours to represent each operation scenario in a year. For example, as used in the project report of Schulze et al. [27], an annual operation could be divided into 16 scenarios, with peak, high, medium, and low of each season, which are represented by 16 hours accordingly. However, using contiguous hours in typical days or weeks 
could better represent the operational behavior of EES interact with wind and solar generation. The tradeoff will be the augmented problem size.

\subsubsection{Variable Cost}

The variable cost, also known as production cost, is defined as the cost associated with the energy output of each generator, expressed as \$/MWh. In the MATPOWER simulation tool, the variable cost of each generator (including user-added generators employing callback functions) could be added into the mpc.gencost matrix directly. Depending on the design of the experiment, the variable cost could incorporate fuel cost, variable O\&M cost, emissions cost, and any subsidy for wind and solar generation.

Fuel price usually has a large impact on the results of generation expansion planning. It is difficult to predict the future fuel price because this is determined by the market of commodities. Normally, fuel prices will be slightly increasing over a typical planning horizon (i.e., 20 to 30 years) due to currency inflation and increased energy consumption. The natural gas price has a relative larger divergence since 1997 according to archived data from the U.S. Energy Information Administration (EIA) (Figure 4.1). The natural gas price is believed to remain uncertain for the future prospective. Therefore, it is necessary to simulate a set of diverse prices to examine their impacts on different planning scenarios.

In this planning study, the levelized cost of energy (LCOE) of fuel cost (if any) and O\&M cost is utilized as an average variable cost for each generation technology. Listed in Table 4.1 are the LCOE data derived by NREL-SEAC ${ }^{6}$ in the report by Tidball et al. [45], which are selected as variable costs in the simulation, except for the fuel costs of natural gas generators.

\footnotetext{
${ }^{6}$ NREL-SEAC: National Renewable Energy Laboratory Strategic Energy Analysis Center
} 

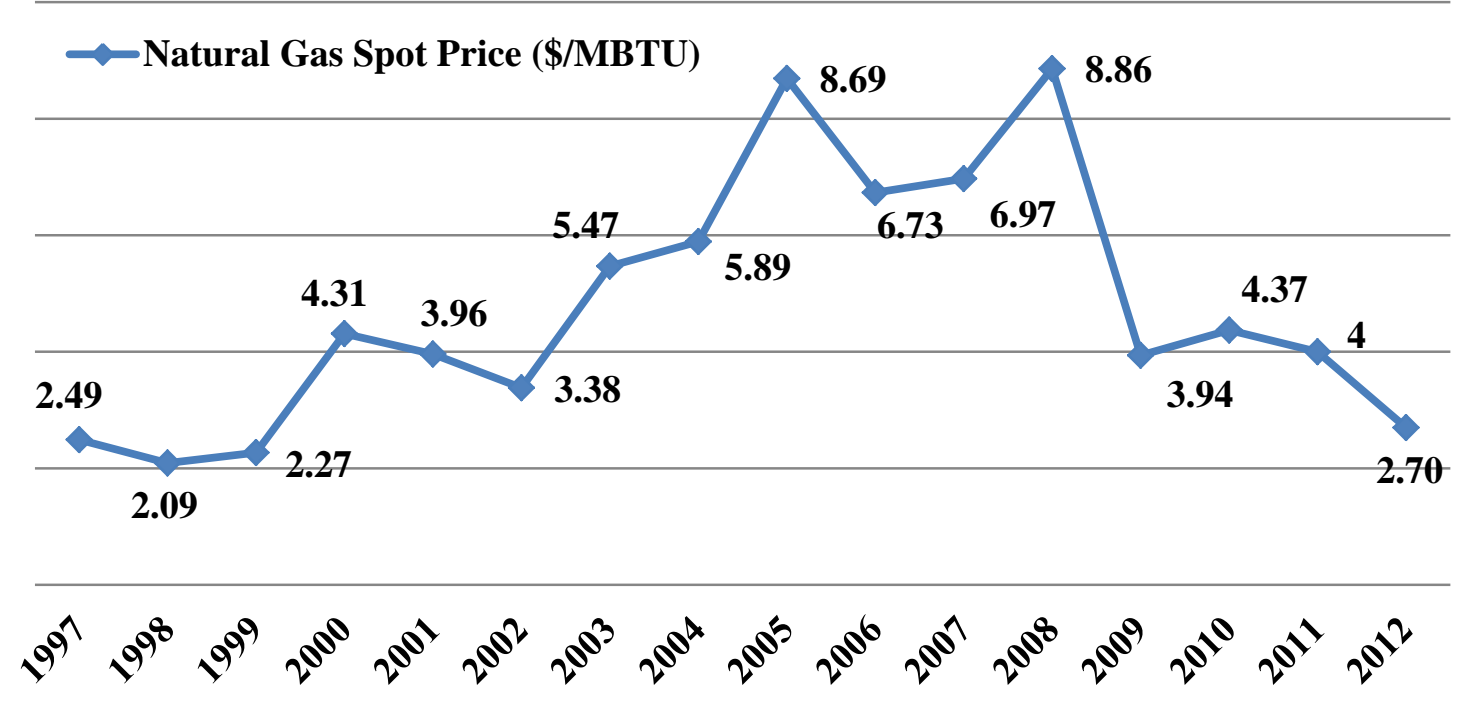

Figure 4.1. Henry Hub Gulf Coast Natural Gas Spot Price.

TABLE 4.1

LEVELIZED FUEL COST AND O\&M COST

\begin{tabular}{|l|c|c|c|c|}
\hline \multirow{2}{*}{ Technology } & \multicolumn{2}{c|}{ Fuel Cost (\$/MWh) } & \multicolumn{2}{c|}{ O\&M Cost (\$MWh) } \\
\cline { 2 - 5 } & $\mathbf{2 0 1 5}$ & $\mathbf{2 0 3 0}$ & $\mathbf{2 0 1 5}$ & $\mathbf{2 0 3 0}$ \\
\hline Coal & 18.70 & 20.49 & 6.54 & 6.54 \\
\hline Natural Gas & as specified & as specified & 5.00 & 5.00 \\
\hline Nuclear & 9.92 & 12.90 & 12.02 & 12.02 \\
\hline Wind (onshore) & 0 & 0 & 8.08 & 7.31 \\
\hline Solar Thermal & 0 & 0 & 17.03 & 17.03 \\
\hline Photovoltaic (utility scale) & 0 & 0 & 5.76 & 3.43 \\
\hline Geothermal & 0 & 0 & 22.86 & 22.86 \\
\hline Biomass & 29.35 & 31.11 & 19.73 & 19.73 \\
\hline
\end{tabular}


To simulate a policy-regulated $\mathrm{CO}_{2}$ emissions reduction, e.g., the Kerry-Lieberman Bill, a variable emissions cost (in $\$ / M W h$ ) is added to each coal or natural gas generator model. According to the emissions-incorporated OPF algorithm developed by Shao [7], it is more accurate to incorporate the $\mathrm{CO}_{2}$ emissions rate in ton/MBTU to the heat rate function, which is usually nonlinear and unique, of each generator. To reduce problem size in the planning study, an average $\mathrm{CO}_{2}$ emissions rate expressed in ton/MWh is designated to each type of generator, listed in Table 4.2, which is calculated as the product of average $\mathrm{CO}_{2}$ emission factors, in ton/MBTU, of coal and natural gas [7] and average heat rates, in MBTU/MWh, of each type of generator [43].

TABLE 4.2

AVERAGE $\mathrm{CO}_{2}$ EMISSION RATE (TON/MWH)

\begin{tabular}{|l|c|}
\hline \multicolumn{1}{|c|}{ Generator Type } & CO2 Emission Rate \\
\hline Coal & 0.8333 \\
\hline Natural gas (combustion turbine) & 0.5117 \\
\hline Natural gas (combined cycle) & 0.3411 \\
\hline
\end{tabular}

\subsubsection{Fixed Cost}

The fixed cost of each generator may include startup cost, fixed O\&M cost, tax, and insurance. The startup cost is often considered in the unit commitment process, which is not included in this planning work. Land rental cost, tax, and insurance are usually expressed as \$MW cost, which is related to the power capacity of each generator. These costs vary by states and will be ignored in this model. The annual fixed O\&M costs from NREL-SEAC data are 
listed in Table 4.3 for different types of generators [45]. The fixed O\&M cost are assumed to be constant throughout the planning horizon.

TABLE 4.3

ANNUAL FIXED O\&M COST IN 2015 (\$/MW)

\begin{tabular}{|l|c|}
\hline \multicolumn{1}{|c|}{ Fuel Type } & Annual Fixed O\&M Cost \\
\hline Coal & 36,780 \\
\hline Natural gas (combustion turbine) & 6,880 \\
\hline Natural gas (combined cycle) & 15,000 \\
\hline Nuclear & 93,770 \\
\hline Wind (onshore) & 11,980 \\
\hline Solar thermal & 48,790 \\
\hline Photovoltaic (utility scale) & 9,920 \\
\hline
\end{tabular}

\subsubsection{Capital Cost}

Except for the fixed O\&M cost, capital cost is another major part of the investment cost for new generators. The overnight capital cost (OCC) is considered a total cost for the overall construction of a power plant. In this study, it is broken down into an annual cost, denoted as annual capital recovery (ACR). The ACR of each power plant is the product of the OCC and the capital recovery factor (CRF), which is normally derived by

$$
C R F=\frac{i(1+i)^{n}}{(1+i)^{n}-1}
$$

where $n$ is the number of years for the loan, and $i$ is the interest rate. In this study, the interest rates for coal and nuclear plants are assumed to be higher due to the longer loan duration and 
higher financial risk, as shown in Table 4.4. The OCC data of 2022 and 2032 are derived from the long-term capital cost forecasted by NREL-SEAC [45].

TABLE 4.4

CAPITAL COST BY FUEL TYPE

\begin{tabular}{|c|c|c|c|c|c|c|c|}
\hline Technology & $n$ & $\begin{array}{c}i \\
(\%)\end{array}$ & $\underset{(\%)}{\text { CRF }}$ & $\begin{array}{c}\text { OCC in } \\
2022 \\
(\$ / k W)\end{array}$ & $\begin{array}{c}\text { OCC in } \\
2032 \\
(\$ / k W)\end{array}$ & $\begin{array}{c}\text { ACR in } \\
2022 \\
(\$ / M W)\end{array}$ & $\begin{array}{l}\text { ACR in } \\
2032 \\
(\$ / M W)\end{array}$ \\
\hline Coal & 60 & 14.57 & 14.57 & 2400 & 2400 & 349,780 & 349,780 \\
\hline $\begin{array}{l}\text { Natural Gas } \\
\text { (CC) }\end{array}$ & 30 & 12 & 12.41 & 820 & 820 & 101,798 & 101,798 \\
\hline Nuclear & 60 & 14.57 & 14.57 & 3200 & 3100 & 466,373 & 451,799 \\
\hline $\begin{array}{l}\text { Wind } \\
\text { (onshore) }\end{array}$ & 20 & 12 & 13.39 & 1600 & 1500 & 214,206 & 207,512 \\
\hline Solar Thermal & 30 & 12 & 12.41 & 4600 & 4600 & 571,061 & 571,061 \\
\hline $\begin{array}{l}\text { Photovoltaic } \\
\text { (utility scale) }\end{array}$ & 30 & 12 & 12.41 & 2200 & 1800 & 273,116 & 223,459 \\
\hline
\end{tabular}

\subsubsection{Energy Storage Data}

The input data of each EES applied in this planning model involves location, minimal and maximum investment allowance (for both power and energy capacity), initial rate, charging and discharging efficiency, ACR of power, ACR of energy, and O\&M cost. Only five technologies that have been used or proven to be potentially applicable as bulk energy storage for energy management are considered in this planning simulation. According to the cost analysis in different study reports [45] [46] [47] [48], capital costs as well as cycle efficiencies always present a wide range of variation. In order to explore the average planning results of each EES technology, the capital cost and efficiency are divided into two levels of situation - the best and the worst. Summarized from two reports [47] and [48], the best situation consists of the lowest capital cost and the highest efficiency, and vice versa. Similar to the ACR calculation of 
generation technologies, under assumptions of 250 cycles per year operation and the $3 \%$ interest rate shown in Table 4.5, the ACR of EES are calculated and presented in Table 4.6.

TABLE 4.5

EES PARAMETERS

\begin{tabular}{|l|c|c|c|c|c|}
\hline \multicolumn{1}{|c|}{ Technology } & $\begin{array}{c}\text { Cycles } \\
\text { in Life }\end{array}$ & $\begin{array}{c}\text { Average } \\
\text { Cycles } \\
\text { per Year }\end{array}$ & $\boldsymbol{n}$ & $\begin{array}{c}\boldsymbol{i} \\
(\boldsymbol{\%})\end{array}$ & $\begin{array}{c}\text { CRF } \\
(\boldsymbol{\%})\end{array}$ \\
\hline Pumped Hydro (PH) & 25,000 & 250 & $50^{\dagger}$ & 3.00 & 3.89 \\
\hline $\begin{array}{l}\text { Compressed Air Energy } \\
\text { Storage (CAES) }\end{array}$ & 25,000 & 250 & $50^{\dagger}$ & 3.00 & 3.89 \\
\hline Sodium Sulfur (Na-S) & 3,000 & 250 & 12 & 3.00 & 10.05 \\
\hline Vanadium Redox (VR) & 5,000 & 250 & 20 & 3.00 & 6.72 \\
\hline Lithium-ion (Li-ion) & 4,000 & 250 & 16 & 3.00 & 7.96 \\
\hline
\end{tabular}

${ }^{\dagger}$ Life cycle of pumped hydro and CAES are assumed to be limited by other components.

TABLE 4.6

CALCULATED ACR OF EES

\begin{tabular}{|c|c|c|c|c|c|c|c|}
\hline Technology & Level & $\begin{array}{l}\text { Capital } \\
\text { Cost } \\
(\$ / k W)\end{array}$ & $\begin{array}{c}\text { Capital } \\
\text { Cost } \\
(\$ / \mathrm{kWh})\end{array}$ & $\begin{array}{c}\text { ACR } \\
(\$ / \mathbf{M W})\end{array}$ & $\begin{array}{c}\mathbf{A C R} \\
(\mathbf{\$} / \mathbf{M W h})\end{array}$ & $\begin{array}{c}\text { O\&M } \\
\text { (\$MWh) }\end{array}$ & $\begin{array}{c}\text { Cycle } \\
\text { Efficiency } \\
(\%)\end{array}$ \\
\hline \multirow{2}{*}{ PH } & Worst & 2440 & 10 & 94,832 & 389 & 4 & 81 \\
\hline & Best & 1500 & 10 & 58,298 & 389 & 4 & 85 \\
\hline \multirow{2}{*}{ CAES } & Worst & 1140 & 3 & 44,307 & 117 & 3 & 50 \\
\hline & Best & 500 & 3 & 19,433 & 117 & 3 & 70 \\
\hline \multirow{2}{*}{$\mathrm{Na}-\mathrm{S}$} & Worst & 305 & 491 & 30,641 & 49,327 & 7 & 75 \\
\hline & Best & 200 & 181 & 20,092 & 18,184 & 7 & 78 \\
\hline \multirow{2}{*}{ VR } & Worst & 1280 & 257 & 86,036 & 17,274 & 1 & 65 \\
\hline & Best & 608 & 88 & 40,867 & 5,915 & 1 & 75 \\
\hline \multirow{2}{*}{ Li-ion } & Worst & 305 & 1000 & 24,281 & 79,611 & 7 & 80 \\
\hline & Best & 200 & 290 & 15,922 & 23,087 & 7 & 85 \\
\hline
\end{tabular}




\section{CHAPTER 5}

\section{TEST SYSTEMS AND SIMULATION RESULTS}

In this chapter, two test systems are applied to the planning model proposed in Chapter 4, with summarized cost data and multiple simulating scenarios. Section 5.1 introduces the small 3bus test system, the formulation of study scenarios, and the simulation results. The organization of Section 5.2 is similar to that of Section 5.1. The simulating scenarios in Section 5.2 aim to verify the practical policies with the validated 240-bus WECC model following the model stress test in Section 5.1.

\subsection{Simple 3-Bus Test System}

\subsubsection{Test System Setup}

As shown in Figure 5.1, a simple 3-bus model is applied to the proposed optimal planning model to test the sensitivity of future energy investment responding to different anticipated energy policies and natural gas prices. The solid lines represent existing transmission lines and generators, and the dashed lines represent new types of generators-solar (S), wind (W) and storage (EES), potentially to be built in the future. Future investments of existing types of generators are assumed to be only invested at the bus where that type of generator is located. For example, future investments of coal $(\mathrm{C})$, natural gas $(\mathrm{G})$, and nuclear $(\mathrm{N})$ generators are placed at bus 1 , bus 2 , and bus 1 , respectively. The reactance of each transmission line is assumed to be j0.1 p.u. with identical transmission capacity of $300 \mathrm{MW}$. Transmission line losses and reactive power in the system will not be considered in the DC OPF model. The peak demand of the system is $600 \mathrm{MW}$, with one-third distributed at bus 2 and two-thirds distributed at bus 3 . 


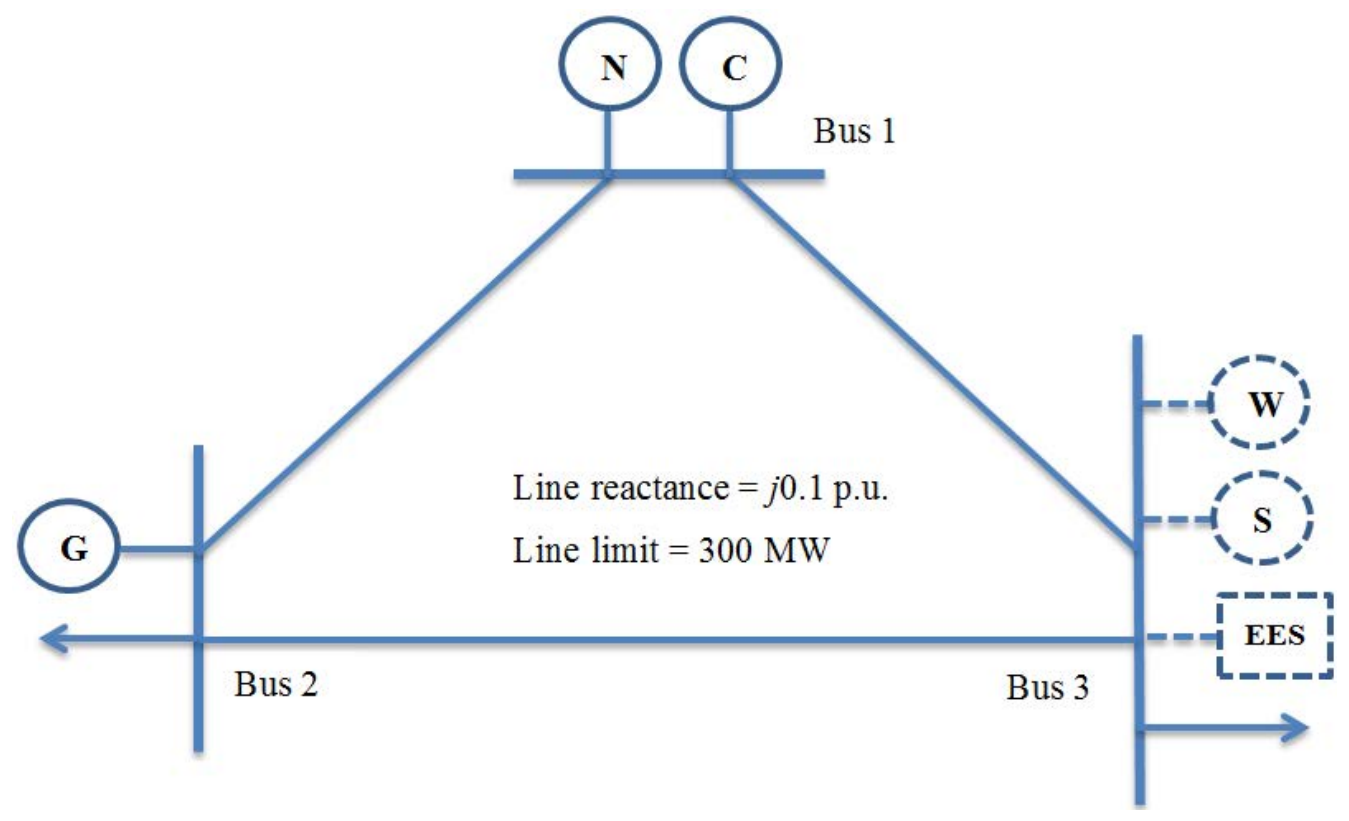

Figure 5.1. Network configuration of 3-bus test system.

Four typical weeks will be used to represent four seasons in a year, with hourly profiles of load and variable renewables (i.e., wind and solar). The load and generation profile is normalized according to the profile provided for the WECC model, as shown in Figure 5.2. Only one wind profile and one solar profile are used for the prospective wind generator and solar generator at bus 3 . Those two data profiles are normalized from the profiles of a wind farm and a solar plant in southern California (i.e., bus 2438 in the WECC model). The total peak demand of the simulation year is $600 \mathrm{MW}$, with total existing generation capacity of $800 \mathrm{MW}$. 


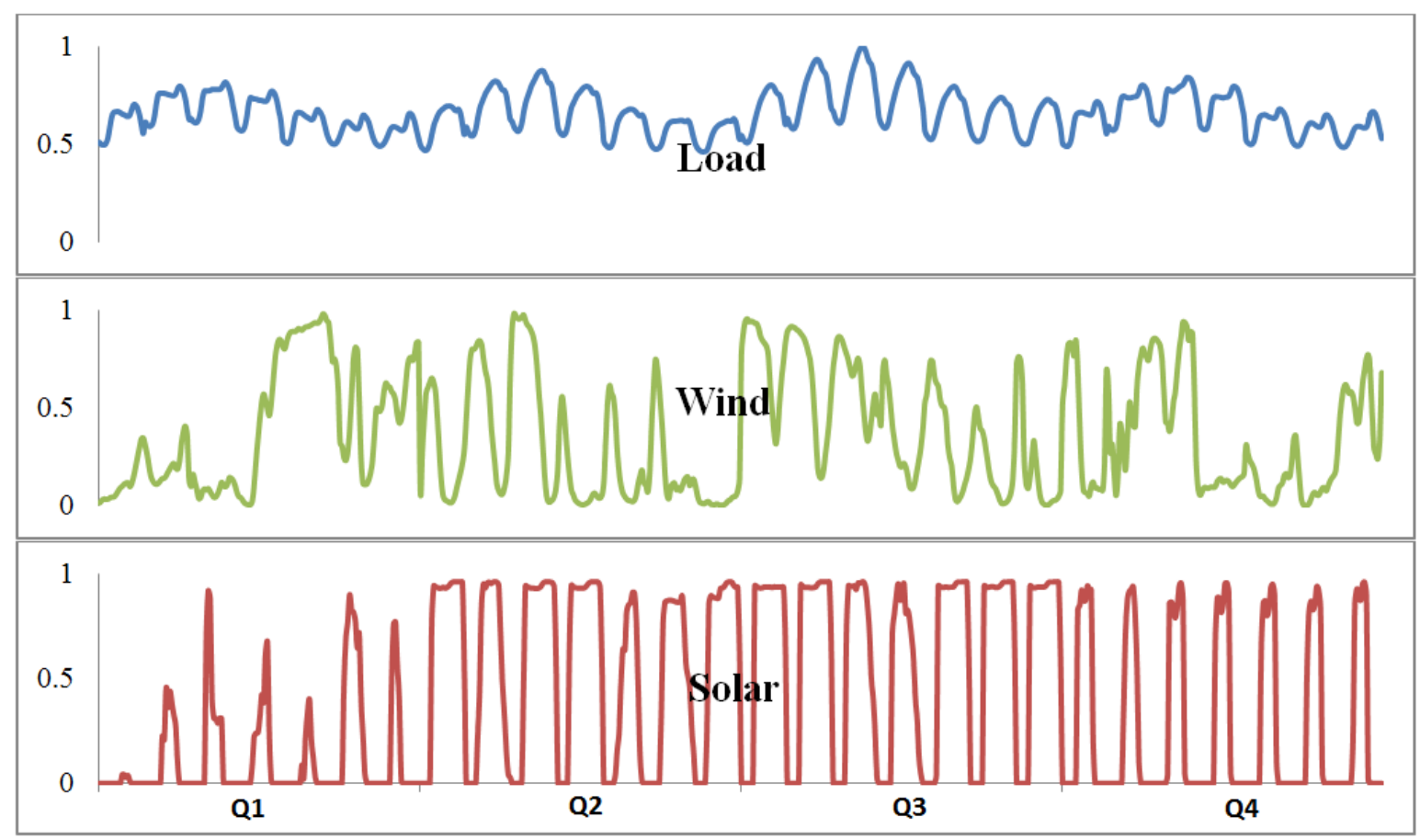

Figure 5.2. Normalized 672-hour profile of load, wind, and solar generation.

The input parameters of the existing generators and the investment targets are listed in Table 5.1. The production cost data approximated from using the forecasted levelized cost of 2015 is shown in Table 4.1. The fixed cost and capital recovery for coal, natural gas, nuclear, wind, and solar generation are taken from Table 4.3 and Table 4.4. Benefited from the advanced combined cycle technology, those new invested natural gas generators are likely to adopt this technology with lower capital and fixed costs, and higher energy conversion efficiency. Thus, an average fuel cost of $\$ 40 / \mathrm{MWh}$, the production of natural gas price at $\$ 5 / \mathrm{MBTU}$, and average heat rate of a combined cycle [43] at $8 \mathrm{MBTU} / \mathrm{MWh}$ are used for the invested natural gas generators (as listed in brackets in Table 5.1). The photovoltaic (PV) cost data is selected for the invested solar generator since it has lower capital, fixed, and production costs, which induce more investment of solar energy in the simulation results. In order to investigate the best scenario for bulk energy storage in the planning study, the cost inputs of energy storage adopt the best case of the CAES technology from Table 4.6. 
TABLE 5.1

GENERATOR PARAMETERS IN 3-BUS TEST SYSTEM

\begin{tabular}{|l|l|l|l|l|l|l|}
\hline Generator Index & 1 & 2 & 3 & 4 & 5 & 6 \\
\hline Bus Index & 1 & 2 & 1 & 3 & 3 & 3 \\
\hline Fuel Type & Coal & Gas & Nuclear & $\begin{array}{l}\text { Wind } \\
\text { (onshore) }\end{array}$ & $\begin{array}{l}\text { Solar } \\
\text { (PV) }\end{array}$ & EES (CAES) \\
\hline $\begin{array}{l}\text { Existing Capacity } \\
\text { (MW) }\end{array}$ & 240 & 400 & 160 & 0 & 0 & 0 \\
\hline $\begin{array}{l}\text { Maximum Investment } \\
\text { Allowed (MW) }\end{array}$ & $\infty$ & $\infty$ & $\infty$ & $\infty$ & $\infty$ & $\infty$ \\
\hline $\begin{array}{l}\text { Maximum Retirement } \\
\text { Allowed (MW) }\end{array}$ & 240 & 400 & 160 & N/A & N/A & N/A \\
\hline Capacity Factor & 0.85 & 0.87 & 0.9 & 0.36 & 0.40 & 0.2 \\
\hline Fuel Cost (\$/MWh) & 18.70 & $50(40)$ & 9.92 & N/A & N/A & N/A \\
\hline O\&M Cost (\$/MWh) & 6.54 & 5.00 & 12.02 & 8.08 & 5.76 & 3 \\
\hline $\begin{array}{l}\text { Annual Fixed Cost } \\
\text { \$/MW) }\end{array}$ & 36,780 & 15,000 & 93,770 & 11,980 & 9,920 & 0 \\
\hline $\begin{array}{l}\text { Annual Capital } \\
\text { Recovery (\$/MW) }\end{array}$ & 349,780 & 101,798 & 566,373 & 214,206 & 273,116 & $19,433 / \$ M W$ \\
\hline Cycle Efficiency & N/A & N/A & N/A & N/A & N/A & 0.7 \\
\hline
\end{tabular}

\subsubsection{Study Cases}

The simulation on the simple 3-bus test system is set up primarily to verify the economic sensitivity of the optimization model with integrated generation planning functions including energy storage. Five study cases with corresponding inputs are set up, as shown in Table 5.2. Cases 1 and 2 test the planning results affected by prospective energy polices such as the $\mathrm{CO}_{2}$ emissions cap and renewable production tax credit (PTC), respectively. In Case 1, six $\mathrm{CO}_{2}$ emission prices ranging from $\$ 0$ to $\$ 100 /$ ton by identical steps of 20 are added to the variable cost to simulate the $\mathrm{CO}_{2}$ emissions regulation under potential policies similar to the Kerry- 
Lieberman Bill. Case 2 incorporates six renewable incentives ranging from $\$ 0$ to $\$ 50 / \mathrm{MWh}$ by identical steps of 10 to simulate the renewable-favorable policies such as the PTC. Case 3 examines the impact to the optimal planning results by a variety of possible natural gas prices covering the EIA recorded lowest and highest annual average from 1997 to 2011 [44]. Case 4 inspects the hourly operational schedule of the CAES in response to wind generation. The planning results with CAES opting out are provided as a comparison in Case 4 to demonstrate the impact of energy storage. In Case 5, the economic feasibility of the five EES technologies listed in Table 4.6 is investigated in this small test environment.

TABLE 5.2

OUTLINE OF STUDY CASES

\begin{tabular}{|c|c|c|c|c|}
\hline $\begin{array}{c}\text { Case } \\
\text { Number }\end{array}$ & $\begin{array}{c}\mathrm{CO}_{2} \text { Price } \\
(\$ / \text { ton })\end{array}$ & $\begin{array}{c}\text { Wind and Solar Subsidy } \\
\text { (\$/MWh) }\end{array}$ & $\begin{array}{c}\text { Natural Gas Price } \\
\text { (\$/MBTU) }\end{array}$ & EES \\
\hline 1 & {$\left[\begin{array}{llllll}0 & 20 & 40 & 60 & 80 & 100\end{array}\right]$} & 0 & 5 & CAES (best) \\
\hline 2 & 0 & {$\left[\begin{array}{llllll}0 & 10 & 20 & 30 & 40 & 50\end{array}\right]$} & 5 & CAES (best) \\
\hline 3 & 40 & 22 & {$\left[\begin{array}{llllll}2 & 4 & 6 & 8 & 10 & 12\end{array}\right]$} & CAES (best) \\
\hline 4 & 40 & 22 & 8 & CAES (best) \\
\hline 5 & 40 & 22 & 8 & ALL \\
\hline
\end{tabular}

\subsubsection{Results Analysis}

Each study case and corresponding figures are summarized here, and then followed by discussion of the individual study case results explained in more detail with specific references to applicable figures. The generation planning results, the annual $\mathrm{CO}_{2}$ emissions from burning coal and natural gas, the average energy production costs, and the installed capacity level of wind, solar, and CAES of Case 1, Case 2, and Case 3 are plotted in Figure 5.3 to Figure 5.11. These bar graphs of generation planning results include only the power capacity results of EES. The 
calculated planning results of both power capacity and energy capacity of each EES are directly specified as numbers at the top of each column, if there is investment in energy storage. The impact of CAES is analyzed in Case 4, with results shown in Figure 5.12 and Figure 5.13. Table 5.3 outlines the planning results simulated in Case 4 to quantify the impact of investing the CAES on total cost, average production cost, renewable investment and energy storage investment. Moreover, the hourly operational results of wind and CAES are demonstrated in Figure 5.14. In Case 5, the potential investment of five bulk storage technologies are simulated with identical emissions cost, renewable subsidy, and natural gas price as in Case 4. The results of Case 5 are summarized in Table 5.4.

Case 1 examines the impact on future planning results by imposing a variety of $\mathrm{CO}_{2}$ emission costs to the coal and gas generators. As shown in Figure 5.3, neither investment nor retirement is necessary without any $\mathrm{CO}_{2}$ emission cost. By adding a moderate $\mathrm{CO}_{2}$ emission cost of $\$ 20 /$ ton or $\$ 40 /$ ton, the most economical way is replacing or upgrading old combustion turbines (CTs) to a new combined cycle (CC) for natural gas generators. The generator-installed capacity of coal starts to be replaced by wind at a $\mathrm{CO}_{2}$ emission cost of $\$ 60 /$ ton. Beyond the $\$ 80 /$ ton $\mathrm{CO}_{2}$ cost, coal generators are completely retired, while PV and more wind are invested. The amount of technology upgrade of natural gas generators is almost identical to where the $\mathrm{CO}_{2}$ cost is $\$ 60 /$ ton. Under a $\mathrm{CO}_{2}$ cost of $\$ 100 /$ ton, most CTs are retired with only a small increase in CC. Investment in wind generation is decreased because nuclear generation becomes economically feasible at this time. Although nuclear generation has a much higher capital cost than wind and solar generation, its capacity factor is much higher, leading to a better solution if the production cost of wind and solar is not compensated by any policy. Investment in CAES occurs in this case only when the $\mathrm{CO}_{2}$ price reaches $\$ 100 /$ ton. With a high installed capacity of 
nuclear (37\%), CAES shifts to more nuclear generation (with a production cost of $\$ 21.92 / \mathrm{MWh}$ ) from off-peak to peak hours in order to offset the emission-penalized costly energy from natural gas generators.

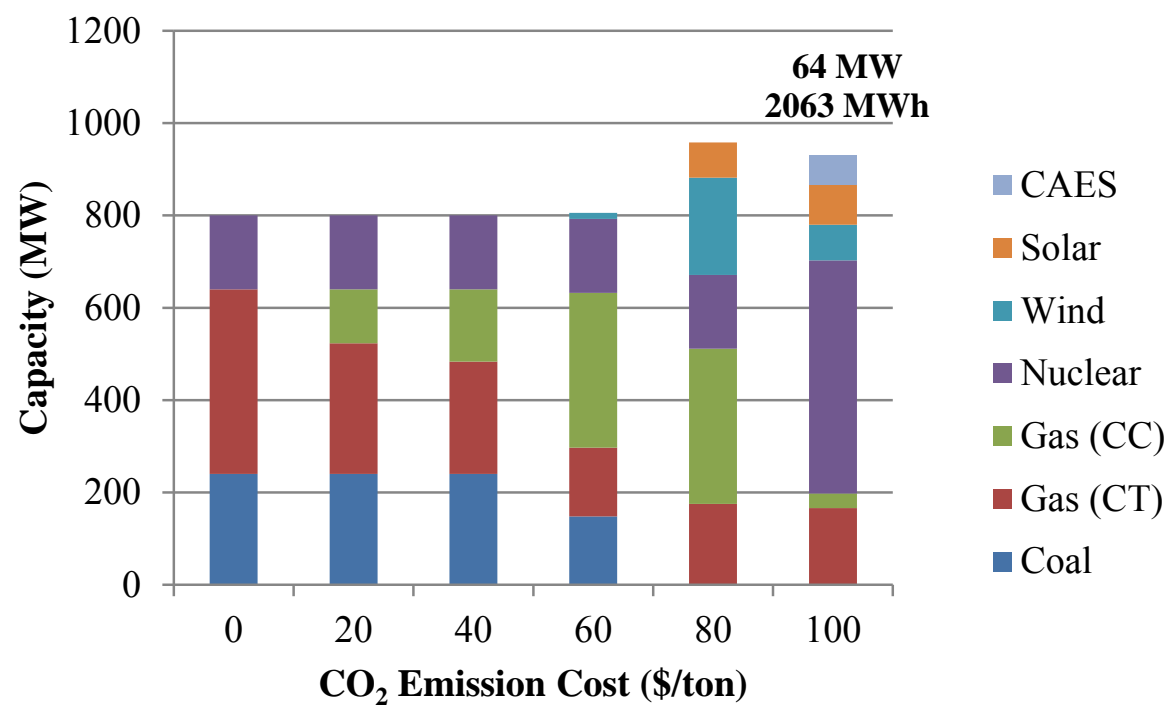

Figure 5.3. Generation planning results of Case 1.

Simulation results of annual $\mathrm{CO}_{2}$ emission cost and average production cost in Case 1 are plotted in

Figure 5.4. It is clear that $\mathrm{CO}_{2}$ emissions from coal start to decrease with a $\mathrm{CO}_{2}$ emission cost between $\$ 40$ and $\$ 60 /$ ton. Within a price range of $\$ 40$ to $\$ 80 /$ ton, some energy generation shifts from coal to natural gas before the decline of natural gas consumption. There are a few generation outputs from natural gas generators with a $\mathrm{CO}_{2}$ cost as high as $\$ 100 /$ ton. Since the production cost is defined as the variable cost including fuel cost, O\&M cost, emission cost, and subsidy, adding the emission cost raises the production cost until the resource shifts. The highest average production cost is nearly $\$ 80 / \mathrm{MWh}$, where only one-third of the coal is retired, and the total capacity of CC and CT are more than the initial state. After that, the average production cost declines with renewable or nuclear investment. 


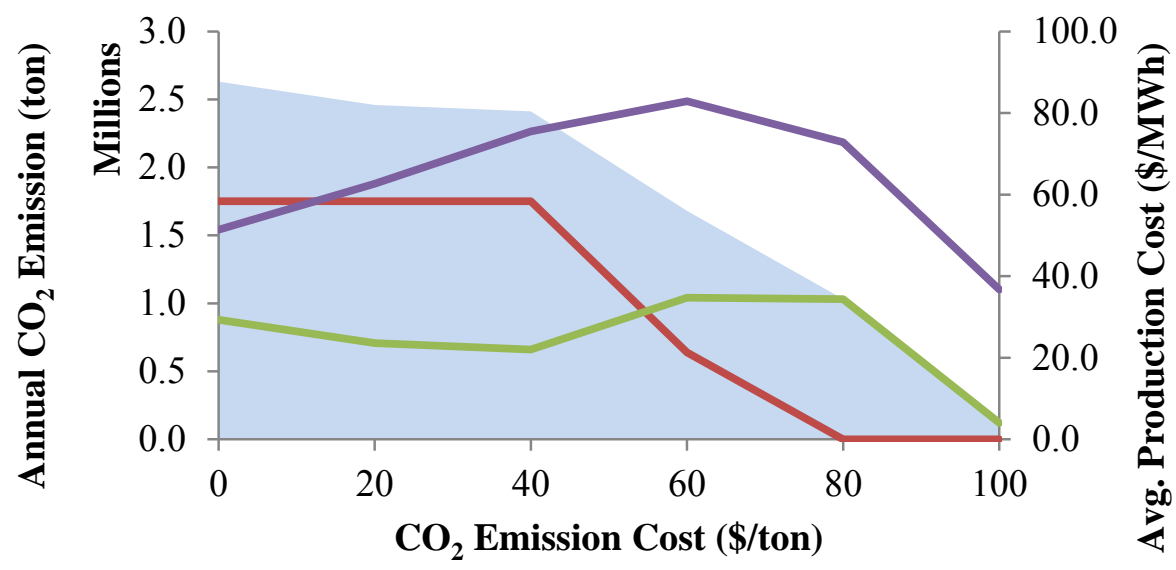

Annual $\mathrm{CO} 2$ Emission $-\mathrm{CO} 2$ emission from coal
$\mathrm{CO} 2$ emission from gas

Figure 5.4. Annual $\mathrm{CO}_{2}$ emissions and average production cost of Case 1

According to the simulated results of Case 1, the bulk CAES operated for energy arbitrage is only economically feasible when the $\mathrm{CO}_{2}$ price reaches $\$ 100 /$ ton, with an installed capacity level of $18 \%$ renewables and $37 \%$ nuclear, as shown in Figure 5.5. Although wind and solar generation has a variable output and lower production cost compared to nuclear generation, the storage is not yet an option with $30 \%$ renewables alone at the $\mathrm{CO}_{2}$ price of $\$ 80 /$ ton.

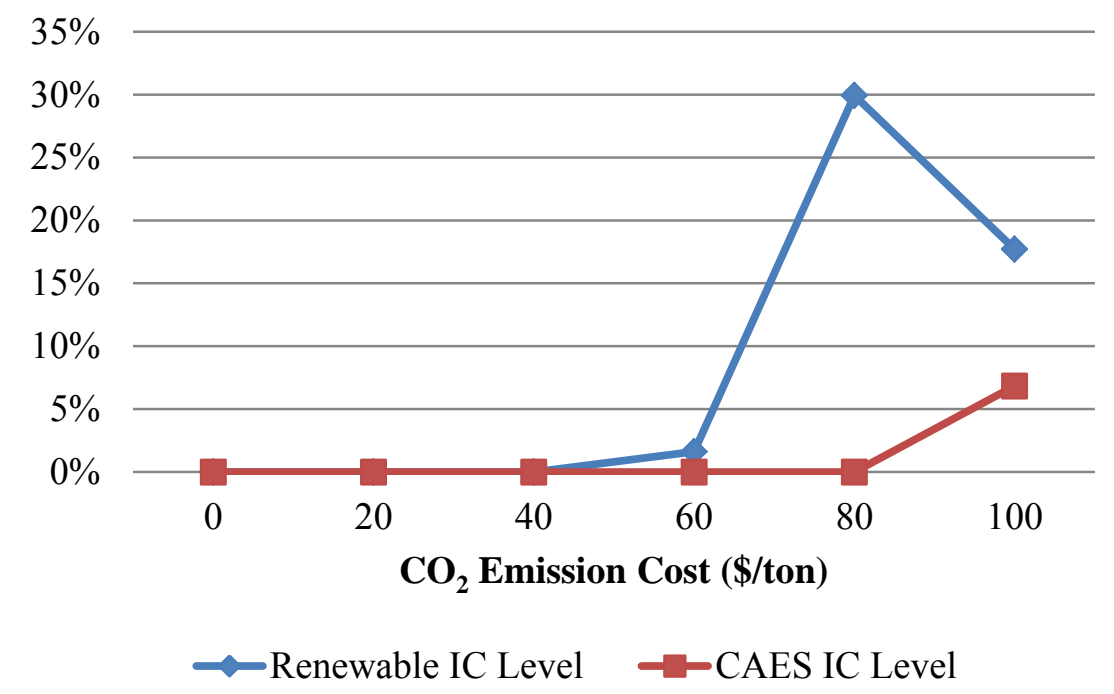

Figure 5.5. Percentage of installed capacity in Case 1 
The planning results of Case 2 are shown in Figure 5.6. Without emission penalties, coal and natural gas capacity are not phased out unless there is a high incentive placed on renewable energy. In this small test system, wind and solar generation start to replace natural gas CT generation under a renewable subsidy between $\$ 20$ and $\$ 30 / \mathrm{MWh}$. Natural gas CT generation is substituted prior to coal and nuclear generation because of its higher production cost (primarily fuel cost). The overall generation capacity increases significantly with the investment in wind and solar energy because of their lower capacity factors (i.e., $36 \%$ and $40 \%$, respectively, in this study).

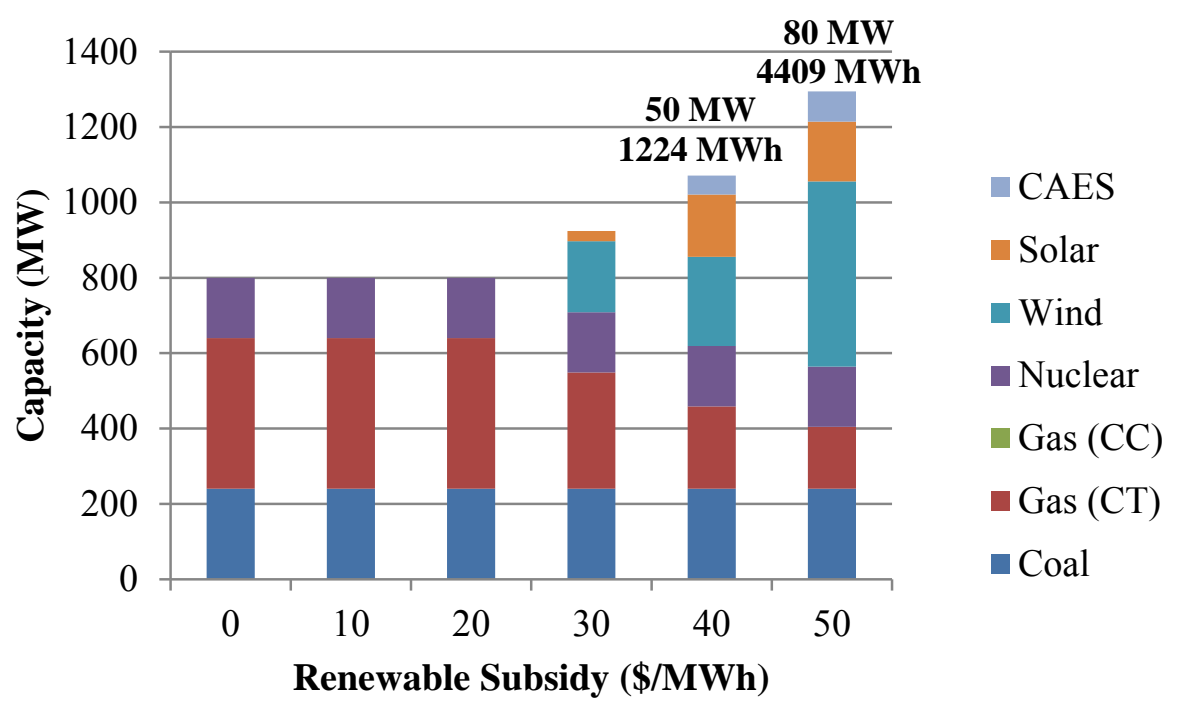

Figure 5.6. Generation planning results of Case 2.

As can be seen in Figure 5.7, building wind and solar generation helps to reduce most $\mathrm{CO}_{2}$ emissions from the natural gas $\mathrm{CT}$, not from the coal generation, as long as the fuel price of natural gas is higher than that of coal. However, in this case, the average production cost is monotonously declining with the increase of renewable subsidies. From both Figure 5.7 and Figure 5.8, it can be seen as noteworthy that at a high incentive of $\$ 50 / \mathrm{MWh}$, the average production cost even drops below zero with $50 \%$ installed capacity of wind and solar energy. 


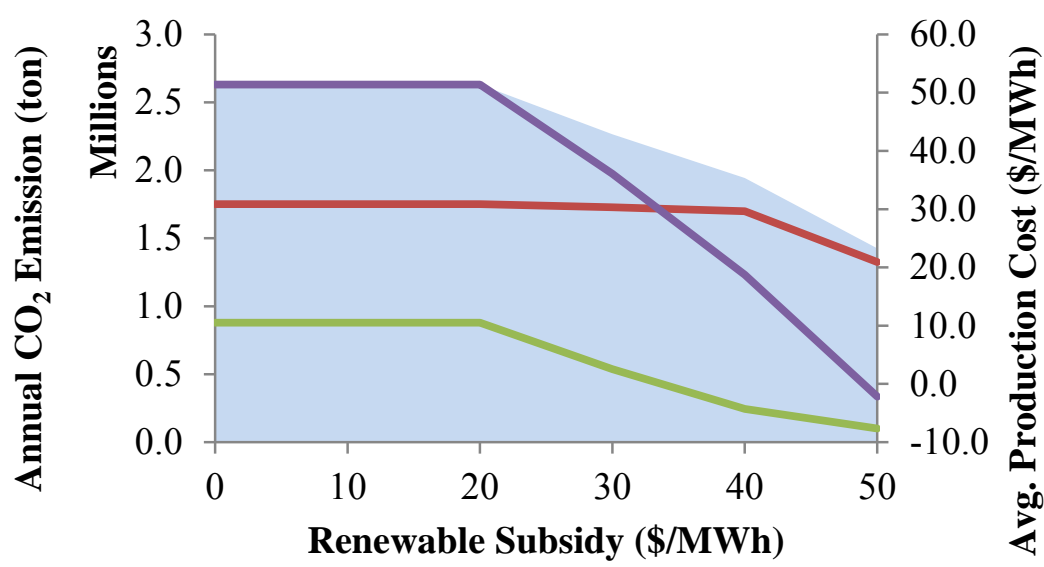

Annual $\mathrm{CO} 2$ Emission $\longrightarrow \mathrm{CO} 2$ emission from coal

$\mathrm{CO} 2$ emission from gas $\longrightarrow$ Average Production Cost

Figure 5.7. Annual $\mathrm{CO}_{2}$ emissions and average production cost of Case 2 .

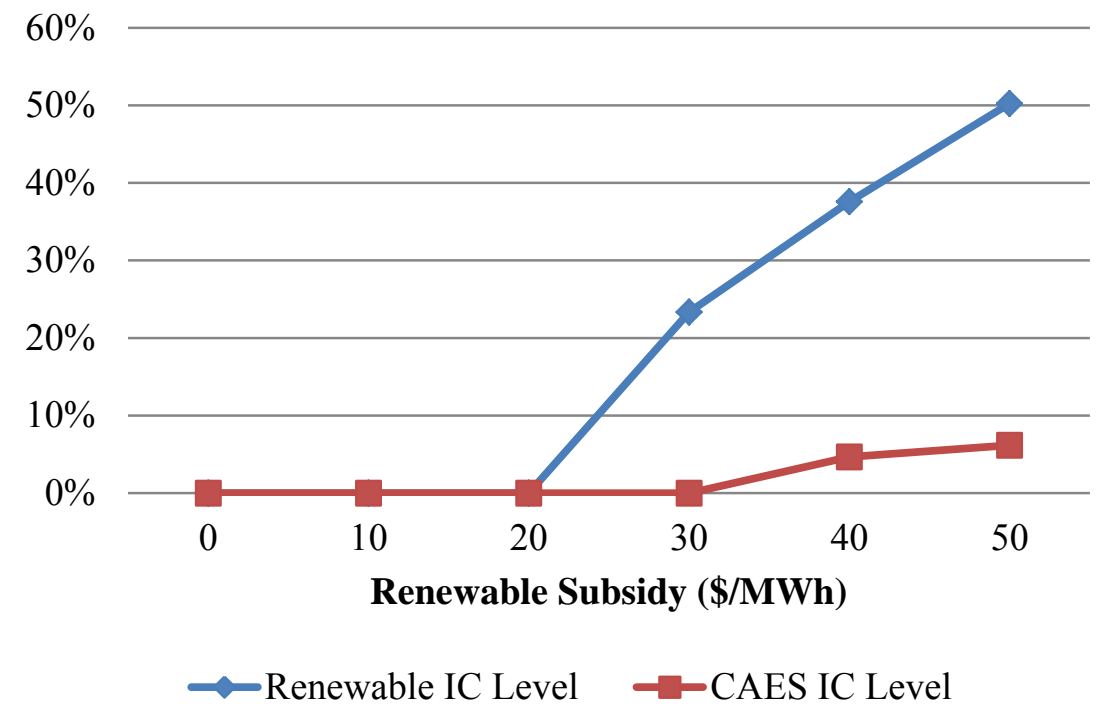

Figure 5.8. Percentage of installed capacity of Case 2.

Figure 5.8 shows the storage investment triggered by the penetration of wind and solar. As stated previously, the size of the bulk energy storage is economically optimized to shift the energy from lower cost hours to higher cost hours. In this test system, installation of $5 \%$ of CAES is the best solution when $38 \%$ of wind and solar generation is invested at a renewable 
subsidy of $\$ 40 / \mathrm{MWh}$, and installation of $6 \%$ of CAES is the best solution when $50 \%$ of wind generation is installed at a renewable subsidy of $\$ 50 / \mathrm{MWh}$.

As described previously, Case 3 simulates the impact of the natural gas price with a designated $\mathrm{CO}_{2}$ emission cost of $\$ 40 /$ ton and renewable incentive of $\$ 22 / \mathrm{MWh}$. From the two previous cases, neither imposing a $\mathrm{CO}_{2}$ cost of $\$ 40 /$ ton nor imposing a renewable subsidy is likely to affect the planning results of coal. This study case, shown in Figure 5.9, indicates that at a very low natural gas price of $\$ 2 / \mathrm{MBTU}$, coal is completely replaced by the new natural gas combined cycle (NGCC), and no wind or solar generation is invested even with a renewable subsidy in place. With higher natural gas prices, the existing capacity of the CT is gradually replaced by wind and solar energy. Natural gas generation will be phased out when the gas price rises above $\$ 12 / \mathrm{MBTU}$. Similar to the previous cases, the investment of energy storage increases along with that of renewables. It can be seen in Figure 5.9 (and later in Figure 5.11) that the increment of renewables and storage slows down when the natural gas price goes beyond \$8/MBTU. Instead, the increment of energy capacity of the CAES rises, which is indicated as a better solution than adding more wind and solar generation.

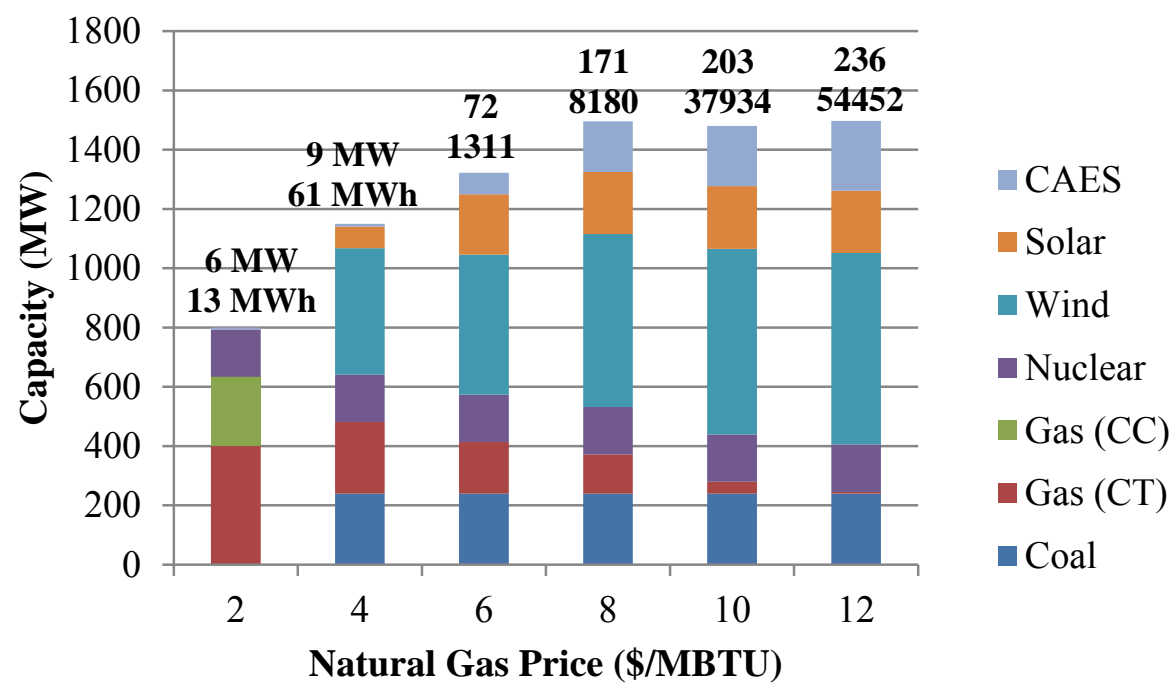

Figure 5.9. Generation planning results in Case 3 
From Figure 5.10, it can be seen that the annual $\mathrm{CO}_{2}$ emissions remains at a relatively constant level in this simulation case. The overall emissions at six simulation points are lower than that of Case 2 because of the $\$ 40 /$ ton emission cost. $\mathrm{CO}_{2}$ emissions from coal and natural gas reverse when the gas price increases from $\$ 2$ to $\$ 4 / \mathrm{MBTU}$. From the coal emission curve, it is clear that coal generation decreases while the gas price increases from $\$ 4$ to $\$ 12 / \mathrm{MBTU}$. Even though coal generation decreases, the installed capacity of coal remains constant to ensure enough capacity to back up wind and solar generation. The average production cost decreases monotonically with the increase in gas price. With both a $\$ 40 /$ ton emission cost and a $\$ 22 / \mathrm{MWh}$ renewable incentive in place, the planning model is highly sensitive to the price of natural gas. At a lower price below $\$ 4 / \mathrm{MBTU}$, the new NGCC is more preferable than coal and renewables in this study scenario. When the gas price increases above $\$ 4 / \mathrm{MBTU}$, adding renewables is the best solution.

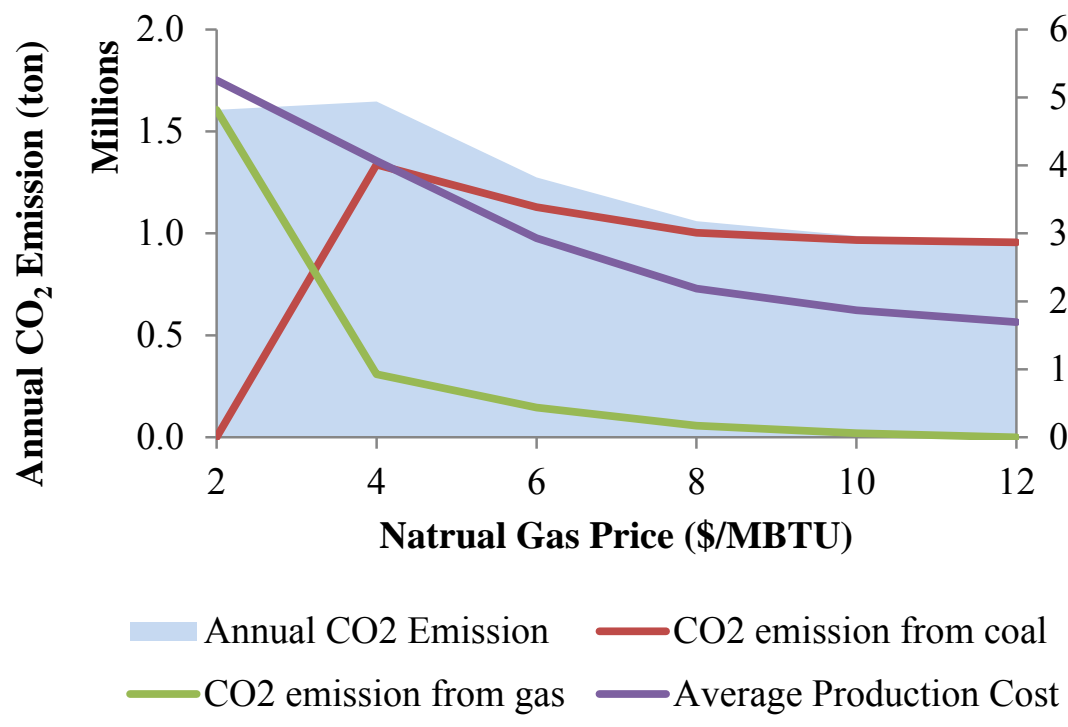

Figure 5.10. Annual $\mathrm{CO}_{2}$ emissions and average production cost in Case 3.

In Case 3, the IC level of energy storage has a noticeable increase when renewables climb to $50 \%$, as shown in Figure 5.11. After that, the increment of energy storage is higher than that of 
renewables. The variable output profiles of wind and solar create an economic ceiling that restricts their growth. If the cost of adding energy storage is higher, then the alternative option will be either keeping more of the capacity of natural gas or building new coal or nuclear plants.

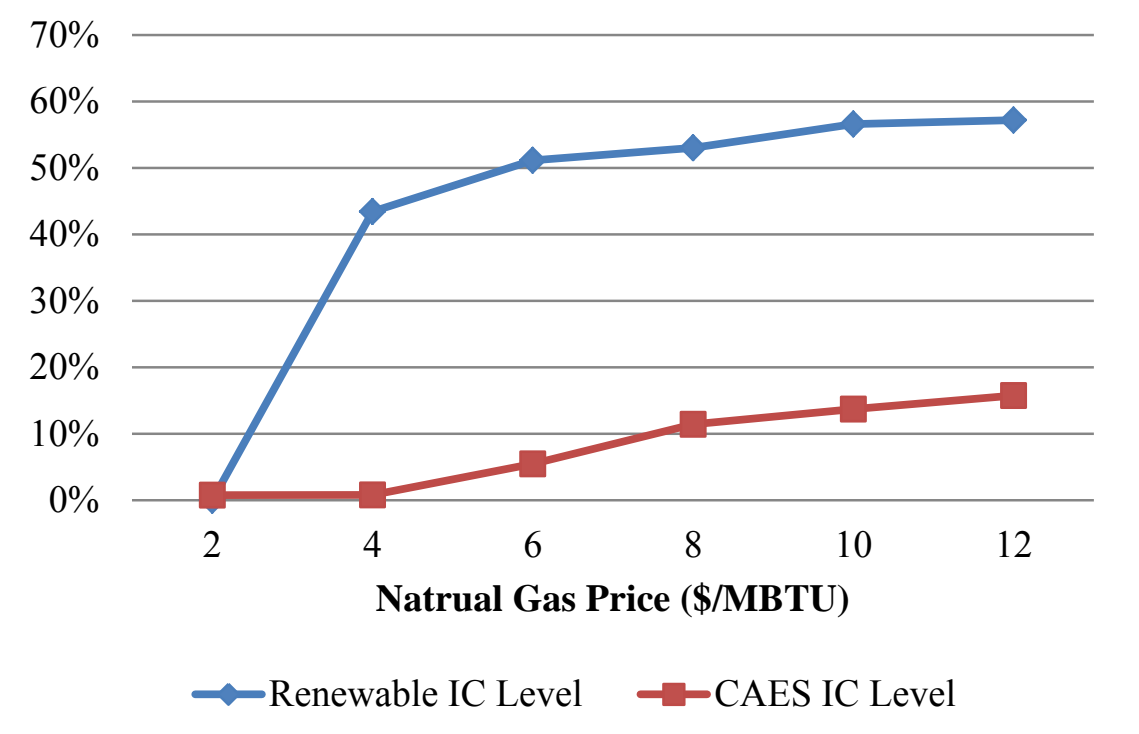

Figure 5.11. Percentage of installed capacity in Case 3.

The simulation shown in Case 4 compares the differences in resource planning, $\mathrm{CO}_{2}$ emissions, and energy prices between adding and not adding the CAES. As stated previously in Table 5.2, a specific scenario is selected as $\$ 40 /$ ton of $\mathrm{CO}_{2}$ emission, $\$ 22 / \mathrm{MWh}$ of renewable subsidy, and $\$ 8 / \mathrm{MBTU}$ of natural gas. The price of natural gas is selected at a higher level in order to induce more investment of renewables, which therefore magnifies the impact of adding CAES.

Figure 5.12 illustrates the resource planning results with and without installing CAES. It can be seen that the investment of CAES replaces a portion of capacity from natural gas generator which could be underused in this study case. Meanwhile, it provides more flexibility with more wind capacity. Although the solar profile is less variable and better coordinated with the load profile than wind profile, it has a slightly higher capital cost and lower capacity factor. 
As long as there is a bulk storage technology with a relatively low unit cost in energy capacity (such as CAES and pumped hydro), wind generation, which benefits from bulk storage, could have a slightly lower cost overall than solar generation.

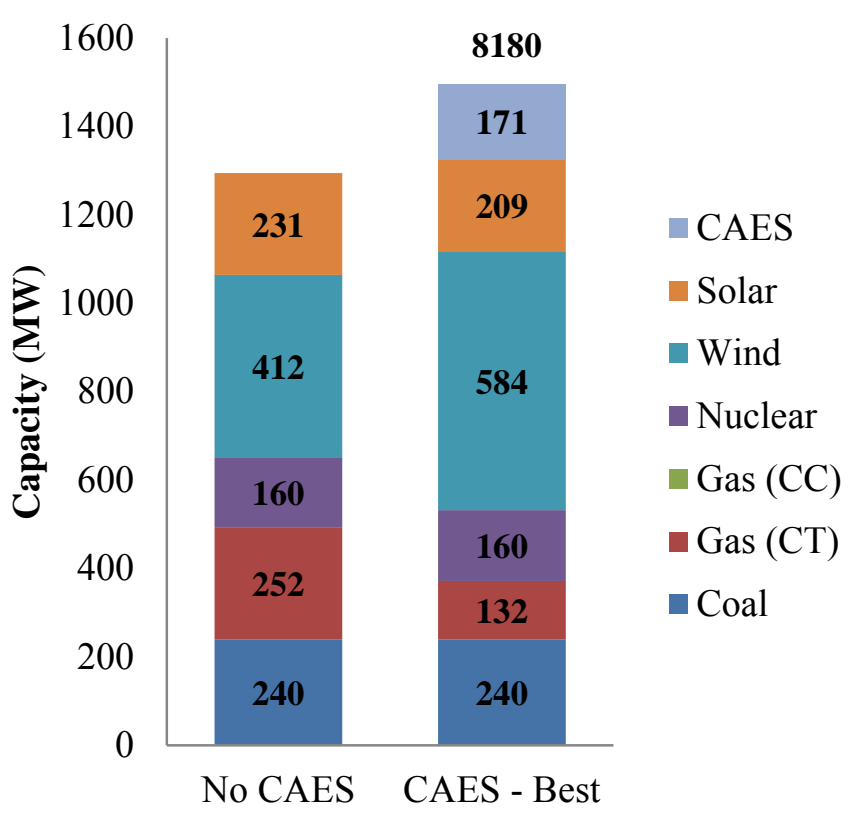

Figure 5.12. Planning results of other resources with and without CAES as an option.

The impact on $\mathrm{CO}_{2}$ emissions by adding CAES is shown in Figure 5.13. As stated previously, CAES promotes more wind investment in this study scenario. Therefore, it is not surprising to observe that optimal investment of CAES could reduce $\mathrm{CO}_{2}$ emissions from both coal and natural gas resources. In this case, emissions from natural gas have a larger ratio of reduction because of the higher production cost compared to that of coal. 


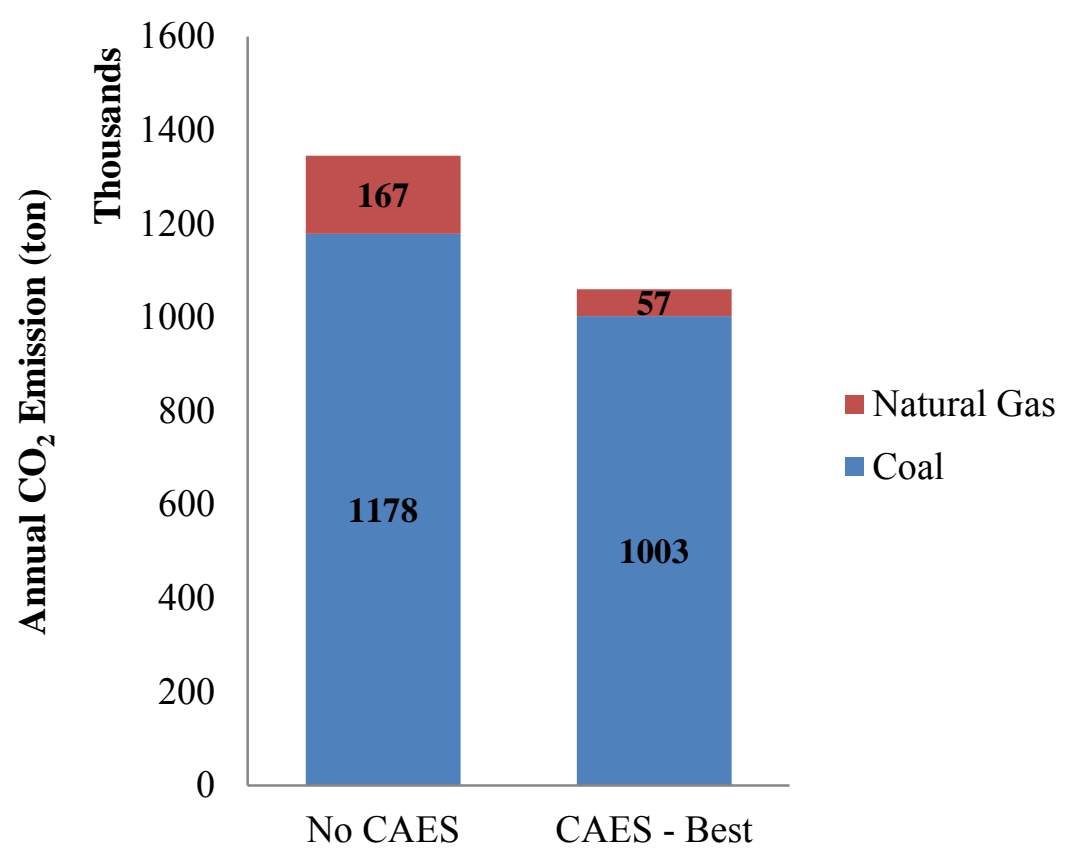

Figure 5.13. Annual $\mathrm{CO}_{2}$ emissions with and without CAES as an option.

Moreover, comparisons of costs and installed capacity levels are listed in Table 5.3. Although there are capital and O\&M costs associated with CAES, the total annual cost is reduced by $1.6 \%$. More generation from wind induces an additional reduction of $\$ 11.4 / \mathrm{MWh}$, or $34 \%$ of the average production cost.

TABLE 5.3

COSTS AND INSTALLED CAPACITY LEVELS

\begin{tabular}{|l|c|c|}
\hline \multicolumn{1}{|c|}{ Scenarios } & NO CAES & CAES - Best \\
\hline Total Annual Cost (\$ million) & 272 & 267 \\
\hline Average Production Cost (\$/MWh) & 33.3 & 21.9 \\
\hline Renewable IC Level (\%) & 50 & 53 \\
\hline CAES IC Level (\%) & 0 & 11 \\
\hline
\end{tabular}

The hourly operation data of wind generation and CAES are plotted in Figure 5.14. As can be seen, the wind resource is relatively more sufficient on the second half of Q1 (represented 
by typical week profile, i.e., from hour 1 to hour 168) and the first half of Q2 and Q3 (i.e., hour 85 to 252 , and 337 to 420 ). As shown, during most of these hours, the CAES is charging with volume increasing. During summer-peaking hours of demand or recession periods of wind (i.e., hour 1 to 80,250 to 320,420 to 480 , and 550 to 650 ), CAES releases energy as dispatched by the DC OPF. The remaining energy at the ending period is identical to the initial value, which is set at $20 \%$ of maximum capacity. In this study case, CAES operates about 28 cycles within this $672-$ hour simulation horizon, averaging one cycle per day. According to the size of power and energy capacity, this CAES is capable of discharging continuously for approximately 40 hours at its rated maximum output. This physical parameter is realistic for up-to-date CAES technology.

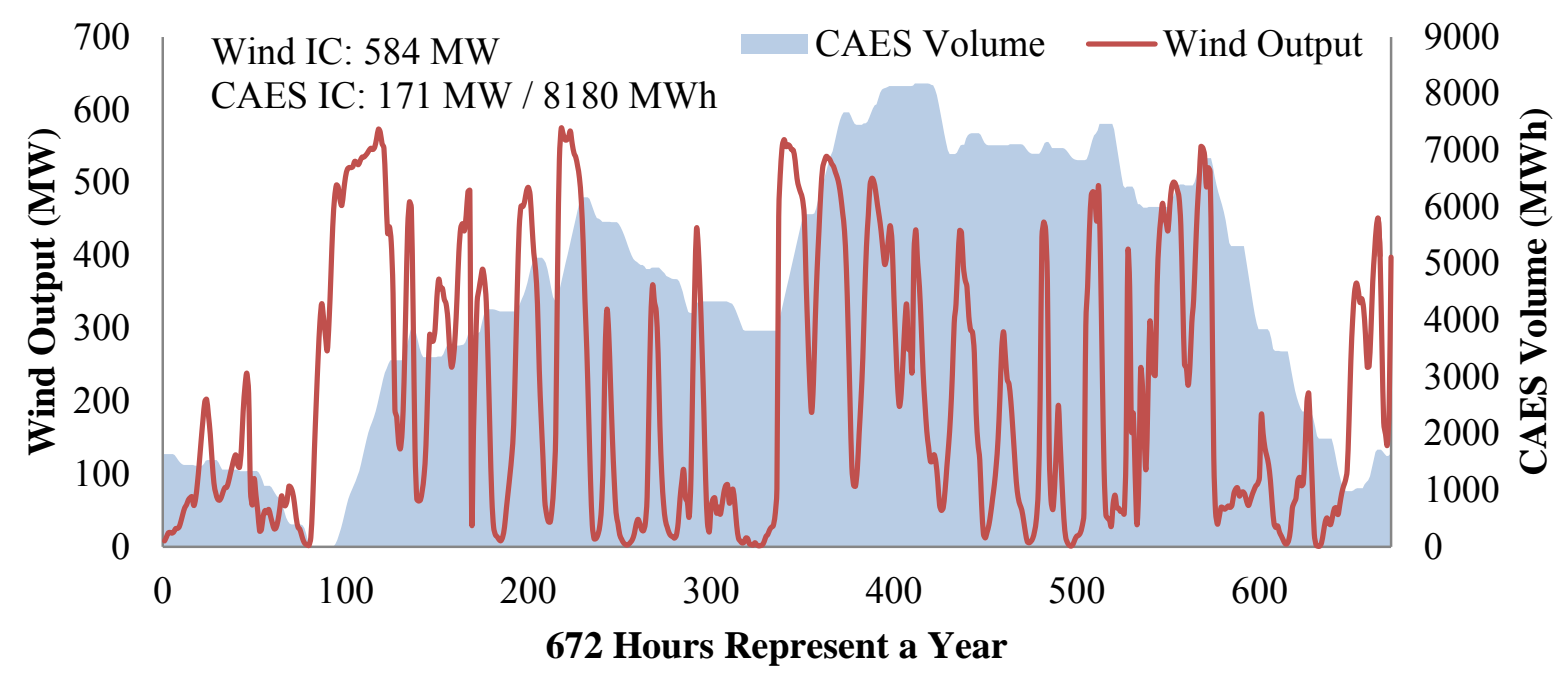

Figure 5.14. Hourly operational results of CAES and wind generator

The simulation scenario in Case 5 is identical to that of Case 4, except that multiple technologies of bulk energy storage are simulated to compare their potential investment in this application. The planning results of each EES technology are listed in Table 5.4. In this energy management scenario, energy storage will be valued through an energy arbitrage operation. Therefore, energy storage with lower capital cost on energy capacity, such as pumped-hydro and CAES, is preferable. Although the PH-Best category has a higher capital cost on power capacity 
than the other three battery technologies, its remarkably low capital on energy capacity makes it highly desirable with high-level wind and nuclear generation. Other than pumped hydro and CAES, the vanadium redox battery has little possibility in this study case, with $5 \mathrm{MW} / 25 \mathrm{MWh}$ installed, capable of providing five hours of continuous discharge.

TABLE 5.4

POTENTIAL OF BULK EES BY TECHNOLOGY

\begin{tabular}{|l|l|c|c|}
\hline Technology & Level & $\begin{array}{c}\text { Power } \\
\text { Capacity } \\
\text { (MW) }\end{array}$ & $\begin{array}{c}\text { Energy } \\
\text { Capacity } \\
\text { (MWh) }\end{array}$ \\
\hline \multirow{2}{*}{ PH } & Worst & 0.7 & 16.7 \\
\cline { 2 - 4 } & Best & 67.0 & $2,401.7$ \\
\hline \multirow{2}{*}{ CAES } & Worst & 0 & 0 \\
\cline { 2 - 4 } & Best & 171.1 & $8,180.0$ \\
\hline \multirow{2}{*}{ Na-S } & Worst & 0 & 0 \\
\cline { 2 - 4 } & Best & 0 & 0 \\
\hline \multirow{3}{*}{ VR } & Worst & 0 & 0 \\
\cline { 2 - 4 } & Best & 5.0 & 24.7 \\
\hline \multirow{2}{*}{ Li-ion } & Worst & 0 & 0 \\
\cline { 2 - 4 } & Best & 0 & 0 \\
\hline
\end{tabular}

\subsubsection{Discussion}

According to the simulation results, this optimal planning model shows moderate sensitivity to regulatory energy policies and the price of natural gas. The results of this 3-bus test system are reasonable for reflecting the prospective trend of each resource including bulk energy storage under realistic energy policies.

There are multiple solutions to reducing $\mathrm{CO}_{2}$ emissions. Normally without any regulation, coal generators, operating as base-load units, contribute to the major portion of $\mathrm{CO}_{2}$ emissions. If 
the average price of natural gas remains under $\$ 4 / \mathrm{MBTU}$, new invested gas generators with $\mathrm{CC}$ technology would likely replace some base-load coal units and therefore reduce overall $\mathrm{CO}_{2}$ emissions. However, the long-term average price of natural gas is about $\$ 4.78 / \mathrm{MBTU}$, as recorded by EIA from 1997 to 2012. It is still a little high to phase out coal units. Imposing a $\mathrm{CO}_{2}$ emission cost is an effective way to reduce $\mathrm{CO}_{2}$ emissions, regardless of the price of natural gas. In this 3-bus test system, a $\mathrm{CO}_{2}$ price between $\$ 40$ and $\$ 460 /$ ton effectively reduces $\mathrm{CO}_{2}$ emissions by $0 \%$ to $36 \%$, and a $\mathrm{CO}_{2}$ price of $\$ 100 /$ ton could reduce $\mathrm{CO}_{2}$ emissions by $95 \%$.

Providing renewable incentives is an indirect way to reduce $\mathrm{CO}_{2}$ emissions. If the average price of natural gas is higher than $\$ 4 / \mathrm{MBTU}$, natural gas generation will be replaced by renewables prior to coal generation. In this test system, coal generation would be replaced by wind and solar generation, only when there is a renewable subsidy higher than $\$ 40 / \mathrm{MWh}$.

Although nuclear energy is emission neutral and has the highest capacity factor, its large capital cost reduces the benefits. In this study, the only investment in nuclear generation occurs when the $\mathrm{CO}_{2}$ price is $\$ 100 /$ ton and no subsidy is provided for wind and solar generation.

The price of natural gas has a large impact on coal generation at a lower price ranging between $\$ 2$ and $\$ 4 / \mathrm{MBTU}$. With a renewable subsidy in place, a high natural gas price could stimulate the investment of wind and solar generation. If wind and solar energy are not policy preferable, the investment in nuclear generation is a feasible option under a high natural gas price or high $\mathrm{CO}_{2}$ price.

In this study, investment in the EES system seems to be economically feasible only under a high penetration level of wind or nuclear generation. With subsidies, the production cost of wind, sometimes even negative, can be extremely lower than that of the traditional resources. Therefore, EES is invested in order to realize more wind capacity at a lower cost, which is an 
optimal solution. It is reasonable to conclude that bulk energy storage could reduce overall system operating cost by smoothing out the variation of wind output or delivering the surplus nuclear energy from off-peak hours to peak hours.

In general, the cap and trade policy, or carbon emissions tax, is the most effective way to achieve an immediate reduction of $\mathrm{CO}_{2}$ emissions. Binding with renewable incentive policies, e.g., collecting extra taxes from $\mathrm{CO}_{2}$ emitting units and distributing them to renewables as subsidies, however, could expedite the energy consumption shift from fossil fuels to renewables instead of nuclear generation. Without any subsidy greater than $\$ 20 / \mathrm{MWh}$ and no emissions cap on $\mathrm{CO}_{2}$, wind and solar technology are not economically competitive with coal, natural gas, hydro, and nuclear energy to generate electricity.

\subsection{WECC 240-Bus System}

\subsubsection{WECC Model Setup for Planning}

The 240-bus aggregated WECC model, as described in Chapter 3, is applied to this optimal planning study. Most of the network topologies and parameters remain intact. Some setups in the planning study are different from the operational analysis. In the planning study, the interface flow limit will not be considered. Since the capacity of each transmission line is not publicly available for the full WECC model, this reduced 240-bus WECC model could not obtain accurate data for all transmission lines. Instead, transmission limits are estimated under a best effort according to voltage level, interface flow limit, and other physical parameters of each single transmission line or group of transmission lines. The physical minimal operating output of each generator is ignored in the planning study. In order to consider spinning reserves, the maximal output of each hydro generator is set to be $87 \%$ of its installed capacity and that of 
natural gas generators is set to be $90 \%$. Therefore, $10 \%$ of natural gas capacity is not subject to retire, regardless of how high the gas price is.

Energy production from conventional hydro generators is predicted to decline gradually in the future [49]. An annual average capacity factor (i.e., $\Delta^{\text {hydro }}$ ) is applied to all hydro units with a general assumption of $45 \%$ for the year 2012, $40 \%$ for 2022 , and $35 \%$ for 2032 . Conversely, the electricity demand is predicted to increase for the next two decades. The demand increment is predicted by considering the expansion rate of the population and economics in the pre-divided areas within the WECC footprint, as shown in Table 5.5. The increased rate of electricity demand for 2022 and 2032 are assumed to be identical.

TABLE 5.5

DEMAND EXPANSION FACTOR OF EACH AREA IN WECC

\begin{tabular}{|l|c|}
\hline WECC Area & Demand Expansion Factor \\
\hline Southwest & 1.296 \\
\hline Mexico (WECC) & 1.064 \\
\hline California & 1.064 \\
\hline Northwest & 1.064 \\
\hline Canada (WECC) & 1.066 \\
\hline Idaho & 1.137 \\
\hline Rocky Mountain & 1.205 \\
\hline North Nevada & 1.137 \\
\hline
\end{tabular}

The configurations of generator retirement and investment are similar to the simulation of 3-bus test system. The under-used capacity of coal, natural gas, and nuclear generators is subject to be retired under an optimal decision. Meanwhile, coal, natural gas, nuclear, wind, and solar 
generators can be invested at any generator bus (i.e., currently any $20 \mathrm{kV}$-bus with one generator or more attached) in the WECC model. It is less likely to be affected by transmission congestion with more locations allowed to build new generators. Altogether there are 53 generator buses in this 240-bus WECC model. Maximum growth rates are considered for coal, natural gas, and nuclear generation by studying the historical data. Wind and solar generation are assumed to provide, at most, $33 \%$ and $20 \%$, respectively, of total demand in 2032 under an average capacity factor of $40 \%$. The two-decade maximum investment of each technology is listed in Table 5.6.

TABLE 5.6

INVESTMENT LIMIT OF EACH TECHNOLOGY BY 2032

\begin{tabular}{|l|c|}
\hline Fuel Type & $\begin{array}{c}\text { Total Addition Limit } \\
\text { by 2032 (GW) }\end{array}$ \\
\hline Coal & 24 \\
\hline Natural Gas & 77 \\
\hline Nuclear & 12 \\
\hline Wind & 94 \\
\hline Solar & 60 \\
\hline
\end{tabular}

In contrast to the operational study, the planning model requires capital cost and fixed O\&M cost for each generator and energy storage. The annual capital recovery and annual fixed cost for each type of generator (i.e., coal, natural gas, nuclear, wind, and solar) are described in Chapter 4. The generation profiles for those potentially invested wind and solar generators are normalized from the wind and solar production forecast investigated by Price and Goodin [9]. The future profile of wind and solar generation, however, covers only a small number of locations with short-term projected wind and solar investment. In this planning study, the future profile for a wind or solar generator at a particular bus may be applied to other wind or solar 
generators to be invested at neighboring buses. The detailed mapping is listed in Table B.1 and Table B.2 in Appendix B, for wind and solar profile, respectively.

In order to keep the problem size acceptable, only six EES units will be deployed in the WECC system, with identical cost data and other parameters. The cost data of CAES-best (data listed in Table 4.6), which was proven to have the highest potential in the 3-bus test system, is selected as the candidate of bulk storage investment in this planning study for the WECC. Through investigating the network topology, the WECC model can be divided into six grand areas: Southwest, Southern California, Northern California, Northwest, Canada, and Rocky Mountain. Each EES is placed at a randomly selected generator bus within each grand area, as listed in Table 5.7.

TABLE 5.7

PRESUMED EES LOCATIONS

\begin{tabular}{|c|l|l|}
\hline Bus Index & Bus Name & \multicolumn{1}{|c|}{ Grand Area } \\
\hline 1131 & CORONADO & Southwest \\
\hline 2638 & CASTAI4G & Southern California \\
\hline 3432 & HELMS PP & Northern California \\
\hline 4035 & JOHN DAY & Northwest \\
\hline 5032 & CMAIN GM & Canada \\
\hline 7031 & COLOEAST & Rocky Mountain \\
\hline
\end{tabular}

The production costs of each generator by fuel type, except natural gas, are specified in Table 4.1 in Chapter 4. The forecasted data of 2015 is used for the 2012 and 2022 run, and that of 2030 is used for the 2032 run. The heat rate function of each aggregated gas unit is derived as a quadratic curve, approximated from combining the piecewise linear functions of each sub-unit. 
The future price of natural gas has many uncertainties and is forecasted to have two possible trends by the study report [27], as specified in Table 5.8

TABLE 5.8

TWO SETS OF NATURAL GAS PRICES (\$MBTU)

\begin{tabular}{|c|c|c|c|}
\hline & $\mathbf{2 0 1 2}$ & $\mathbf{2 0 2 2}$ & $\mathbf{2 0 3 2}$ \\
\hline High & 2.5 & 7 & 12 \\
\hline Low & 2.5 & 4.77 & 5.86 \\
\hline
\end{tabular}

\subsubsection{Study Cases}

The study cases are designed primarily to assess the planning trend of generator capacity by fuel type under uncertain energy policies and fuel prices in the next two decades. The setup of the study cases is similar to that in the PSERC M-24 report [27]. There is a base case without any policies involved, a cap and trade (C\&T) case, and an Environmental Protection Agency (EPA) case with energy policies. Each case has two possible natural gas prices: high gas price (HG) and low gas price (LG). Therefore, six cases are simulated to represent six possible future scenarios, as outlined in Table 5.9.

TABLE 5.9

OUTLINE OF STUDY CASES

\begin{tabular}{|c|c|c|c|c|c|}
\hline Case No. & Policy & $\begin{array}{c}\text { Natural } \\
\text { Gas Price }\end{array}$ & $\begin{array}{c}\mathrm{CO}_{2} \\
\text { Emissions } \\
\text { Price }\end{array}$ & $\begin{array}{c}\text { EPA } \\
\text { Regulation }\end{array}$ & $\begin{array}{l}\text { Renewable } \\
\text { Incentive }\end{array}$ \\
\hline 1 & \multirow{2}{*}{ Base } & HG & \multirow{2}{*}{$x$} & \multirow{2}{*}{$x$} & \multirow{2}{*}{$x$} \\
\hline 2 & & LG & & & \\
\hline 3 & \multirow{2}{*}{$\mathrm{C} \& \mathrm{~T}$} & $\mathrm{HG}$ & \multirow{2}{*}{$\checkmark$} & \multirow{2}{*}{$x$} & \multirow{2}{*}{$\checkmark$} \\
\hline 4 & & $\mathrm{LG}$ & & & \\
\hline 5 & \multirow{2}{*}{ EPA } & $\mathrm{HG}$ & \multirow{2}{*}{$x$} & \multirow{2}{*}{$\checkmark$} & \multirow{2}{*}{$\checkmark$} \\
\hline 6 & & LG & & & \\
\hline
\end{tabular}


In each case, three representing years $(2012,2022$, and 2032) are simulated with each year representing a ten-year investment cycle. The simulation of year 2012 uses present generation capacity without any energy storage involved as a benchmark for comparison. Although a low price of $\$ 2.5 / \mathrm{MBTU}$ is used to represent the shale gas price in 2012 , the investment decision of natural gas generators should rely on a long-term average price of natural gas, which is higher, for the 2022 and 2032 runs that represent the next two investment cycles. The initial condition of the 2032 run is the planning results of the 2022 run. This ensures that the retired capacity in the 2022 run cannot be used in the 2032 run and that the invested capacity in 2022 cannot be retired in 2032 .

In the cap-and-trade case, a $\mathrm{CO}_{2}$ price is incorporated as a price cap to simulate a capand-trade auction, which is similar to the proposed Kerry-Lieberman Bill for $\mathrm{CO}_{2}$ regulation. According to the report [27], $\mathrm{CO}_{2}$ prices of $\$ 36.94 /$ ton and $460.18 /$ ton are suggested to be used for 2022 and 2032, respectively. The $\mathrm{CO}_{2}$ prices are not imposed on the EPA case, which represents the new coal regulations [51] proposed by the EPA. The anti-coal regulation prohibits the construction of new coal plants unless it meets the emissions requirement of no more than $1,000 \mathrm{lbs} / \mathrm{MWh}$. The carbon sequestration adds too much cost to the coal plant, which is not economically feasible nowadays. In this study, coal investment is effectively prohibited in the EPA case.

To model the Federal Renewable Electricity Production Tax Credit, \$22/MWh, which is equivalent to 2.2 cent $/ \mathrm{kWh}$, is directly subtracted from the production cost model of each wind and solar generator. Referred to as a renewable incentive, it is applied to both the C\&T case and the EPA case. Because wind and solar are the only renewables to be built in this model, the renewable incentive is not applied to other existing renewables in the WECC model. 


\subsubsection{Results Analysis}

The planning results of 2022 and 2032 are plotted in Figure 5.15 to Figure 5.22 for each type of generator including energy storage. The retirement and investment value of each fuel type is compared across different simulation environment. The installed capacity level of renewables and CAES are illustrated in Figure 5.23. Finally, the average production cost and annual $\mathrm{CO}_{2}$ emissions are shown in Figure 5.24 and Figure 5.25, respectively.

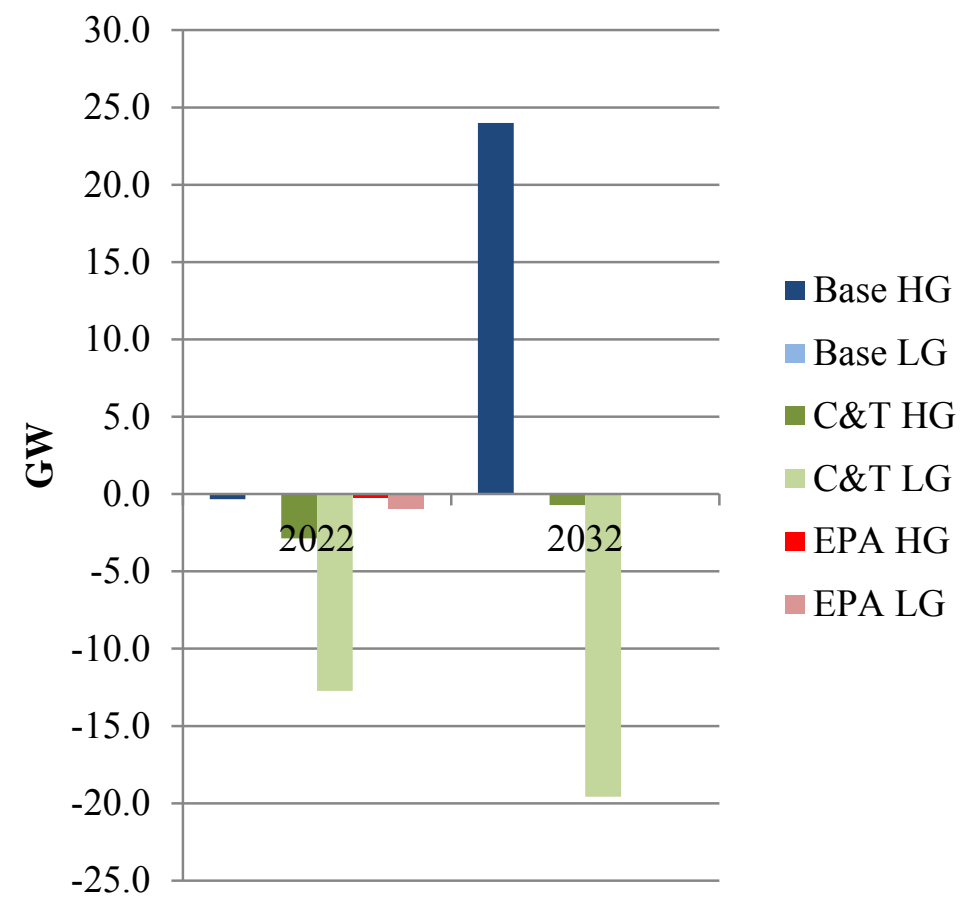

Figure 5.15. Coal retirement and investment in WECC.

There is about $36.8 \mathrm{GW}$ of coal capacity, $18 \%$ of the total capacity, existing in the current WECC system. As shown in Figure 5.15, most of the coal capacity will be retired in the C\&T LG case, with 8.2 GW retired on 2022 and then $22.9 \mathrm{GW}$ retired on 2032. Most of the coal capacity will be replaced by natural gas, which has a lower production cost including the cost of emissions. In the C\&T HG case, coal has less retirement in 2032 because the price of natural gas is extremely high (i.e., $\$ 14 / \mathrm{MBTU}$ ) in this case. In the Base HG case, coal is not competitive when natural gas is $\$ 7 / \mathrm{MBTU}$ but becomes very economical when the natural gas price reaches 
\$14/MBTU. Coal capacity remains constant in the Base LG case because coal generation stays economically competitive under the normal natural gas price without any regulations. In general, the EPA regulation rule prohibits the investment of new coal plants, while the C\&T regulation rule precipitates shutdowns of existing coal generators. Only the soaring natural gas price could slow down the retirement of coal-fired generators.

The installed capacity of natural gas generator occupies $38 \%$ in the WECC system, the highest among all types of resources. There is a total of $77.8 \mathrm{GW}$ of natural gas capacity in this WECC model, with most of the generators located in California. From the planning results shown in Figure 5.16, the price of natural gas plays an important role, together with regulation policies. Highest retirement occurs in the Base HG case in 2032 where most of the capacity is replaced by coal. Although new NGCC technology increases overall efficiency of natural gas plants, it is not a feasible solution in EPA cases because the existing coal is still competitive, and wind and solar generation are preferable to being built with a renewable subsidy.

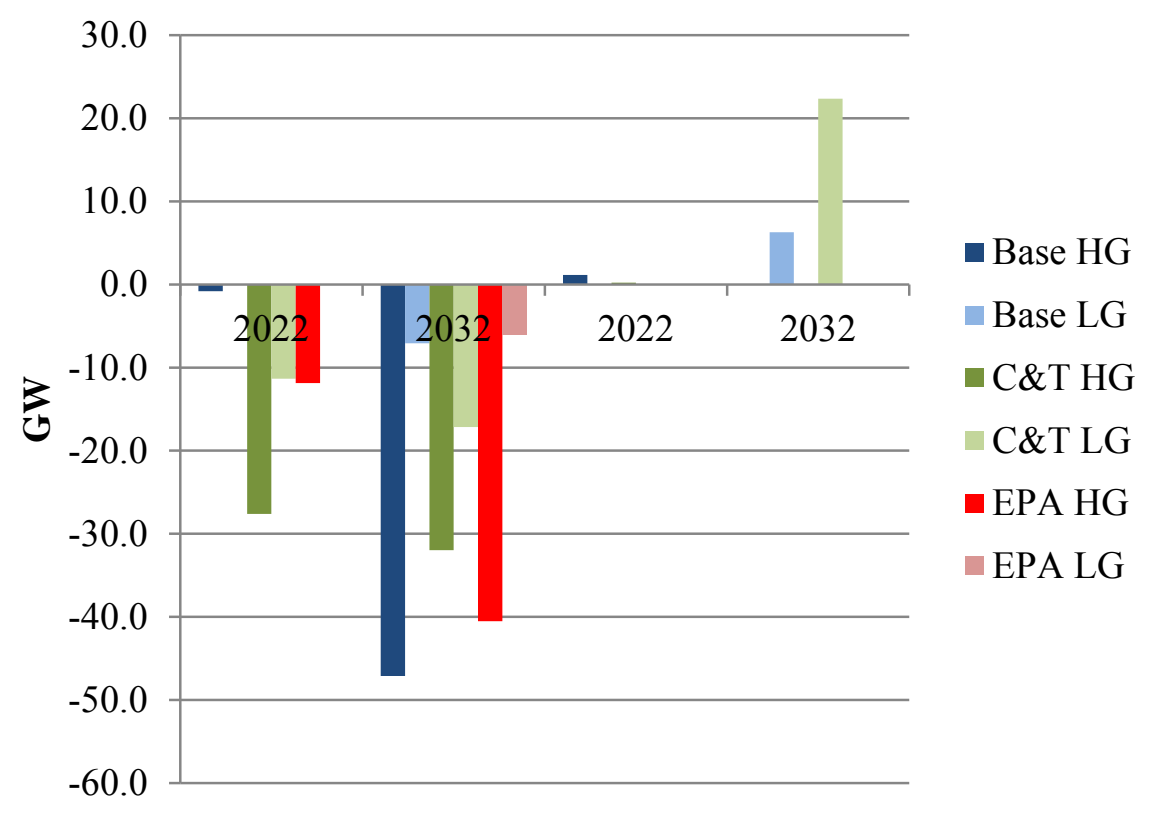

Figure 5.16. Natural gas retirement and investment in WECC. 
Nuclear energy is clean, cheap, and stable when generating electricity. However, the large overnight capital cost and high risk of operational reliability compromise its benefits. There are only four nuclear plants on the current WECC footprint, with an install capacity of $9.7 \mathrm{GW}$. This number is much less compared with the Eastern Interconnection. Most of the nuclear plants were built decades ago, while few have been constructed recently. Without any federal backup, no utility wishes to invest in this long-term, expensive, and unpredictable project. According to an NREL report [45], the overnight capital cost of a nuclear plant falls in the range of $\$ 2,500 / \mathrm{kW}$ to $\$ 4800 / \mathrm{kW}$. From the analyzed data of NREL-SEAC, $\$ 3,200 / \mathrm{kW}$ is selected in this simulation. Lower capital cost data in the range might be derived with the nuclear loan guaranty program from DOE [50] considered in the model.

The results of nuclear investment are plotted in Figure 5.17. The investment of nuclear generation reaches the maximum additions in the C\&T HG case in 2032, when the natural gas price is $\$ 14 / \mathrm{MBTU}$ and the cost of $\mathrm{CO}_{2}$ emissions is $\$ 60.18 /$ ton. A second high of $9.6 \mathrm{GW}$ of nuclear is invested in the EPA HG case, where there is no emission cost. The Base HG case invests the least amount in nuclear energy, rather investing in coal energy, which is a cheaper solution. No nuclear plant will be built in 2022 because the natural gas price, emission cost, and net demand (i.e., demand increase plus hydro energy decrease) are not extremely high as in 2032. In those cases with low natural gas prices, nuclear generation has no advantage of competing with natural gas, the NGCC technology. 


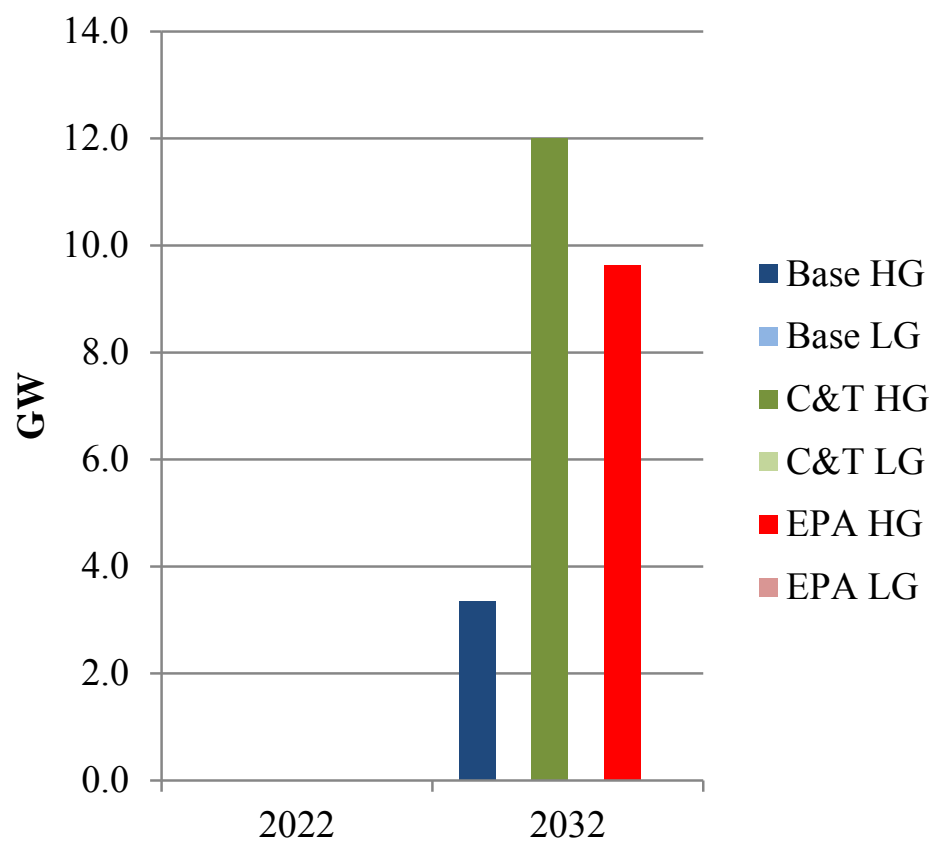

Figure 5.17. Nuclear investment in WECC.

As of year 2012, 6,579 MW of wind capacity is installed in the WECC footprint, only 3\% of the total capacity. Future additions of wind generation in 2022 and 2032 are shown in Figure 5.18. If not mandatory, the investment in wind energy in the future has more uncertainties compared to the results shown in the M-24 report, where wind investment reached a maximum in C\&T HG, C\&T LG, EPA HG, and EPA LG. With the more accurate wind model in this work, i.e., using 672 typical hours representing a year and different capacity factors of different locations, results show less investment in the latter three cases. Wind investment reaches the two-decade limit only in the C\&T HG and C\&T LG cases. The total two-decade investment of wind in C\&T HG, C\&T LG, EPA HG, and EPA LG are 94 GW, 94 GW, 88 GW, and 36.1 GW, respectively. There is less wind investment in EPA HG than C\&T HG because the existing coal generators are not retired in the EPA cases, and they stay competitive without emission penalties. The relatively lower wind investment in EPA LG indicates that wind generation does not have an evident advantage compared to NGCC technology when the natural gas price stays reasonable. 
In the C\&T cases, wind investment is expedited by emission regulations, whereas in the EPA cases, wind expands slower in the beginning and faster when the gas price and net demand increase. In the base cases, wind is only installed in 2032 in the Base HG case. If current PTC policy ends, the future situation would correspond more to the Base LG, where wind is not an economic solution.

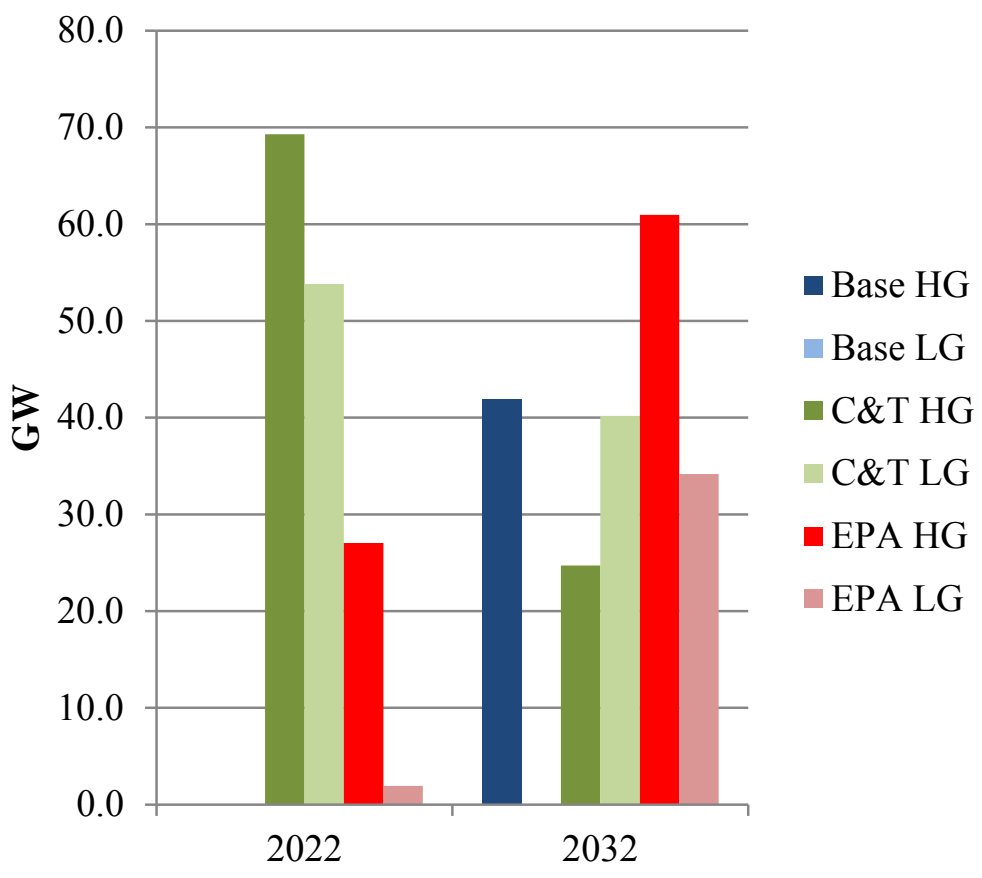

Figure 5.18. Wind investment in WECC.

The investment trend of solar is similar to wind in the WECC system, as shown in Figure 5.19. As stated previously, solar generation is more expensive than wind generation in terms of capital cost, especially solar thermal. For the WECC study here, it is assumed that the additional capacity of solar has $30 \%$ solar thermal and $70 \% \mathrm{PV}$, which leads to a higher capital cost than the $100 \%$ PV assumption used in the 3-bus model study. From the results figures, even with renewable incentives, only solar energy has a similar potential as nuclear energy. 


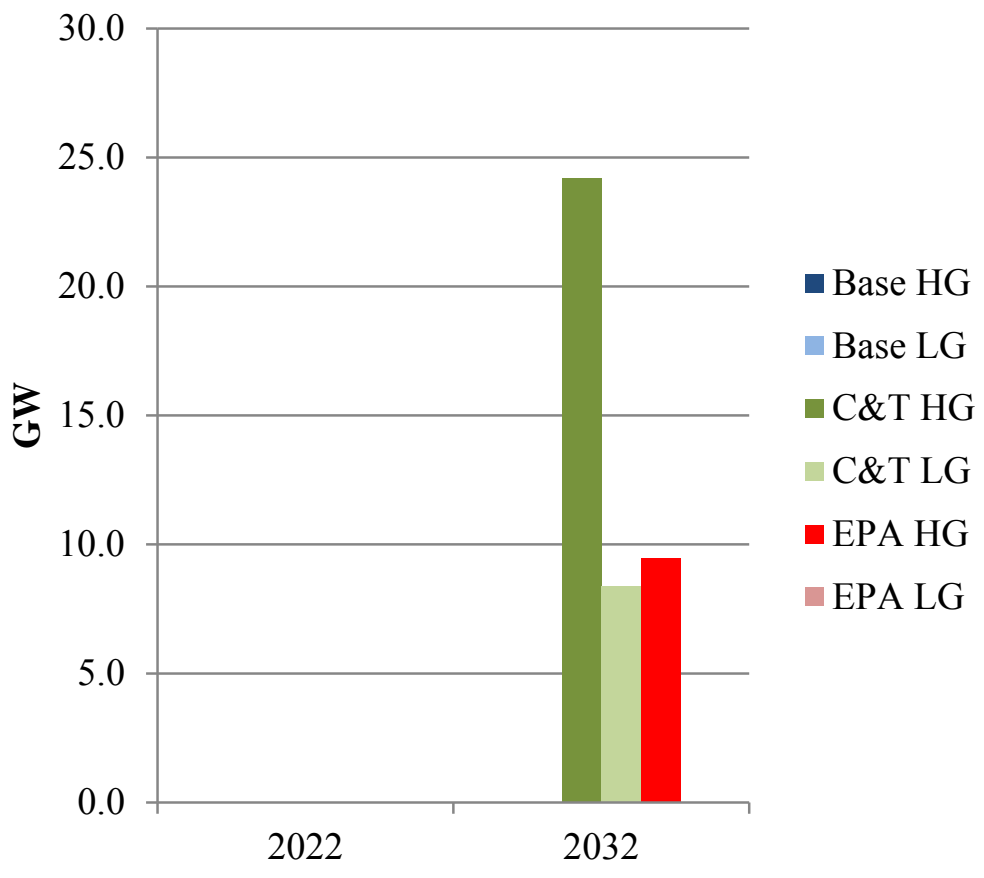

Figure 5.19. Solar investment in WECC.

The results of CAES investment, assuming no energy storage operation in 2012, are plotted in Figure 5.20 and Figure 5.21. The planning results reflect the potential of CAES technology as bulk energy storage. The trend of CAES is correlated with that of wind and nuclear energy. It is interesting to observe that the highest investment of storage occurs in the EPA HG case because this case not only has maximum wind operation in 2032 but also has the most coal generation, which needs to be transported from off-peak to peak when most of the natural gas capacity, $67.3 \%$ of 2012 , is retired in 2032 . Although not included in the simulation, it is necessary to point out that the current bulk storage in the WECC model, all pumped-hydro units, have a total capacity of $3.02 \mathrm{GW}$ and $201.4 \mathrm{GWh}$. With the increased level of renewables, the EPA HG case requires an additional $675 \%$ of power capacity and $498 \%$ of energy capacity for CAES in 2032, while the Base LG and EPA LG cases do not need any additions to the existing capacity of pumped-hydro storage. 


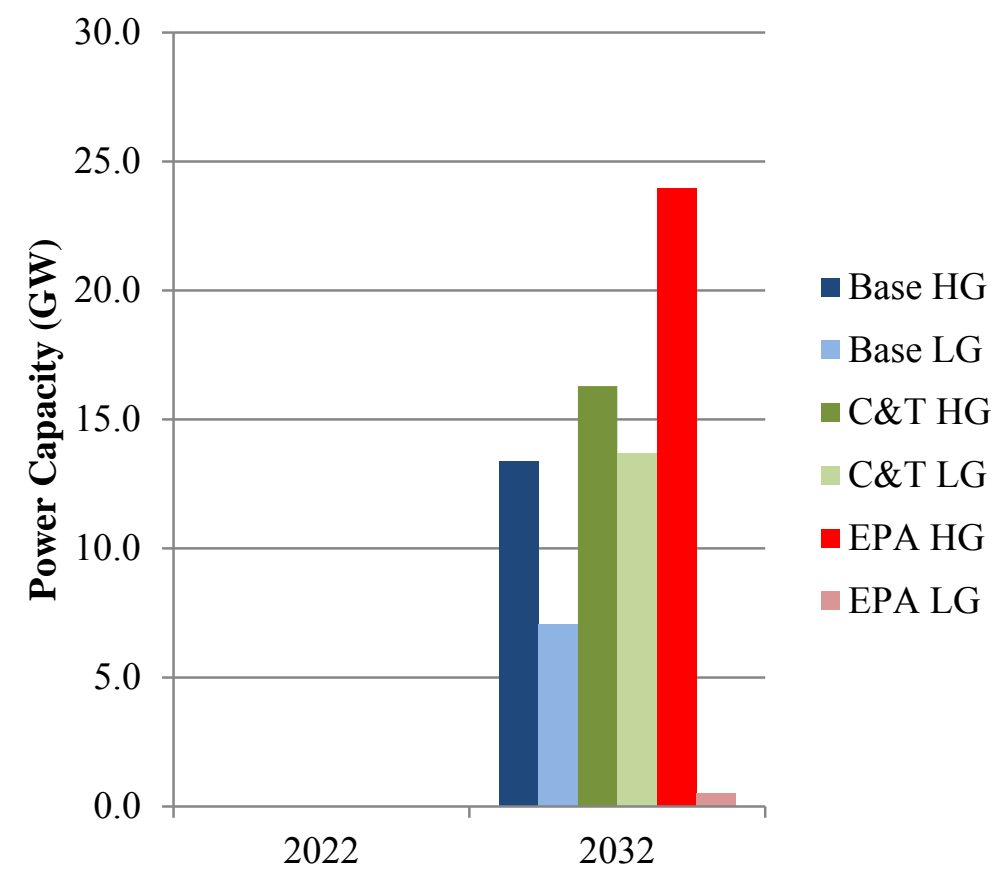

Figure 5.20. Power capacity of EES investment in WECC.

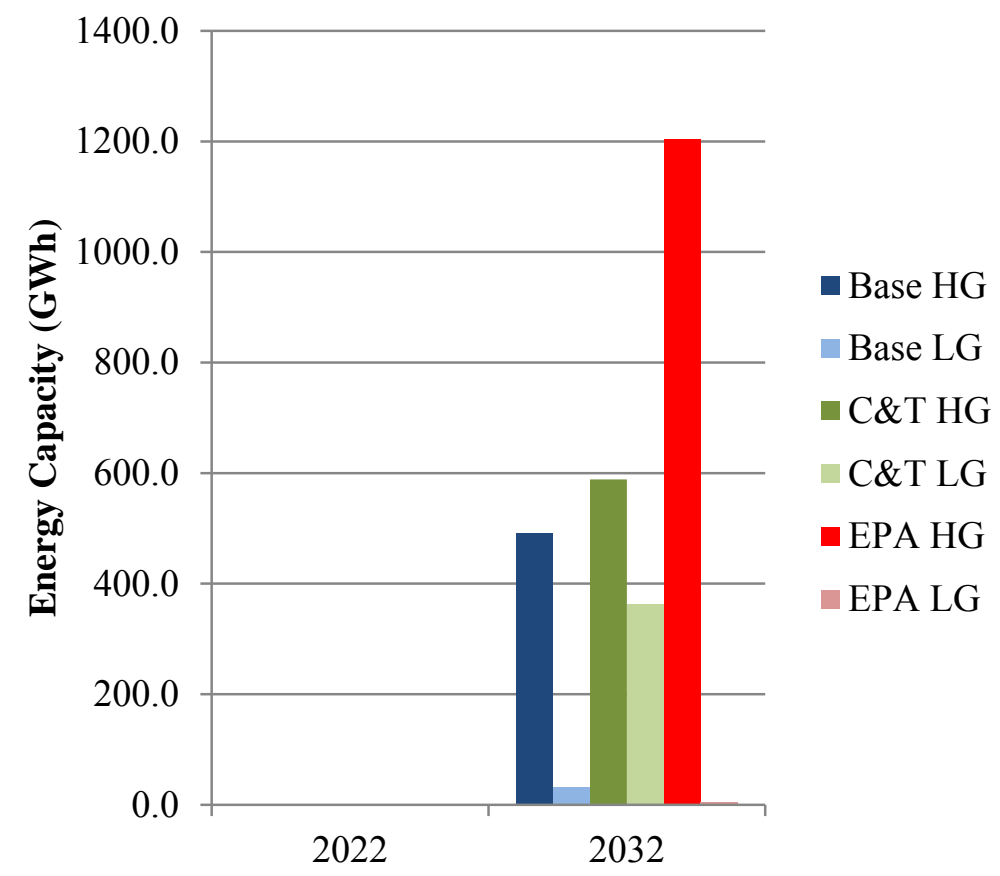

Figure 5.21. Energy capacity of EES investment in WECC. 
As an example, with the EPA HG case, the investment of CAES in 2032 at six locations is shown in Figure 5.22. It is surprising to see that the Southwest has the highest potential for building CAES. Currently no bulk energy storage exists in the Southwest area (i.e., Arizona, New Mexico, and southern Nevada in the WECC model) including pumped-hydro. Normally, bulk energy storage prefers to be placed at a load pocket or congested import areas, which is California in this WECC model. Thus, $82 \%$ of existing pumped-hydro capacity is located in California (42\% in southern California and $40 \%$ in northern California), and the rest is in the Rocky Mountain area. There are a couple of reasons for the Southwest having the highest potential for bulk energy storage in 2032. First, it has the highest demand expansion factor, i.e., 1.296, for the next two decades, as shown previously in Table 5.5. It gradually shifts from an energy exporter to an energy importer. The second reason is that the capacity factors of both wind and solar generation at locations in the Southwest are relatively high, which leads to more wind and solar investment.

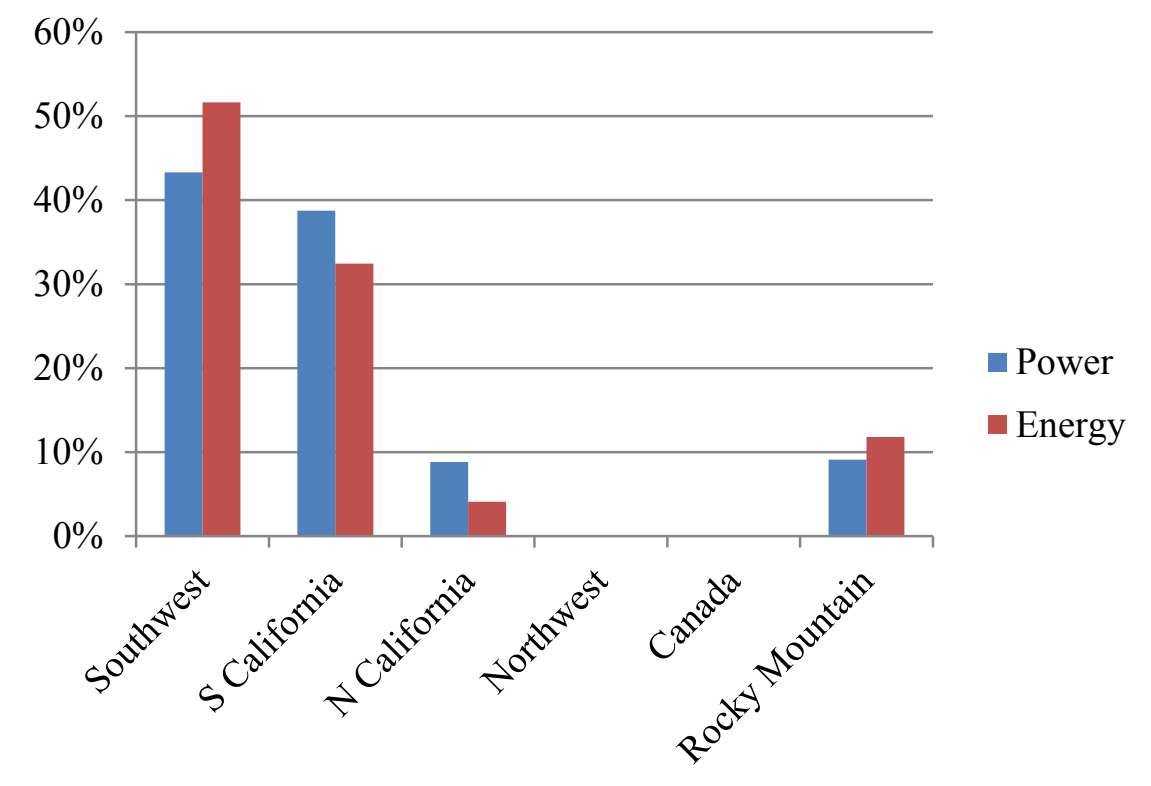

Figure 5.22. CAES investment at each location in $2032 \mathrm{EPA} H \mathrm{HG}$ case. 
Figure 5.23 confirms that the installed capacity of energy storage (i.e., only power capacity of CAES here) could be affected by the investment of wind and solar generation, but not necessarily. A comparison of the installed capacity levels of Base HG and EPA LG shows they have similar IC levels of wind and solar energy but completely different IC levels of CAES. This implies that natural gas generators can provide flexibility with $20 \%$ of wind and solar generation in the system, and it is a better solution than CAES at a normal natural gas price.

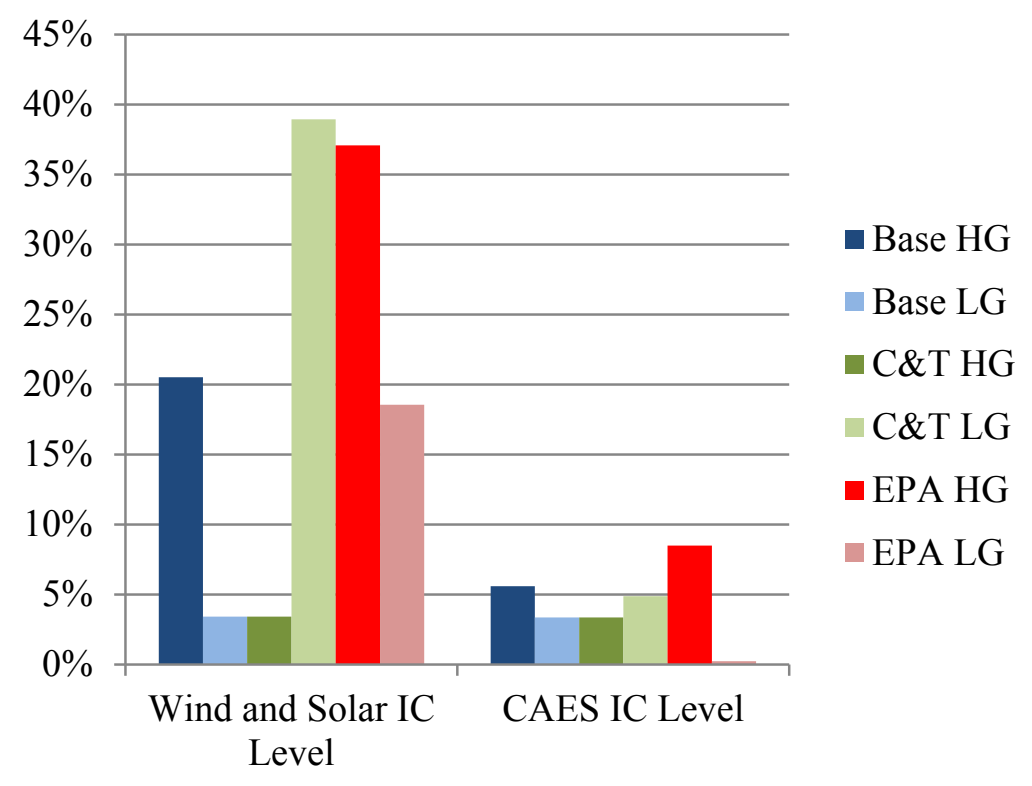

Figure 5.23. 2032 wind and solar installed capacity level and CAES installed capacity level.

The average production cost in this study is calculated as the total production cost (including EES) divided by the total energy produced. The simulation results are plotted in Figure 5.24. Since the capital cost is not represented, the production cost is lower with more wind, solar, nuclear, or coal generation. In HG cases, the average production costs in 2032 are lower than that in 2022 , where the extremely high gas price induces a significant shift from natural gas to coal, nuclear, wind, or solar generation. The results of Base LG represent the linear increase in production cost as the linear increase in electricity demand because there is no renewable investment in this case. 


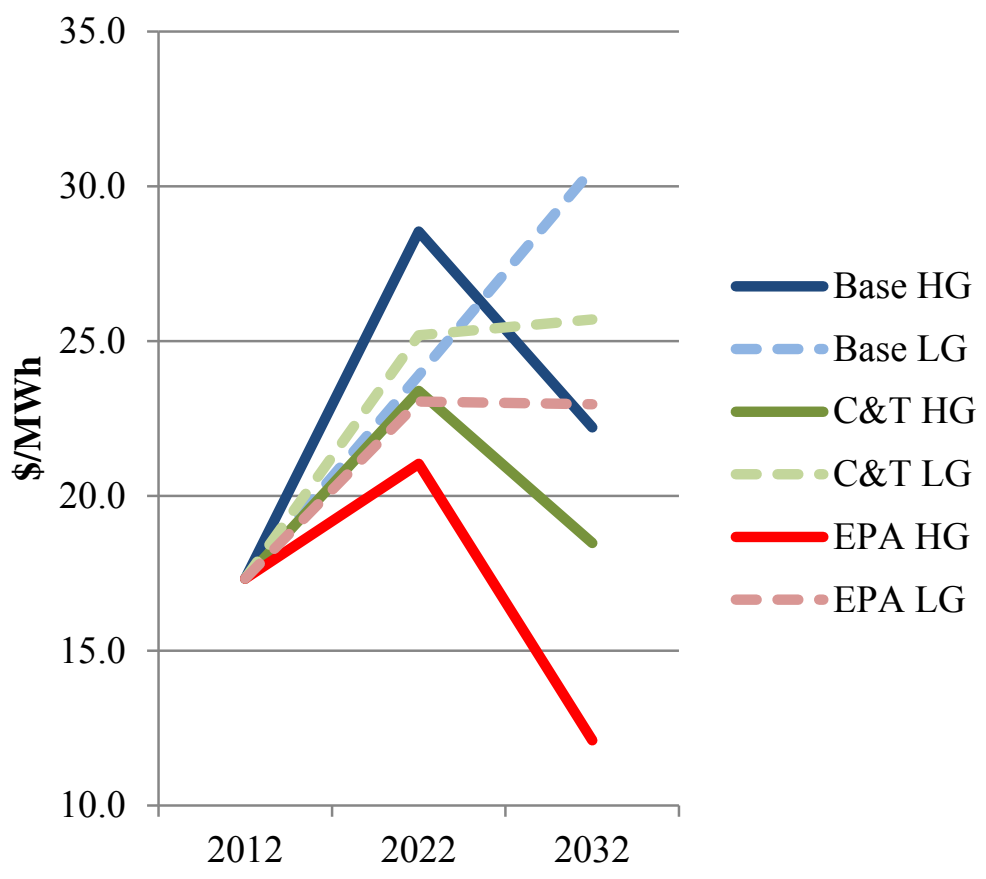

Figure 5.24. Average production cost in WECC.

The results of average annual $\mathrm{CO}_{2}$ emissions, shown in Figure 5.25, provide important information that indicates the effectiveness of the emission regulatory policies. As expected, only C\&T cases effectively regulate the $\mathrm{CO}_{2}$ emissions with increased demand and decreased hydro electricity generation. The $\mathrm{CO}_{2}$ emissions in EPA cases are sensitive to the price of natural gas. In EPA LG, renewable incentives even fail to reduce the $\mathrm{CO}_{2}$ emissions in 2022. In other words, with a continuation of the current low shale gas price, renewable incentives of $\$ 22 / \mathrm{MWh}$ are not likely to help bring more renewables. If so, either more incentives or $\mathrm{CO}_{2}$ emission caps, or both, should be added to regulate emissions. 


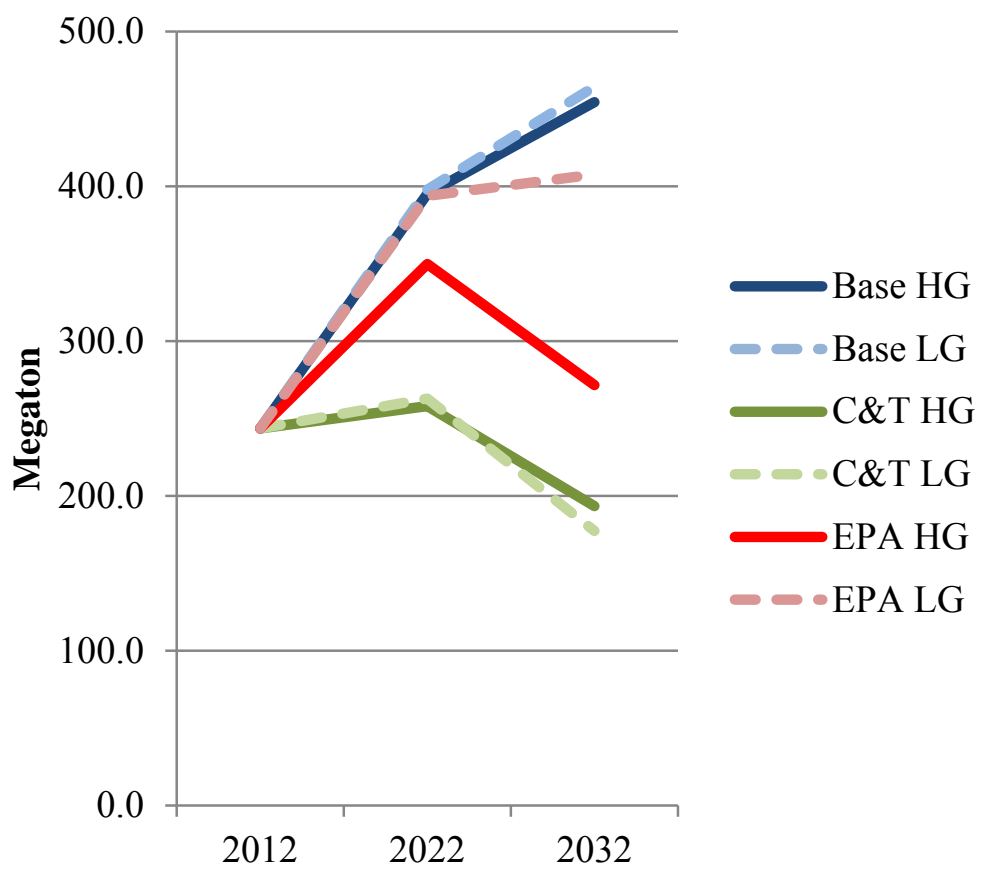

Figure 5.25. Annual $\mathrm{CO}_{2}$ emissions in WECC.

\subsubsection{Discussion}

Although the simulation results of the WECC model are different from those shown in the M-24 report, the deviations reflect the modeling differences, such as the modeling of renewable, hydro, EES, and demand response. Some new observations found in this study include the investment uncertainty of wind and solar generation; the higher potential of nuclear and coal generation, and NGCC in certain cases; and the great potential of CAES.

The planning results in this study are critically based on the cost data and the network topology. The cost data of each fuel type are collected from multiple reports with some assumptions through derivation. The transmission interface limits are not used in the planning study because the operating limits are subject to change in the future. The power limit of each transmission line is estimated from the rated voltage, impedance, surge impedance loading (SIL) and thermal rating, and then adjusted to satisfy the power flow limits on each transmission path. These estimations are the major factors that influence the simulation results. 
The CAES technology, instead of conventional pumped-hydro storage, is selected as the representative for the investment test of bulk EES. Similar to conventional pumped-hydro storage, CAES has a much lower cost per MWh than its cost per MW. The per unit energy capacity cost of CAES is even lower than pumped hydro. Although the current data report that the average cycle efficiency of CAES is lower than that of pumped hydro, the overall value of CAES is higher than that of pumped hydro. In addition, air is more abundant than water as a media to store energy, and it avoids any future limitations on water use [52]. In general, CAES technology has the potential to surpass pumped hydro, which has been dominating the bulk storage application for more than a half century. 


\section{CHAPTER 6}

\section{CONCLUSIONS AND FUTURE WORK}

\subsection{Conclusions}

The major accomplishment of this research is the development of an optimization model for generation and energy storage planning research. This model incorporated energy regulatory policies, hourly renewable profiles, and optimal operation-based investment of EES. The work also constructed the 240-bus WECC model in MATPOWER and analyzed the short-term operations under different renewable penetration levels. All optimization problems in this dissertation were solved by utilizing MATPOWER's extensible OPF framework, which provides users with the flexibility of adding extra variables, constraints, and costs by either direct formulation or by using callback functions. In order to test the proposed optimization model, the 3-bus test system and the WECC model were set up and applied to the problem in multiple study scenarios. The key observations and conclusions are summarized as follows:

- The increased penetration level of wind and solar generation challenges both the operation and planning of a power system. The practical models developed in this dissertation research will allow for a study of their impacts before connecting them to the grid.

- The generation planning model that includes energy storage developed in this dissertation research is needed for researchers, engineers, and policy makers to quantify the potential impacts of the market, costs, and policies on future investment. The cost analysis mechanism, the algorithm of network simplification, and the simulation environments affect simulation results to a great extent. 
- The economic value of current CAES and pumped-hydro storage are ahead of other technologies when built as bulk energy storage. Their benefits from energy arbitrage are determined by the LMP deviations at their locations. A higher LMP deviation at a certain bus could be caused by the following: a higher penetration level of a variable renewable, especially wind; a high penetration level of low-production-cost generators, such as nuclear and coal; and one or more congested connected transmission lines.

- Wind and solar generation are limited by resource-dependency, variability, and expensive capital cost. Without emission regulations or renewable incentives, wind and solar investment will slow down in the near future.

- If the natural gas price remains at a lower average of around \$3/MBTU, with the shale gas supply, more natural gas generators with advanced combined cycle technology will be installed and operate as base-load units. Coal generators in the WECC system will be phased out automatically because they are located far away from the load center, and their produced energy is not accepted by California.

- If the price of natural gas increases unreasonably, e.g., with the annual average price above $\$ 10 /$ ton, the investment in wind, solar, nuclear, and bulk energy storage will be notably increased.

- The size of this optimization problem is larger than the planning model in the M-24 report in terms of having more simulation time points (672 typical hours annually instead of 12 representative hours), the additional optimal planning model of EES, and optimization of hydro generation. With the DELL Workstation (Intel Xeon $1.60 \mathrm{GHz} 8$ cores, 54 GB RAM), 64-bit MATLAB, and Gurobi high-performance solver, the average 
solving time of the proposed planning model for the 3-bus test system is 5 seconds. For the 240-bus WECC model, it takes approximately 3,000 seconds to solve each single year.

\subsection{Future Work}

According to the observations and conclusions throughout this dissertation, the following future work is recommended:

- Add unit commitment and ramp rates to short-term operation studies to analyze the value of EES.

- Combine the stochastic two-stage solver in SuperOPF with the EES model for short-term operation studies.

- Apply the EES model to the market operation model to verify the practical value of EES in different power markets, or design the market according to a specific application of EES.

- Add a seasonal or even monthly capacity factor for each hydro generator if the data are available in long-term planning studies.

- Reduce the simulation time points (typical hours) to shrink the problem size without losing too much accuracy in long-term planning studies.

- Add a transmission planning model to the generation planning model.

- Add a demand response to either the operation model or the planning model. 
REFERENCES 


\section{REFERENCES}

[1] Federal Incentive/Policies for Renewables \& Efficiency, Renewable Electricity Production Tax Credit (PTC), URL: http://dsireusa.org/incentives/incentive.cfm? Incentive Code=US13F [cited Nov. $10,2012]$.

[2] California Environmental Protection Agency, "Assembly Bill 32: Global Warming Solutions Act," URL: http://www.arb.ca.gov/cc/ab32/ab32.htm [cited Nov. 10, 2012].

[3] California Energy Commission, "Integrated Energy Policy Report," URL: http://www.energy.ca.gov/energypolicy/ [cited Nov. 10, 2012].

[4] California Public Utility Commission, "California Renewables Portfolio Standard (RPS)," URL: http://www.cpuc.ca.gov/PUC/energy/Renewables/index.htm [cited Nov. 10, 2012].

[5] R. Wiser and G. Barbose, "Renewables Portfolio Standards in the United States, A Status Report with Data through 2007,” Lawrence Berkeley National Laboratory, April 2008.

[6] Center for Climate and Energy Solutions, Comparison Chart of Waxman-Markey and Kerry-Lieberman, URL: http://www.c2es.org/federal/congress/111/comparison-waxmanmarkey-and-kerry-lieberman [cited Nov. 10, 2012].

[7] M. Shao, "The Effects of Greenhouse Gas Limits on Electric Power System Dispatch and Operations," Ph.D. dissertation, Wichita State University, Wichita, KS, 2008.

[8] Daily Renewables Watch, California Independent System Operator, URL: http://www.caiso.com/market/Pages/ReportsBulletins/DailyRenewablesWatch.aspx [cited Nov. 10, 2012].

[9] J. E. Price and J. Goodin, "Reduced Network Modeling of WECC as a Market Design Prototype," IEEE General Meeting, Detroit, MI, Jul. 2011.

[10] Western Electricity Coordinating Council, URL: www.wecc.biz.

[11] A. J. Wood and B. F. Wollenberg, Power Generation Operation and Control, Second Edition, John Wiley \& Sons, Inc., 1996.

[12] S. Dutta and T. J. Overbye, "Optimal Storage Scheduling for Minimizing Schedule Deviations Considering Variability of Generated Wind Power," IEEE Power Systems Conference and Exposition, Phoenix, AZ, Mar. 2011.

[13] P. Denholm, E. Ela, B. Kirby and M. Milligan, "The Role of Energy Storage with Renewable Electricity Generation,” Technical Report, NREL/TP-6A2-47187, Jan. 2010. 


\section{REFERENCES (continued)}

[14] R. D. Zimmerman and C. E. Murillo-Sanchez, MATPOWER User's Manual, [Online]. Available: http://www.pserc.cornell.edu/matpower/ [cited Nov. 10, 2012].

[15] R. D. Zimmerman, C. E. Murrillo-Sanchez, and R. J. Thomas, "MATPOWER: SteadyState Operations, Planning, and Analysis Tools for Power Systems Research and Education," IEEE Trans. Power Syst., vol. 26, no. 1, pp.12-19, Feb. 2011.

[16] L. T. Anstine and R. J. Ringlee, "Susquenhanna River Short-Range Hydrothermal Coordination,” AIEE Trans., vol. 82, part III, pp. 185-191, Apr. 1963.

[17] T. Y. Lee and N. Chen, "The Effect of Pumped Storage and Battery Energy Storage Systems on Hydrothermal Generation Coordination," IEEE Trans., EC-7, vol. 4, pp. 631637, 1992.

[18] K. Aoki, T. Satoh, and M. Itoh, "Unit Commitment in a Large-Scale Power System Including Fuel Constrained Thermal and Pumped-Storage Hydro," IEEE Trans. PWRS-2, vol. 4, pp. 1077-1084, 1987.

[19] R. Walawalkar and J. Apt, "Market Analysis of Emerging Electric Energy Storage Systems," Final Report, DOE/NETL-2008/1330, Jul. 2008.

[20] H. Liu, L. Tesfatsion, and A. A. Chowdhury, "Derivation of Locational Marginal Prices for Restructured Wholesale Power Markets," California Independent System Operator.

[21] Z. Hu and W. T. Jewell, "Optimal Power Flow Analysis of Energy Storage for Congestion Relief, Emissions Reduction, and Cost Savings," IEEE Power Systems Conference and Exposition, Phoenix, AZ, Mar. 2011.

[22] H. Oh, "Optimal Planning to Include Storage Devices in Power Systems," IEEE Trans. Power Syst., vol. 26, no. 3, pp. 1118-1128, Aug. 2011.

[23] A. J. Lamadrid, T. D. Mount, and R. J. Thomas, "Scheduling of Energy Storage Systems with Geographically Distributed Renewables," Ninth IEEE International Symposium on ISPAW, Busan, South Korea, May 2011.

[24] D. J. Swider, "Compressed Air Energy Storage in an Electricity System With Significant Wind Power Generation," IEEE Trans. Power Syst., vol. 22, no. 1, pp. 95-102, Mar. 2007.

[25] A. Tuohy and M. O’Malley, "Impact of Pumped Storage on Power Systems with Increasing Wind Penetration,” IEEE PES GM, Alberta, Canada, Jul. 2009. 


\section{REFERENCES (continued)}

[26] H. Daneshi, A. K. Srivastava, and A. Daneshi, "Generation Scheduling with Integration of Wind Power and Compressed Air Energy Storage," IEEE PES TDCE, New Orleans, LA, Apr. 2010.

[27] W. Schulze, W. Jewell, D. Tylavsky, J. Taber, J. Yan, D. Shi, N. Li, Y. Qi, T. Hardy, and Z. Hu, "Interactions of Multiple Market-Based Energy and Environmental Policies in a Transmission-Constrained Competitive National Electricity Market," Final Project Report of PSERC Project M-24, Sept. 2012.

[28] R. D. Zimmerman and C. E. Murrillo-Sanchez, SuperOPF 1.0 User's Manual, Jun. 2011.

[29] R. D. Zimmerman, C. E. Murrillo-Sanchez, and R. J. Thomas, "MATPOWER's Extensible Optimal Power Flow Architecture," IEEE PES GM, Alberta, Canada, Jul. 2009.

[30] P. Poonpun, "Effects of Low Carbon Emission Generation and Energy Storage on Greenhouse Gas Emissions in Electric Power Systems," Ph.D. dissertation, Wichita State University, Wichita, KS, 2009.

[31] PowerWorld Corporation, PowerWorld Simulator Version 14 User's Guide.

[32] H. Wang, C. E. Murillo-Sanchez, R. D. Zimmerman, and R. J. Thomas, "On Computational Issues of Market-Based Optimal Power Flow," IEEE Trans. Power Syst., vol. 22, no. 3, pp. 1185-193, Aug. 2007.

[33] MINOPF. [Online]. URL: http://www.pserc.cornell.edu/minopf/ [cited Nov. 10, 2012].

[34] TSPOPF. [Online]. URL: http://www.pserc.cornell.edu/tspopf/ [cited Nov. 10, 2012].

[35] BPMPD. [Online]. URL: http://www.pserc.cornell.edu/bpmpd/ [cited Nov. 10, 2012].

[36] MOSEK. [Online]. URL: http://www.mosek.com/ [cited Nov. 10, 2012].

[37] CPLEX, IBM ILOG CPLEX Optimizer. [Online].

URL: http://www-01.ibm.com/software/integration/optimization/cplex-optimizer/ [cited Nov. 10, 2012].

[38] GUROBI, Gurobi Optimization. [Online]. URL: http://www.gurobi.com/ [cited Nov. 10, 2012].

[39] N. P. Yu, C. C. Liu, and J. Price, "Evaluation of Market Rules Using a Multi-Agent System Method," IEEE Trans. Power Syst., vol. 25, no. 1, pp. 470-479, Jan. 2010. 


\section{REFERENCES (continued)}

[40] J. Jung, C. C. Liu, S. Tanimoto, and V. Vital, "Adaptation in Load Shedding under Vulnerable Operating Conditions," IEEE Trans. Power Syst., vol. 17, no. 4, pp. 11991205, Nov. 2002.

[41] Description of the PTI Load Flow Data Format, URL: http://www.ee.washington.edu/research/pstca/formats/pti.txt [cited Nov. 10, 2012].

[42] C. Grigg, etc., “ The IEEE Reliability Test System - 1996, A Report Prepared by the Reliability Test System Task Force of the Application of Probability Methods Subcommittee," IEEE Trans. Power Systems, vol. 14, no. 3, pp. 1010-1020, Aug. 1999.

[43] EIA, Average Operating Heat Rate for Selected Energy Sources, 2001 through 2010. URL: http://www.eia.gov/electricity/annual/pdf/table5.3.pdf [cited Feb. 2012].

[44] EIA, Henry Hub Gulf Coast Natural Gas Spot Price, URL: http://www.eia.gov/dnav/ng/hist/rngwhhdA.htm [cited: Nov. 2012].

[45] R. Tidball, J. Bluestein, N. Rodriguez, and S. Knoke, "Cost and Performance Assumptions for Modeling Electricity Generation Technologies," Subcontract Report, NREL/SR-6A20-48595, Nov. 2010.

[46] P. Poonpun and W. Jewell, "Analysis of the Cost per Kilowatt Hour to Store Electricity," IEEE Trans. Power Systems, vol. 23, no. 2, Jun. 2008.

[47] M. Kintner-Meyer, P. Balducci, W. Colella, M. Elizondo, C. Jin, T. Nguyen, V. Viswanathan and Y. Zhang, "National Assessment of Energy Storage for Grid Balancing and Arbitrage: Phase 1, WECC,” PNNL-21388, Jun. 2012.

[48] S. Schoenung, "Energy Storage Systems Cost Update, A Study for the DOE Energy Storage Systems Program,” SANDIA Report, SAND2011-2730, Apr. 2011.

[49] S. Phinney, R. McCann, M. Cubed, G. Franco and M. Fagundes, "Potential Changes in Hydropower Production From Global Climate Change in California and the Western United States," prepared in support of 2005 Integrated Energy Policy Report Proceeding (Docket \# 04-IEPR-01G), Jun. 2005.

[50] Loan Programs of Office, U. S. Department of Energy, URL: https://lpo.energy.gov/?page id=31 [cited: Dec. 2012].

[51] EPA, Carbon Pollution Standard for New Power Plants, URL: http://epa.gov/carbonpollutionstandard/index.html [cited Feb. 25 2013]. 


\section{REFERENCES (continued)}

[52] W. Jewell, J. Twomey, M. Overcash, J. Cardell, and L. Anderson, "Future Grid: The Environment," Future Grid Initiative White Paper, PSERC Publication 12-04, May 2012. 


\section{APPENDIXES}




\section{APPENDIX A \\ INPUT DATA FORMAT}

The input data format of the constructed $\mathrm{m}$-files that support the planning model proposed in this work are listed in Table A.1, Table A.2, and Table A.3.These data are specified as matrices in the case struct file.

TABLE A.1

EES DATA (mpc.storage2)

\begin{tabular}{|c|c|c|}
\hline Name & Column & Description \\
\hline BUS & 1 & Bus number (EES location) \\
\hline PS_MIN & 2 & Minimum investment of power capacity \\
\hline PS_MAX & 3 & Maximum investment of power capacity \\
\hline ES_MIN & 4 & Minimum investment of energy capacity \\
\hline ES_MAX & 5 & Minimum investment of energy capacity \\
\hline PS_CC & 6 & ACR of power capacity \\
\hline ES_CC & 7 & ACR of energy capacity \\
\hline OM_CC & 8 & $\mathrm{O} \& \mathrm{M}$ cost \\
\hline INI_RATE & 9 & Initial rate of energy storage $(0 \sim 1)$ \\
\hline EFF_C & 10 & Efficiency of charging cycle \\
\hline EFF_D & 11 & Efficiency of discharging cycle \\
\hline $\mathrm{PS}^{\dagger}$ & 12 & Power capacity invested \\
\hline $\mathrm{ES}^{\dagger}$ & 13 & Energy capacity invested \\
\hline
\end{tabular}

${ }^{\dagger}$ Only included in OPF output, i.e., results.storage2 
APPENDIX A (continued)

TABLE A.2

GENERATOR RETIREMENT DATA (mpc.retire)

\begin{tabular}{|l|l|l|}
\hline Name & Column & Description \\
\hline GEN_IDX & 1 & $\begin{array}{l}\text { Sequence number of generator that can be } \\
\text { retired in } m p c . g e n\end{array}$ \\
\hline R_MIN & 2 & Requirement of minimum retirement \\
\hline R_MAX & 3 & Allowance of maximum retirement \\
\hline CR_R & 4 & Annual total fixed cost $(\$ / M W)$ \\
\hline CF_R & 5 & Capacity factor \\
\hline $\mathrm{R}^{\dagger}$ & 6 & Retirement result \\
\hline
\end{tabular}

${ }^{\dagger}$ Only included in the OPF output, i.e. results.retire

TABLE A.3

GENERATOR INVESTMENT DATA (mpc.invest)

\begin{tabular}{|l|l|l|}
\hline Name & Column & Description \\
\hline BUS & 1 & Bus number that new generator can be placed \\
\hline TYPE & 2 & $\begin{array}{l}\text { Fuel type }-1 \text { _coal, 2_natural gas, 3_nuclear, } \\
\text { 4_wind, 5_solar }\end{array}$ \\
\hline I_MIN & 3 & Requirement of minimum investment \\
\hline I_MAX & 4 & Allowance of maximum investment \\
\hline CI & 5 & Annual capital recovery $(\$ / M W)$ \\
\hline CR_I & 6 & Annual total fixed cost $(\$ / M W)$ \\
\hline CF & 7 & $\begin{array}{l}\text { Production cost including emission cost and } \\
\text { renewable subsidy }(\$ / M W h)\end{array}$ \\
\hline R_IDX & 8 & $\begin{array}{l}\text { Column index of the associated renewable } \\
\text { profile (particularly for wind and solar) }\end{array}$ \\
\hline CF_I & 9 & Capacity factor \\
\hline I $^{\dagger}$ & 10 & Investment result \\
\hline
\end{tabular}

${ }^{\dagger}$ Only included in the OPF output, i.e., results.invest 


\section{APPENDIX B}

RENEWABLE PROFILE APPROXIMATED FROM AVAILABLE DATA

TABLE B.1

WIND PROFILE MAPPING AT EACH GENERATOR BUS

\begin{tabular}{|c|c|c|c|}
\hline Bus Index & Name & Wind Profile Index & $\begin{array}{c}\text { Capacity Factor } \\
(\%)\end{array}$ \\
\hline 1032 & FCNGN4CC & \multirow{7}{*}{ CORONADO $\{1131 \mathrm{~W}$ future $\}$} & \multirow{7}{*}{35.18} \\
\hline 1034 & SJUAN G4 & & \\
\hline 1131 & CORONADO & & \\
\hline 1232 & NAVAJO 2 & & \\
\hline 1331 & HOOVER & & \\
\hline 1333 & H ALLEN & & \\
\hline 1431 & PALOVRD2 & & \\
\hline 2030 & MEXICO & \multirow{11}{*}{ MESA CAL $\{2438$ SW future $\}$} & \multirow{11}{*}{37.03} \\
\hline 2130 & IMPERIAL & & \\
\hline 2233 & MISSION & & \\
\hline 2332 & IMPRLVLY & & \\
\hline 2438 & MESA CAL & & \\
\hline 2533 & S.ONOFRE & & \\
\hline 2630 & HAYNES3G & & \\
\hline 2631 & OLIVE & & \\
\hline 2634 & INTERM1G & & \\
\hline 2637 & OWENS G & & \\
\hline 2638 & CASTAI4G & & \\
\hline 3133 & SANMATEO & \multirow{8}{*}{ PITSBURG $\{3234$ NW future $\}$} & \multirow{8}{*}{15.82} \\
\hline 3135 & POTRERO & & \\
\hline 3234 & PITSBURG & & \\
\hline 3333 & METCALF & & \\
\hline 3432 & HELMS PP & & \\
\hline 3433 & MC CALL & & \\
\hline 3531 & FULTON & & \\
\hline 3631 & HUMBOLDT & & \\
\hline
\end{tabular}




\begin{tabular}{|c|c|c|c|}
\hline Bus Index & Name & Wind Profile Index & $\begin{array}{c}\text { Capacity Factor } \\
(\%)\end{array}$ \\
\hline 3731 & SUMMIT & & \\
\hline 3831 & DIABLO1 & \multirow{6}{*}{ TESLA $\{3933$ NW future $\}$} & \multirow{6}{*}{16.26} \\
\hline 3835 & MIDWAY & & \\
\hline 3836 & MORROBAY & & \\
\hline 3931 & ROUND MT & & \\
\hline 3932 & MOSSLAND & & \\
\hline 3933 & TESLA & & \\
\hline 4031 & MALIN & MALIN $\{4031 \mathrm{~W}$ future $\}$ & 22.45 \\
\hline 4035 & JOHN DAY & JOHN DAY $\{4035 \mathrm{~W}$ future $\}$ & 23.87 \\
\hline 4039 & DALLES21 & DALLES21 $\{4039 \mathrm{~W}$ future $\}$ & 21.49 \\
\hline 4131 & COULEE & COULEE $\{4131 \mathrm{~W}$ future $\}$ & 25.86 \\
\hline 4132 & HANFORD & HANFORD $\{4132 \mathrm{~W}$ future $\}$ & 19.80 \\
\hline 4231 & NORTH G3 & \multirow{2}{*}{ WCASCADE $\{4232 \mathrm{~W}$ future $\}$} & \multirow{2}{*}{16.37} \\
\hline 4232 & WCASCADE & & \\
\hline 5031 & CANAD G1 & \multirow{2}{*}{ CMAIN GM $\{5032 \mathrm{~W}$ future $\}$} & \multirow{2}{*}{42.48} \\
\hline 5032 & CMAIN GM & & \\
\hline 6132 & MIDPOINT & MIDPOINT $\{6132 \mathrm{~W}$ future $\}$ & 20.35 \\
\hline 6231 & COLSTRP & \multirow{2}{*}{ MONTA G1 $\{6235 \mathrm{~W}$ future $\}$} & \multirow{2}{*}{32.69} \\
\hline 6235 & MONTA G1 & & \\
\hline 6333 & BRIDGER & \multirow{2}{*}{ BRIDGER $\{6333 \mathrm{~W}$ future $\}$} & \multirow{2}{*}{41.41} \\
\hline 6335 & NAUGHT & & \\
\hline 6433 & VALMY & \multirow{2}{*}{ VALMY $\{6433 \mathrm{~W}$ future $\}$} & \multirow{2}{*}{25.83} \\
\hline 6533 & EMERY & & \\
\hline 7031 & COLOEAST & \multirow{2}{*}{ COLOEAST $\{7031 \mathrm{~W}$ future $\}$} & \multirow{2}{*}{36.72} \\
\hline 7032 & CRAIG & & \\
\hline 8033 & COTWDWAP & \multirow{2}{*}{ TESLA $\{3933$ NW future $\}$} & \multirow{2}{*}{16.26} \\
\hline 8034 & RNCHSECO & & \\
\hline
\end{tabular}


TABLE B.2

SOLAR PROFILE MAPPING AT EACH GENERATOR BUS

\begin{tabular}{|c|c|c|c|}
\hline Bus Index & Name & Solar Profile Index & $\begin{array}{c}\text { Capacity Factor } \\
(\%)\end{array}$ \\
\hline 1032 & FCNGN4CC & \multirow{6}{*}{ H ALLEN $\{1333 \mathrm{~S}$ future $\}$} & \multirow{6}{*}{36.03} \\
\hline 1034 & SJUAN G4 & & \\
\hline 1131 & CORONADO & & \\
\hline 1232 & NAVAJO 2 & & \\
\hline 1331 & HOOVER & & \\
\hline 1333 & H ALLEN & & \\
\hline 1431 & PALOVRD2 & PALOVRD2 $\{1431 \mathrm{~S}$ future $\}$ & 36.53 \\
\hline 2030 & MEXICO & \multirow{4}{*}{ IMPERIAL $\{2130 \mathrm{~S}$ future $\}$} & \multirow{4}{*}{41.73} \\
\hline 2130 & IMPERIAL & & \\
\hline 2233 & MISSION & & \\
\hline 2332 & IMPRLVLY & & \\
\hline 2438 & MESA CAL & \multirow{7}{*}{ MESA CAL $\{2438$ SS Future $\}$} & \multirow{7}{*}{41.73} \\
\hline 2533 & S.ONOFRE & & \\
\hline 2630 & HAYNES3G & & \\
\hline 2631 & OLIVE & & \\
\hline 2634 & INTERM1G & & \\
\hline 2637 & OWENS G & & \\
\hline 2638 & CASTAI4G & & \\
\hline 3133 & SANMATEO & \multirow{15}{*}{ PALOVRD2 $\{1431 \mathrm{~S}$ future $\}$} & \multirow{15}{*}{36.53} \\
\hline 3135 & POTRERO & & \\
\hline 3234 & PITSBURG & & \\
\hline 3333 & METCALF & & \\
\hline 3432 & HELMS PP & & \\
\hline 3433 & MC CALL & & \\
\hline 3531 & FULTON & & \\
\hline 3631 & HUMBOLDT & & \\
\hline 3731 & SUMMIT & & \\
\hline 3831 & DIABLO1 & & \\
\hline 3835 & MIDWAY & & \\
\hline 3836 & MORROBAY & & \\
\hline 3931 & ROUND MT & & \\
\hline 3932 & MOSSLAND & & \\
\hline 3933 & TESLA & & \\
\hline
\end{tabular}




\begin{tabular}{|c|c|c|c|}
\hline Bus Index & Name & Solar Profile Index & $\begin{array}{c}\text { Capacity Factor } \\
(\%)\end{array}$ \\
\hline 4031 & MALIN & \multirow{18}{*}{ EMERY $\{6533 \mathrm{~S}$ future $\}$} & \multirow{18}{*}{32.40} \\
\hline 4035 & JOHN DAY & & \\
\hline 4039 & DALLES21 & & \\
\hline 4131 & COULEE & & \\
\hline 4132 & HANFORD & & \\
\hline 4231 & NORTH G3 & & \\
\hline 4232 & WCASCADE & & \\
\hline 5031 & CANAD G1 & & \\
\hline 5032 & CMAIN GM & & \\
\hline 6132 & MIDPOINT & & \\
\hline 6231 & COLSTRP & & \\
\hline 6235 & MONTA G1 & & \\
\hline 6333 & BRIDGER & & \\
\hline 6335 & NAUGHT & & \\
\hline 6433 & VALMY & & \\
\hline 6533 & EMERY & & \\
\hline 7031 & COLOEAST & & \\
\hline 7032 & CRAIG & & \\
\hline 8033 & COTWDWAP & \multirow{2}{*}{ PALOVRD2 $\{1431 \mathrm{~S}$ future $\}$} & \multirow{2}{*}{36.53} \\
\hline 8034 & RNCHSECO & & \\
\hline
\end{tabular}

